\title{
ETHNOCULTURAL NEUTRALITY AND NATION-BUILDING
}

A critical evaluation of Will Kymlicka's fairness based argument for minority cultural rights

By

Steven Guy Riley

A thesis

submitted to the Victoria University of Wellington

in fulfillment of the requirements for the degree of

Master of Arts

in Philosophy 
Abstract: This thesis looks at an argument by Will Kymlicka in which he claims that the idea of an ethnoculturally neutral state is "manifestly false" and should be replaced by liberal political theorists with a model of the state as engaging in "nation-building" (Kymlicka 2001 pp23 - 27). Once we do this, Kymlicka argues, we see that the burden of proof regarding minority cultural rights has shifted away from the defender of such rights and falls equally on those who seek to deny those rights. We see this, Kymlicka claims, because the nation-building model of the state highlights a number of burdens that are placed on cultural minorities, burdens which are otherwise disguised by a norm of ethnocultural neutrality. Kymlicka argues that this means that the debate over minority cultural rights has moved on from substantive debates about the worth of cultural units (including his well known argument that we have a fundamental interest in the success of our own culture). In this thesis I argue for two main claims. The first is that the idea of ethnocultural neutrality is not manifestly false so long as it is understood as part of a requirement that state institutions and policies should be capable of an appropriate justification. Moreover I shall suggest that acceptance of such a norm can in fact be used by Kymlicka in order to ground the specific fairness based claims that he wants to make about majority nation-building in liberal democratic states. Secondly I shall argue that Kymlicka's claims about the fairness of majority nation-building rely upon the kind of substantive account supplied by his earlier argument that we have a fundamental, autonomy based, interest in the survival of our own societal-culture. In this respect, then, Kymlicka is wrong to suggest that the debate has moved on. My defence of ethnocultural neutrality helps us to see where there is underlying agreement amongst liberals on a number of multicultural policies and also highlights the areas of substantive disagreement which, I shall suggest, do not revolve around acceptance, or not, of a norm of ethnocultural neutrality but instead are deep rooted disagreements about the worth of our cultural and national attachments and how they are to be weighed against each other and against other interests that we have. On this score I suggest that Kymlicka's own autonomy argument is unconvincing.

Acknowledgments: I would like to thank my supervisor, Ramon Das, who offered insightful comments and help principally on later drafts of this thesis particularly concerning the structure and presentation of my ideas. I would also like to thank Laura McCarthy who kindly, and patiently, proof-read a number of versions of this thesis. I would also like to acknowledge her ongoing support which has been invaluable in the writing of this thesis. I would also like to acknowledge the useful questions I received on various presentations of parts of this thesis by fellow post-graduate students at Victoria University of Wellington's philosophy student seminar series. In particular I want to thank Adrian Currie who, in sharing an office with me, offered many insightful comments as this thesis progressed in addition to tolerating my tendency to spread my work liberally around a shared space. Finally I would like to thank my examiners, Simon Keller and Liezl van Zyl, for their useful and fair comments and criticism. Any errors in either reasoning or presentation remain, of course, entirely my own. 


\section{Contents}

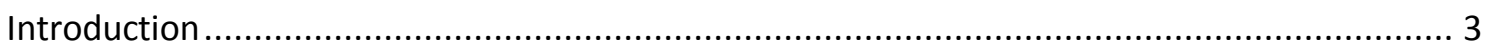

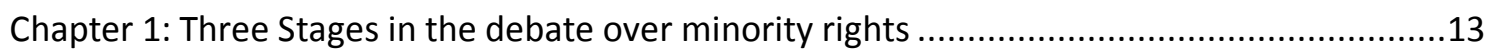

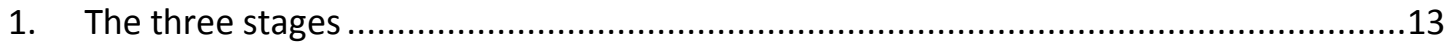

2. Two kinds of neutrality: separation of culture and state and neutrality of justification.15

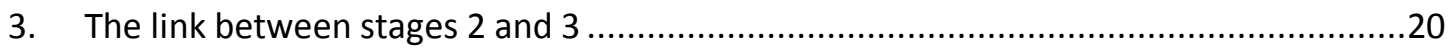

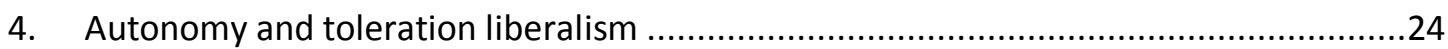

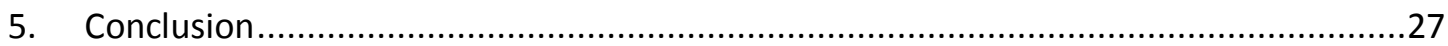

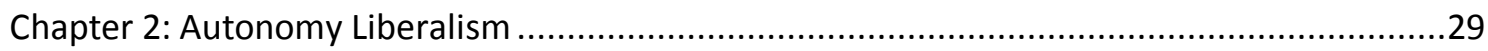

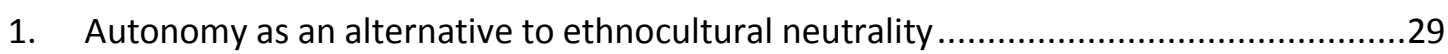

2. Autonomy, societal culture, and perfectionist moral pluralism ..................................30

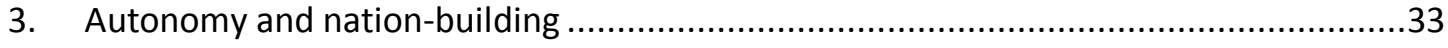

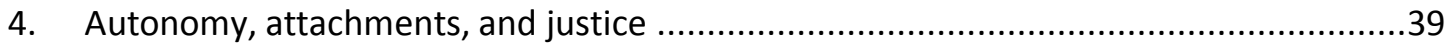

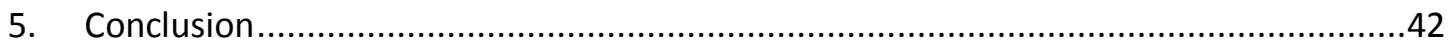

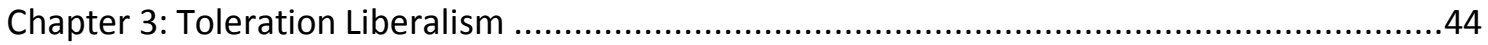

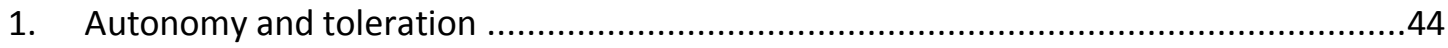

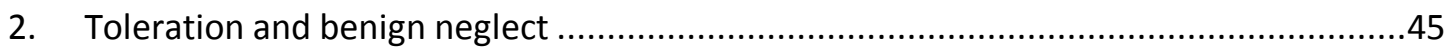

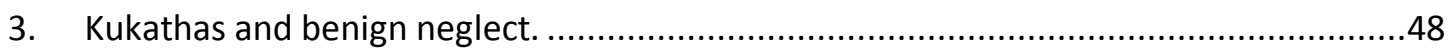

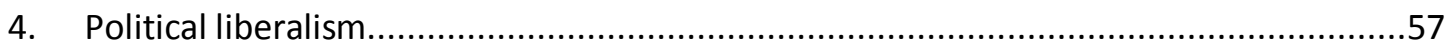

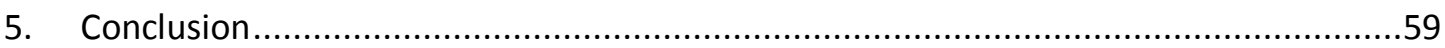

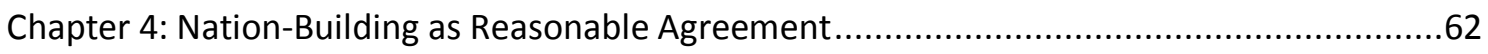

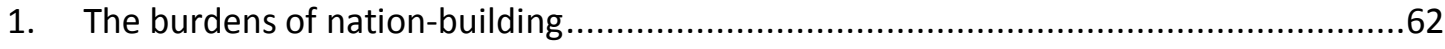

2. Reasonable agreement, ethnocultural neutrality and nation-building ..........................64

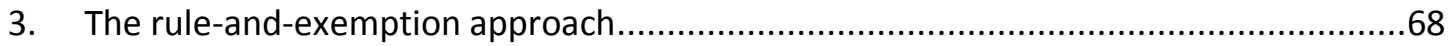

4. A Change in the terms of the debate or a change in focus? Francophone commercial

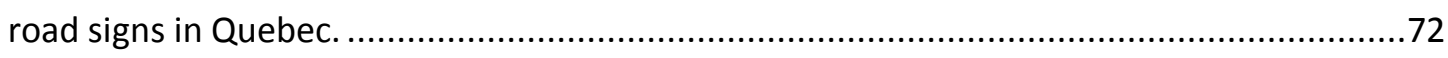

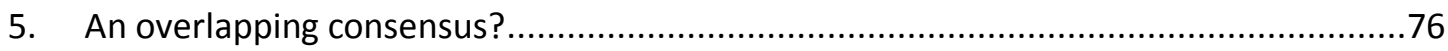

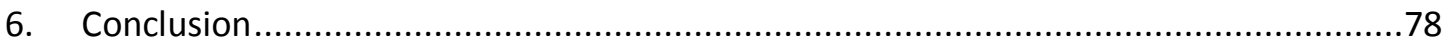

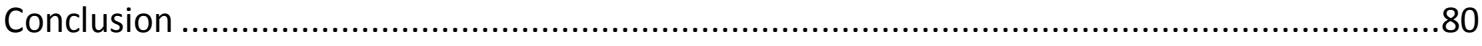

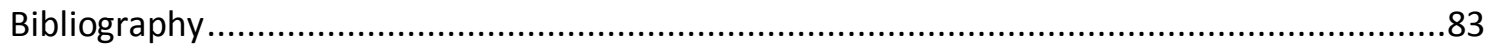




\section{Introduction}

"To be an Indian is to be a man, with all a man's needs and abilities. To be an Indian is also to be different. It is to speak different languages, draw different pictures, tell different tales and to rely on a set of values developed in a different world... But to be a Canadian Indian today is to be someone different in another way. It is to be someone apart-apart in law, apart in the provision of government services and, too often, apart in social contacts" - Statement of the Government of Canada on Indian Policy, 1969

The Canadian government's 1969 White paper on Indian policy set out to ensure "the fundamental right of Indian people to full and equal participation in the cultural, social, economic and political life of Canada" (cited in Turner 2006 p130). The White Paper was bitterly opposed by many Indians as "yet another manifestation of European colonialism" (Turner 2006 p12). It has been criticized for embodying a liberal response to diversity that stresses the importance of individual freedom and equality between individuals. As such, it is argued, the White Paper cannot take adequate account of "equality between legitimate political entities - nations" (ibid p31). Liberalism stands accused, in its focus on individual rights and duties, of assuming that, within any state, there is but one demos that is to be the author and addressee of it own laws. The challenge of national-minority groups, such as indigenous peoples or sub-state nations, such as the Scots, Quebecois, and Catalans is that this assumption is unfounded. Within some liberal-democratic states there are multiple demoi (Requejo 2001 p165).

For their part some liberals have expressed hostility to the idea of minority nationalism. For these liberals the liberal democratic state is marked only by adherence to certain principles of justice and democracy. If states do privilege majority national groups then the answer is not to support the 'equality between nations' that we saw Dale Turner endorse, but rather to dispense with nationalism altogether (cf. Franck 1999 pp45-46). We might think of this as the ideal of the neutral state. It is neutral in the sense that it neither endorses nor supports any ethnocultural group or identity. If people wish to engage in cultural practices and join with others in cultural associations they may, of course, do so, just so long as the rights of others without such affiliations are respected. But those individuals can expect no state help in going about this. Some liberals, however, argue that a shared sense of national identity is not only inevitable even in liberal democratic states but that such a shared identity is desirable too, insofar as it is an enabling condition for liberal democratic principles of justice. For example, Will Kymlicka argues that a shared sense of nationality engenders the trust required in large 
scale anonymous communities for redistributive justice and deliberative democracy. He even argues, as we shall see, that belonging to a nation supports individual freedom (Kymlicka 2001 pp225 - 229).

One might, then, think that there is a clear gap between liberals. On the one hand we have those who think that the liberal ideal is the culturally neutral political state and on the other those who think that, in addition to defending the traditional individual liberties of our first set of liberals, it is desirable for the state to engage in collective projects to support some shared national structure. In one formulation of this division Michael Walzer, following Charles Taylor, distinguishes between 'Liberalism I' which is indeed "committed in the strongest possible way to individual rights and...to a rigorously neutral state.... without cultural...projects" and 'Liberalism II', which "allows for a state committed to the survival and flourishing of a particular nation...or...a (limited) set of nations...so long as the basic rights of citizens who have different commitments or no such commitments are all protected" (Walzer 1992 p99). Crucially, however, Walzer suggests that Liberalism I is an option that a state may take within Liberalism II (ibid p100).

Kymlicka rejects Liberalism I, the idea that there can be a complete separation between culture and state, as "manifestly false" and argues that it should be replaced with a different model of the state, the nation-building model (Kymlicka 2001 pp24 - 27). Once we recognize that states are not ethnoculturally neutral but instead actively promote integration into a shared language and social institutions, so the argument goes, we can see that the burden of proof no longer lies solely on the defender of group differentiated rights to show why the norm of ethnocultural neutrality should be abandoned in the case of the group in question. Instead the nation-building model of the state highlights a number of burdens ${ }^{1}$ that are placed upon members of minority groups, burdens that the model of the ethnoculturally neutral state disguises. Once we see that these burdens are placed on minorities in the normal operation of the state (and are not some anomaly) we can view group differentiated rights as "compensation for unfair disadvantages" rather than a form of cultural discrimination (ibid p33). This nation-building argument seems to represent something of a break from Kymlicka's earlier argument that access to what he calls our own 'societal culture' ${ }^{2}$ is necessary to enable

\footnotetext{
${ }^{1}$ I will say a little more about the nature of these burdens as this thesis progresses. One of my key claims is that what is to count as a burden here, and what weight we ought to attribute to it, is what accounts for significant differences amongst liberals regarding the fairness of group differentiated cultural rights. I explore this more fully in chapter 4.
}

\footnotetext{
${ }^{2}$ A 'societal culture', in Multicultural Citizenship is "a culture which provides its members with meaningful ways of life across the full range of human activities, including social, educational, religious, 4
} 
our fundamental interest in living an autonomous life (Kymlicka 1995 pp80 - 93) as this latter argument, Kymlicka claims, presupposes that the liberal state is ethnoculturally neutral (Kymlicka 2001 p24). Kymlicka's autonomy argument, in short, seems designed to meet a burden of proof that, if Kymlicka is correct, no longer needs to be met.

Kymlicka's nation-building argument is not as widely discussed as his better known argument that access to our own societal culture is an enabling condition for our higher order interest in autonomy and should thus be protected (cf. Kymlicka 1995 pp80 - 93). ${ }^{3}$ It has however received some attention in a recent article by Alan Patten who offers it qualified support. In that article Patten notes that Kymlicka's nation-building argument takes a "fairness-based approach" to minority cultural rights, seeing the existence of such rights "as an injustice preventing condition of majority nation-building" (Patten 2009 p122). Just as Kymlicka seems to do he presents this argument as separate from the one that argues that the protection of cultural structures is required to ensure individual autonomy. The autonomy argument presupposed that the state was ethnoculturally neutral and tried to present a compelling reason to depart from that (Kymlicka 2001 p24). In the nation-building argument it is the recognition of particular injustices caused to minority cultural groups by majority nationbuilding that grounds minority cultural rights (ibid p34).

In this thesis I shall argue for two main claims. First, that Kymlicka's nation-building argument, and some of the normative claims that he wants to make about majority nation-building, can be plausibly made by a proponent of ethnocultural neutrality. Second, neither nation-building nor the autonomy argument stands alone, as both Kymlicka and Patten suggest, but rather are mutually supportive of one another. Kymlicka's fairness based, nation-building argument requires the kind of substantive claims regarding our fundamental interests that are made by his autonomy argument if it is to be compelling. The autonomy argument too requires some

recreational, and economic life, encompassing both public and private spheres" (Kymlicka 1995 p76). A societal culture on this reading is comprehensive and is used, as we shall see in chapter 2 , to ground our fundamental interest in living an autonomous life. In Politics in the Vernacular, on the other hand, a societal culture is less comprehensive being a "territorially-concentrated culture, centred on a shared language which is used in a wide range of social institutions" (Kymlicka 2001 p25). It is, perhaps, less clear how the latter might be necessary for the exercise of our autonomy and, I think, reflects the fact that Kymlicka believes that he no longer requires his autonomy argument to ground the normative claims that he wants to make. I shall not make much of this change in the content of the societal culture. Its main role in this thesis will be in chapter 2 where I discuss Kymlicka's autonomy argument (and thus rely on his earlier account of societal culture which, intuitively, sits more easily with that argument).

${ }^{3}$ Indeed, a recent paper has complained that the trouble with Kymlicka's account of ethnocultural justice that Kymlicka assumes that the normative baseline from which his argument must proceed is that of the impartial, or neutral, state (Cassatella 2006 p94). The argument that I am considering specifically repudiates at least ethnocultural neutrality. 
account of fair distribution if it is going to ground the kind of claims regarding minority nationbuilding and immigrant accommodation that Kymlicka wishes to make. ${ }^{4}$ Further, I suggest that Kymlicka's autonomy argument is not well placed to offer the kind of support that his nationbuilding, fairness based argument seems to require.

The first claim, that Kymlicka's nation-building argument can be plausibly made by a proponent of ethnocultural neutrality, suggests that there is in fact a significant amount of agreement between Kymlicka, who claims to reject the norm of ethnocultural neutrality, and those, such as Brian Barry, who endorse it. However, in establishing that there is this agreement I shall argue that the norm of ethnocultural neutrality cannot be understood as Kymlicka seems to do so, in the rigorous sense of Liberalism I, but rather in the sense that ethnocultural neutrality places limits on appropriate justifications that can be given to legitimize nation-building projects. That is, ethnocultural neutrality does not require that the state undertake no projects that will have effects on some cultural affiliation or other as this is an implausible position. But it is misleading to claim that the only alternative to Liberalism I is a state committed to the survival of a particular culture (as with Liberalism II). ${ }^{5}$ The crucial point of a liberal commitment to ethnocultural neutrality is that state actions that affect cultural (or other) groups within the state must be appropriately justified. The principle of ethnocultural neutrality simply requires that such a justification cannot make reference to the supposed superiority of some culture or other. For some, such as Clare Chambers (Chambers 2003 pp297 - 303) and Alan Patten (Patten 2009 p123), this justificatory account of ethnocultural neutrality is a rival to Kymlicka's own fairness based claims about majority nation-building. I shall suggest that this need not be the case once we recognize that a justification that makes no reference to cultural superiority is not sufficient for some policy or set of arrangements to be considered just. ${ }^{6}$ Instead, a commitment to ethnocultural neutrality merely serves to rule out one kind of justification for a policy or institutional arrangement; that a policy that negatively affects some culture can be justified by reference to the inferiority of that culture or the superiority of some other. But there can be justifications that meet this minimal requirement without thereby being necessarily just as I shall illustrate in chapter $1 .^{7}$ It is for

${ }^{4}$ I will say more about what these claims are as the thesis progresses.

${ }^{5}$ In other words, Walzer's distinction between Liberalism I and Liberalism II upon which Kymlicka implicitly relies is an unhelpful one and should be rejected.

${ }^{6}$ This is a point that Patten concedes (Patten 2009 p123).

${ }^{7}$ I do this by adapting an argument made by Steven Wall (cf. Wall 2001 pp389 - 410). 
this reason that I suggest, in chapter 4 , that a commitment to ethnocultural neutrality must be seen as part of a broader commitment to reasonable agreement amongst individuals.

I do not mean to suggest that a liberal commitment to ethnocultural neutrality can meet everyone's demands or keep everyone happy with its outcomes. There are still going to be disagreements about whether indigenous peoples ought to be assimilated or not, for example. And there are still going to be those who try to justify such a policy by appeal to the supposed 'backward' nature of certain cultural groups (e.g. Flanagan 2000 pp4 - 7). Such a justification will be ruled out by a commitment to ethnocultural neutrality as it rests upon the supposed inferiority of the culture in question. Nor will the principle of ethnocultural neutrality appease those who think that certain demands should be met simply because they are demanded. ${ }^{8}$ Such a justification will be ruled out by the requirement that legitimate justifications must be such that they can be reasonably accepted by others who do not share that way of life or culture. If, however, we recognize the need for compromise or consensus ${ }^{9}$ when faced with (cultural) diversity and disagreement then the principle of ethnocultural neutrality gives us the normative tools with which to approach ensuring that such a compromise is fair.

But even within the normative framework provided by a commitment to ethnocultural neutrality, disagreements will persist. In noting the significant areas of agreement between Kymlicka's position and a commitment to ethnocultural neutrality we shall be better placed to notice the points upon which Kymlicka and those liberals who take a more sceptical view of multicultural policies, such as Barry, differ. These differences, I shall argue, are deep rooted and concern disagreements about what kind of things constitute our higher-order, fundamental interests. ${ }^{10}$ And some account of these interests is necessary if we are to understand what is to count as a burden and how we are to go about distributing those burdens according to the criterion of fairness established by a commitment to ethnocultural neutrality. Such an account of our fundamental interests is given by Kymlicka's autonomy based argument. This argument, of course, relates to my second main claim that Kymlicka's

\footnotetext{
${ }^{8}$ There is something of this position in some of Kymlicka's more recent work where he moves away from the justice based underpinning of minority cultural rights evident in Politics in the Vernacular to accept that the recognition of minority rights claims may be necessary simply to ease ethnic tensions and violence (Kymlicka 2007 p236; cf. Jung 2007 p266).
}

\footnotetext{
${ }^{9}$ For the distinction between the two cf. (Weinstock 2006 pp16 - 19). I will not rely upon a distinction between consensus and compromise in this thesis.

${ }^{10} \mathrm{Cf}$. Caney 2002 who makes a similar argument in relation to Brian Barry's Culture and Equality (Barry 2001). 
fairness based, nation-building argument requires the kind of account given by Kymlicka's substantive, autonomy based argument if it is to be plausible. But this autonomy argument is contentious and is certainly not accepted by all liberals. It is, moreover, not clear how we are to go about distributing the grounds of autonomy (cf. chapter 2). The focus of the debate, then, should not be seen in terms of those who accept the principle of ethnocultural neutrality on the one hand and those who reject it on the other as Kymlicka suggests. This is an unhelpful characterization of the debate. Instead the debate is about what, in regards to culture, is to count as a burden and why. On this issue, despite Kymlicka's claims that the debate has moved on, there is much work to be done.

I shall structure my argument for my two main claims around a distinction drawn by Kymlicka between two ways that liberal principles can be grounded. For Kymlicka the choice facing liberals is between a version of liberalism that sees the ability of individuals to stand back from, and question, their ends as being of paramount importance on the one hand and the toleration of "illiberal groups, so long as they do not seek any support from the larger society, and do not seek to impose their values on others" on the other (Kymlicka 1995 pp154 - 155). The former view Kymlicka equates with his own autonomy argument. The latter view is characterized by Kymlicka by the argument of Chandran Kukathas but also includes the political liberalism of the later Rawls (ibid p155; pp158-170). Faced with this distinction I shall argue that neither position is particularly satisfactory and that, in any case, liberals do not need to accept such a stark choice. With Brian Barry we can say "'Neither of the above"' (Barry 2001 p119). Indeed, as I argue that neither version of liberalism can adequately ground the kind of fairness claims that Kymlicka wants to make about majority nation-building, I shall suggest that the alternative justificatory account of ethnocultural neutrality can also be usefully adopted by Kymlicka, further supporting my claim that there is in fact significant agreement on general principles of fairness between Kymlicka and the liberal tradition that he claims to reject. I will look at autonomy liberalism in more detail in chapter 2 and look at Kukathas' toleration liberalism in chapter 3.

It is important to be clear at the outset about a possible source of confusion in talking about ethnocultural neutrality. When Kymlicka claims that ethnocultural neutrality, understood as the separation of culture and state, does not exist it is not clear whether he understands ethnocultural neutrality as a normative claim, regarding what states ought to do, or as a descriptive claim regarding what they do, in fact, do. Kymlicka claims to be arguing that states are not in fact ethnoculturally neutral. In this respect he points to various ways in which the "proto-typically" neutral USA in fact privileges the English language (Kymlicka 2001 pp24 - 25). The rejection of ethnocultural neutrality appears to be a descriptive thesis. By contrast I will 
defend a normative thesis that claims that in order to be fair policies and institutions should have an appropriate justification.

But distinguishing between normative and descriptive claims does not appear to clear things up. For a start it is not clear who Kymlicka is arguing with. Kymlicka names Michael Walzer as supporting such an account of the ethnoculturally neutral state. But Walzer is clear that, although such ethnocultural neutrality might be the ideal, it is always going to be incomplete (Walzer 1992 p102). Besides, if a liberal, faced with Kymlicka's descriptive argument, were to endorse ethnocultural neutrality as a strict separation between culture and state then they could simply point out that they think that this is what the USA ought to have, even if it does not. The normative ideal of a separation of church and state, they could argue, is not proved false by the existence of a liberal country that does not have such a separation (e.g., Great Britain) nor would it be if no supposedly liberal state actually had such a separation. The separation of church and state is a normative requirement. ${ }^{11}$ Surely, it might be said, so is ethnocultural neutrality. ${ }^{12}$ We can put this concern another way. When Kymlicka talks about states engaging in nation-building he is clearly making a descriptive claim, albeit one that is intended to underwrite normative claims about fairer terms of immigrant integration or minority nation-building. But there are many possible responses to such nation-building. We can apply Walzer's argument that Liberalism I is a possible approach that liberals can take and argue that one response to majority nation-building is to say that it ought not to be done, that there ought to be a complete separation between culture and state. ${ }^{13}$ Why would a response that reaffirmed the norm of ethnocultural neutrality and a commitment to a shared set of liberal principles, such as democracy, individual rights, and unitary citizenship not be a good response as to what the state ought to do instead of majority nation-building?

\footnotetext{
${ }^{11}$ Albeit one fraught with its own complexities and interpretations as even a cursory glance at the history of the US First Amendment indicates. As historian JR Pole notes of the early US republic, many "wished at heart for a system that would be neutral but hospitable to religion, as opposed to the alternative of a neutrality that would seem positively unhospitable...The dilemma has never yielded a completely satisfactory solution" (Pole 1979 p85). That is, Kymlicka is perhaps too quick to suggest that there is a clear application of neutrality to religion that is lacking in the case of culture. Both involve their own complexities.
}

${ }^{12}$ As Clare Chambers puts it, "if the USA does not live up to liberal principles of justice, the conclusion should be that the USA is not a paradigmatically liberal state rather than that such liberal principles are...false" (Chambers 2003 p298).

\footnotetext{
${ }^{13}$ There is something of this in Habermas' approach when he argues that the "level of the shared political culture must be strictly separated from the level of subcultures and pre-political identities (including that of the majority), which deserve equal protection provided only that they conform to constitutional principles" (Habermas 1996 p133).
} 
The answer, I think, lies in understanding the role that nation-building plays for Kymlicka in the formation and maintenance of liberal-democratic states. Understood as a normative claim about what states ought to do (instead of nation-building) the idea of a strict separation of culture and state is simply incoherent, Kymlicka claims (Kymlicka 1995 p113). States cannot help supporting some language more than others, by using it as the language of the state (ibid p111), or in drawing political boundaries that determine the cultural make-up of political units (that make decisions on important cultural matters) (ibid p133). Furthermore, a shared sense of nation-hood is closely linked with the development of liberal-democratic values such as distributive justice amongst large-scale, anonymous communities, deliberative democracy, and even individual freedom (Kymlicka 2001 pp224 - 229). The strict separation of state and culture is false as a description of the actual practice of states. But it is also false as an account of what the state ought to do, partly because it is undesirable (i.e., nation-building grounds liberal principles of justice) and also because it is in any case incoherent (i.e., the state could not do it, even if it wanted to). Ethnocultural neutrality is ruled out as a normative response to nation-building. ${ }^{14}$ I shall not be concerned to argue that states are, in fact, or could ever be rigorously ethnoculturally neutral in the sense of there being a complete separation between culture and state. That is, we can grant Kymlicka his claim that states engage in majority nation-building. The question is, given this, what ought they to do? Kymlicka, of course, rules out the answer that the state should not support or recognize any particular cultural group. But it does not automatically follow that the only remaining viable normative response to nation-building is to recognize minority nation-building or to grant cultural minorities exemptions from generally applicable laws. As will be clear by now, I argue that there is a plausible alternative and that is that majority nation-building ought to be appropriately justified.

The rest of this thesis will proceed as follows;

In chapter 1 I set out Kymlicka's argument that the idea of the ethnoculturally neutral state is false and that majority nation-building places unfair burdens upon members of minority cultural groups and Alan Patten's allegedly rival view of a justificatory account of ethnocultural neutrality (Patten 2009 p123). I will argue that Kymlicka's account of ethnocultural neutrality as the strict separation of culture and state is flawed but that Patten's rival view can also be

\footnotetext{
${ }^{14}$ This normative dimension is important and comes through more clearly in a similar argument in Multicultural Citizenship than it does in his presentation in Politics in the Vernacular. His argument is not only with those who claim that the state is neutral but also with those who claim that the state ought to be ethnoculturally neutral in order to deny minority cultural claims (Kymlicka 1995 p111).
} 
doubted, at least as an account of ethnocultural justice. I will consider the relationship between what Kymlicka has called the second and third stages of the debate over minority rights and introduce his distinction between autonomy and toleration liberalism that will form the basis for chapters 2 and 3 .

In chapter 2 I shall look at autonomy liberalism in more detail. Kymlicka wants to make certain fairness based claims about majority nation-building. One way of grounding such claims is to say that the state ought to avoid nation-building altogether. ${ }^{15}$ This would be the ideal of the ethnoculturally neutral state understood in terms of the strict separation of culture and state. Another alternative would be to say that nation-building is fair just so long as it has an appropriate (ethnoculturally neutral) justification. As Kymlicka explicitly rejects the first option and does not comment upon the second I shall consider an alternative approach that he might take. I shall consider whether autonomy, understood as the fundamental liberal value, can ground a plausible alternative to ethnocultural neutrality and a plausible normative response to majority nation-building. I shall argue that a commitment to autonomy cannot ground an adequate response to majority nation-building. It thus cannot serve as an alternative to ethnocultural neutrality and must be supplemented by the fairness based argument of the third, nation-building, stage. When we do attempt to supplement it with a fairness based argument, however, we shall see that Kymlicka needs to give a more detailed account of our supposedly fundamental interest in our own societal culture, and how it is to be weighed against other interests, if it is to be of use in ascertaining the kind of burden we face if we lose access to our own societal culture. This will be important in chapter 4 where I argue that a complete account of the fair distribution of the burdens and benefits of nation-building requires the kind of account that Kymlicka gives as part of his autonomy based argument. ${ }^{16}$

In chapter 3 I will look at toleration liberalism in more detail. I examine the position taken by Chandran Kukathas in his recent work (Kukathas 2003) and argue that his defence of a policy of benign neglect cannot ground an adequate response to cultural diversity and disagreement. Kukathas' account, I shall suggest, is incomplete. I will then look at Kymlicka's rejection of Rawls' political liberalism and argue that Kymlicka misunderstands the position of those who endorse political liberalism. This defence of political liberalism will be used to highlight the

\footnotetext{
${ }^{15}$ Indeed, perhaps that it should attempt to undo past nation-building.
}

\footnotetext{
${ }^{16}$ That is, Kymlicka's autonomy argument attempts to show that we have a morally weighty interest in our own culture (as a precondition for our higher order interest in living an autonomous life). If we accept this then we will have some reason to think of the loss of our own culture (due to majority nation-building) as a significant burden and perhaps one it is unfair to expect members of minority cultures to face.
} 
important features of the account of ethnocultural neutrality that I shall endorse, in particular the requirement that fair terms of compromise are terms that could be reasonably accepted by others who have a different (cultural) world view. Such an account of ethnocultural neutrality, I will argue, represents a plausible alternative to the autonomy liberalism of chapter 2 and the toleration based liberalism of Kukathas. It also offers Kymlicka a way to normatively assess the fairness of majority nation-building.

In chapter 4 I will look at the justificatory account of ethnocultural neutrality as part of the liberal ideal of reasonable agreement as a response to majority nation-building. I will be concerned to show where those seemingly hostile to minority cultural rights (such as Brian Barry) nonetheless overlap with Kymlicka's account and, importantly, say why I think that this is the case. I will also illustrate this with an example of where I think that Kymlicka's normative claims about majority nation-building rely upon the idea of reasonable agreement (limited by ethnocultural neutrality) in the case of French commercial road signs in Quebec. Employing an argument that Simon Caney makes against Barry in the latter's Culture and Equality, I will attempt to show why the third-stage argument relies upon the debate of the second-stage regarding the interest that we have in our cultural affiliations. This is a pressing worry for Kymlicka, I shall suggest, given the indeterminacy of his own account of such interests (chapter 2). 


\section{Chapter 1: Three Stages in the debate over minority rights}

\section{The three stages}

In his essay 'The New Debate over Minority Rights' in Politics in the Vernacular (hereafter PV) Kymlicka distinguishes three different stages that the debate over the rights of minority cultural groups has taken. (By minority rights we can understand such things as exemptions, on cultural grounds, from generally applicable laws, the funding of cultural groups and associations, guaranteed representation in the political units of the state, and selfdetermination for certain cultural groups (cf. Kymlicka 1995 pp26 - 33)). The three stages, in outline, are as follows;

Stage 1; The debate in stage one is between communitarians and liberals. Liberals, broadly speaking, opposed granting rights to cultural groups as this threatened the privileged status of the individual whilst communitarians saw the protection of such rights as necessary to stave off the pernicious effects of precisely that liberal individualism (Kymlicka 2001 p19). This debate was superseded by the second stage once it was realised that the first stage debate was "an unhelpful way to conceptualize most minority rights claims in Western democracies" (ibid p20). ${ }^{17}$

Stage 2; Once it is recognized that most minority groups do not seek "to be protected from the forces of modernity in liberal societies" (ibid) we can move on to view the debate concerning such rights claims as being a debate that takes place within liberal theory. That is, the debates of this stage are "between individuals and groups who endorse the basic liberal-democratic consensus, but who disagree about...the proper role of language, nationality, and ethnic identities within liberal democratic societies and institutions" (ibid p21). At this stage the debate revolves around why, if such groups are committed to liberalism, they want more than

\footnotetext{
${ }^{17}$ It should be noted that Kymlicka's autonomy based 'context-of-choice' argument, which I shall look at in more detail in the next chapter, also offers a philosophical challenge to the communitarian claim. It says, in effect, that liberalism does not need to rely upon a purely voluntarist conception of our communal attachments and can accept that many of our beliefs are grounded in our cultural community. As a liberal account, however, it also claims that we are able (indeed, and this is more controversial, it is desirable for us) to step back and assess the worth of these ends from within that context-of-choice (cf. Kymlicka 1989b). The concern of this thesis is with the move from stage two to stage three, which has been the subject of less discussion in the literature, and so I will not say much about this stage one argument.
} 
"the traditional common rights of citizenship" (ibid). Kymlicka places his own argument that access to a secure cultural structure is necessary as a 'context-of-choice' for our higher order interest in leading autonomous lives (and thus deserves protection from the activities of majorities) (Kymlicka 1995 pp80 - 93) in this second stage. But this stage is also superseded, claims Kymlicka, as it misunderstands the particular burdens that the liberal state places on minority groups (Kymlicka 2001 p23).

Stage 3; The second-stage, Kymlicka claims, assumed that the liberal democratic state "is 'neutral' with respect to the ethnocultural identities of its citizens, and indifferent to the ability of ethnocultural groups to reproduce themselves over time" (ibid). As such it was assumed that the burden of proof lay with those who wanted to depart from this norm. But, Kymlicka claims, this norm of ethnocultural neutrality is "manifestly false" (ibid p24) as the liberal state, in its normal operation, in fact engages in majority nation-building which Kymlicka understands as the "process of promoting a common language, and a sense of common membership in, and equal access to, the social institutions based on that language" (ibid p27). Whilst this process can be beneficial in terms of integrating immigrant groups, especially, into the mainstream society it can nonetheless place burdens on both immigrants and members of national-minorities who are placed under pressure to adopt the majority culture or face economic and political marginalization (ibid pp27-28). As Alan Patten puts it the third stage sees "minority cultural rights as an injustice-preventing condition of majority nation-building" (Patten 2009 p122).

In the remainder of this chapter I set out Kymlicka's argument that the idea of the ethnoculturally neutral state is false and that majority nation-building places unfair burdens upon members of minority cultural groups. I will also outline the supposedly rival view of a justificatory account of ethnocultural neutrality. I will argue that Kymlicka's account of ethnocultural neutrality as the strict separation of culture and state is flawed but that the justificatory account of ethnocultural neutrality can also be doubted. I consider the relationship between what Kymlicka has called the second and third stages of the debate over minority rights and introduce his distinction between autonomy and toleration liberalism that will form the basis for chapters 2 and 3 . 


\section{Two kinds of neutrality: separation of culture and state and neutrality of justification}

When liberals talk about neutrality, and the neutral state, what do they mean? We have already seen that Kymlicka, following Walzer, takes such a state to be 'rigorously neutral', to undertake no cultural projects. As Clare Chambers has pointed out, however, Walzer in fact claims that most states do not claim to be neutral in this sense at all. Most liberal democratic states do support the culture of the majority group "with no visible anxiety" (Walzer 1992 p100) and make no claim to be ethnoculturally neutral in the sense that Kymlicka means (Chambers 2003 p301). But Walzer does claim that at least one state, the USA, is neutral in the rigorous sense (Walzer 1992 p101). Kymlicka points out that this is not the case, that even the "proto-typically 'neutral"' state that is the US has made decisions (including the admission of States into the Union, the requirement to learn English in public schools and, for immigrants, to gain citizenship and as a condition of employment for government jobs) that has "helped establish the dominance of English throughout the territory of the United States" (Kymlicka 2001 pp24-25).

However, even in regards to the US Walzer admits that "state neutrality is often hypocritical, always...incomplete" (Walzer 1992 p102). When proponents of Walzer's Liberalism I talk about neutrality it seems implausible to suggest that they mean the kind of separation of culture and state that Kymlicka attributes to them. ${ }^{18}$ It would certainly seem strange to think that they had not noticed that most states have a de facto or de jure official language, to take Kymlicka's example. As Chambers puts it, "(i)f ethnocultural neutrality can be violated simply by the existence of an official language - regardless of the effect that language has on ethnocultural groups or the reasons given for preferring that language - surely it would be perverse for any liberal to propose that states should be run according to ethnocultural neutrality, much less that any existing states are run in such a way" (Chambers 2003 p300).

To return to a point made in the introduction to this thesis, Kymlicka seems to be putting forward a particular descriptive thesis about what states do and do not do (or, perhaps, can

\footnotetext{
${ }^{18}$ Walzer's rendering of Liberalism I follows that of Charles Taylor who argues that liberalism aims to "offer a neutral ground on which peoples of all cultures can meet and coexist" but that this is not the case because it will inevitably conflict with some (i.e., illiberal) world view (Taylor 1992 p62). As Brian Barry pointedly puts it; "Unless you take it as axiomatic that liberals are complete cretins, prudence might counsel caution here. If the claim to offer 'neutral ground' can be dismissed as easily as Taylor supposes, would it ever have been put forward?" (Barry 2001 p27). Barry's answer is, of course, that it would not.
} 
and cannot do). They do not, because they cannot, separate culture entirely from the normal operation of the state. Instead, Kymlicka claims, they engage in nation-building programmes that aim to diffuse a shared language and institutions throughout the state (Kymlicka 2001 p27). But Kymlicka does want to make certain normative claims regarding the fairness of that nation-building. And liberals who endorse the principle of ethnocultural neutrality will also want to make normative claims about the actions of states that affect cultural groups. Kymlicka, of course, argues that they cannot make the normative judgement that nationbuilding is unfair insofar as such nation-building ignores the separation between culture and state, because such a position is incoherent. It can never be realised. But does this mean that we should give up on ethnocultural neutrality altogether and simply accept the particular normative claims that Kymlicka wants to make about majority nation-building, such as the claim that minority national groups should be given the tools to nation-build as a requirement of fairness (ibid pp28 - 29)? I do not think that liberals who endorse ethnocultural neutrality need accept this conclusion. They do not need to accept this conclusion even if they accept Kymlicka's descriptive claim about the nation-building state and this is because it is far from clear that liberals who endorse the principle of ethnocultural neutrality actually do endorse the separation of culture and state. That is to say, when faced with the description of the state as nation-building there are a number of normative responses that can be made. The question is, is there any way of understanding ethnocultural neutrality as a normative response to nation-building that does not rely upon the separation between culture and state? I think that there is.

When liberals talk about the neutral state they almost certainly do not mean that there is, or even necessarily ought to be, the complete separation of culture and state that Kymlicka attributes to them. As John Rawls points out, 'neutrality' can be understood in a number of different ways and some of these ways are impractical and some highly misleading (Rawls 2005 p191). Rawls favours what I am calling neutrality of justification ${ }^{19}$ which claims that the state is neutral insofar as it does not do anything that is intended to promote some (cultural) way of life over another (ibid). But this is somewhat ambiguous as it stands. When the USA requires schoolchildren to learn English in schools it might plausibly be said that it favours that language over others even if it is to achieve some other, desirable end. Indeed, Kymlicka specifically notes that majority nation-building is undertaken with the intention of spreading a particular national culture throughout society (Kymlicka 2001 p27). In order to get around these difficulties in determining what it is that states intend to do when they endorse an official language, for example, we can say instead that a policy such as ensuring that English is

\footnotetext{
${ }^{19}$ He calls it neutrality of aim (Rawls 2005 p193).
} 
taught as a first language in all schools is neutral if it the policy in question does not have as its justification the supposed fact that English is a superior or more worthy language than any other. In this sense, if the intention of the USA was to teach English in public schools in order to ensure more equal access to the economy then this would seem to pass the test of ethnocultural neutrality despite the fact that it marginalizes other languages.

It is this account of ethnocultural neutrality, understood in terms of giving suitable justifications for policies and institutions, which I am defending in this thesis. Such an account is not shown by Kymlicka to be manifestly false. But I want to say a bit more than this. In particular I want to argue that such a justificatory account of ethnocultural neutrality, if it is to be an account of what constitutes fair action on the part of the state, must be part of a broader account of reasonable agreement amongst individuals. That is, what is important in assessing the fairness of a policy is to ask whether it is such that those who will be likely burdened in some way by it could be asked to reasonably accept it. If they could not because there is some alternative, viable policy that means that no-one need bear those burdens, then the policy is unfair and can be rejected on those grounds.

Why is it not enough to say that a policy is fair just so long as it does not have as its fundamental justification the superiority of some culture or other or the advantaging of some way of life? This, for example, is the position taken by Clare Chambers when she argues, as I will, that Kymlicka does not show that the principle of ethnocultural neutrality is manifestly false (Chambers 2003 p299). It is also how Patten characterizes the rival view to Kymlicka's own fairness based claims (Patten 2009 p123). Both suggest that an adequate response to a charge of unfairness might be to point to justifications for the putatively unfair arrangement that are based on something other than the superiority of some culture or other. But such an answer, although not manifestly false, is unlikely to convince many liberals as to the fairness of any particular policy, nation-building or otherwise. To see this, consider the following example;

A group of mining companies seek approval from the Australian government to mine Coronation Hill, or Guratba, in Kakadu National Park, Australia. Coronation Hill is a registered sacred site for the indigenous Jawoyn people who claim traditional ownership over the land and for whom the land has special significance as the resting place of Bula, a Creation era ancestor (Cf. Hamilton 1996 p4).

Here are two justifications in favour of mining:

(A) The beliefs of the Jawoyn are "fantasy, stupidity and claptrap". Mining should be permitted so that Australia can rid itself "of the burden of primitive superstition" (cf. 
Mandle 1991, cited in Hamilton 1996 p11). The mining goes ahead and has the intended effect - the Jawoyn community, and associated beliefs, lose adherents.

(B) The government decides to permit mining. It justifies its decision in relation to the economic value of mining and because not mining "would have a major impact on the national investment climate and would be regarded by many as acting as a precedent for future decisions" (Business Council of Australia, cited in ibid p14). The policy is not intended to disadvantage the way of life of the Jawoyn but (and this would be reasonably foreseeable) the Jawoyn community, and associated beliefs, lose adherents.

The significant moral difference between $(A)$ and (B), according to Chamber's approach, lies in the intention behind the justification. $(A)$ is not a neutral justification and is for that reason prohibited whilst (B) does seem to count as a neutral justification and so would be permitted. ${ }^{20}$ Of course the Jawoyn might see things differently but, as any state of affairs is likely to place burdens on some, they have no cause for complaint so long as (B) provided the relevant justification. But this is not only unlikely to satisfy members of the Jawoyn but is also unlikely to be satisfactory for many liberals, at least as an account of justice. It is unlikely that those committed to liberal principles of justice will hold that (B) is sufficient for justice and this is because they will also hold other, deeply held beliefs about justice. Let us take two examples, both from Ronald Dworkin. Firstly, Dworkin argues for a kind of resource egalitarianism ${ }^{21}$ which, as Kymlicka succinctly puts it, allows for "differences in holdings due to people's choices, but rectify inequalities due to people's natural endowments or social circumstances" (Kymlicka 2001 p330). In both cases members of the Jawoyn lose the same goods (e.g. resources over which the Jawoyn claim traditional ownership and a viable community, and associated way of life, based around the religious significance of those resources). In both cases, then, we might say that the Jawoyn suffer a disadvantage that is a matter of circumstance (Guratba having valuable mineral deposits that others want and the actions of

\footnotetext{
${ }^{20}$ That is, it is neutral in the sense that Chambers understands neutrality. Justification (B) does not have as its fundamental rationale the privileging of some cultural way of life or other (or the truth, or goodness etc of some conception of the good as opposed to some other - for example, that of the Jawoyn). My aim in this section is to suggest that simply providing a justification that does not make reference to the worth of some conception of the good or other will not necessarily be sufficient for the resulting policies based upon such a justification to be considered just.

${ }^{21}$ Cf. Dworkin 2004 pp340 - 341. Kymlicka also endorses resource egalitarianism (Kymlicka 2001 pp330 -331).
} 
individuals outside of the Jawoyn community ${ }^{22}$ ) rather than choices made by members of the Jawoyn. In (A) and (B) the Jawoyn's disadvantage is the result of social circumstances and not a choice that they themselves have made. The straightforward sense of justificatory neutrality, which claims that policies that meet its criteria are acceptable "regardless of the effects on cultures" (Chambers 2003 p299) is in some tension with another plausible criterion of liberal justice. $^{23}$

A similar concern can be expressed about the status of rights within the account of justificatory ethnocultural neutrality given by Chambers. A neutral justification, such as (B) will not tend to be sufficient, for example, where acting on that justification will result in the violation of some right possessed by the individual (or group). This is the sense in which Dworkin claims that rights act as 'trumps' "over some background justification for political decisions that states a goal for the community as a whole" (Dworkin 1985 p359, emphasis added) . ${ }^{24}$

Chambers is correct to point out that Kymlicka's account of the ethnoculturally neutral state, as realizing a complete separation between culture and state, is not an account of ethnocultural neutrality that liberals need be, or are, committed to. She rightly points to other

${ }^{22}$ We might, however, think that in (B) the government has simply not acted if we take Steven Wall's account of state inaction; “The state 'allows' an event to happen if and only if it does not prevent the event from happening and it was in the state's power to prevent it from happening" (Wall 2001 p392). As with Wall's account of the tension between neutrality of justification and principles of distributive justice, a tension which my account draws upon, the distinction between doing/ not doing makes little difference to my argument. Besides, as we are concerned with nation-building programmes many state policies (that seek a neutral justification) will be examples of 'doing' (e.g., "promoting a common language" (Kymlicka 2001 p27), not merely allowing a common language to take root).

${ }^{23} \mathrm{cf}$. Wall 2001 pp389 - 410 for a more complete version of this argument including the claim that neutrality of justification collapses into neutrality of effect. Wall argues that neutrality of justification is incompatible with egalitarian principles of justice, as I too have suggested, but also that it is incompatible with what he calls the 'comparative-possibilities approach' (ibid p395). I shall endorse this comparative-possibilities approach in chapter 4 but do so by making justificatory neutrality (as put forward by Chambers and Patten) act as a limitation on reasonably acceptable justifications which, I shall claim, underpins the comparative-possibilities approach.

\footnotetext{
${ }^{24}$ I do not wish to imply that the Jawoyn, individually or as a community, necessarily have a right that would be claimable against (B). The point is rather that the norm of ethnocultural neutrality as presented by both Patten and Chambers is not always going to be sufficient for some policy to be just. To assert that they have such a right would be to beg the question at this stage. The point is, however, that it is equally question-begging to assume that they do not have such a right. We might, of course, hold that an account of our rights needs to be neutrally justified and (if we hold an interest based account of rights) perhaps consider appropriately justified rights to trump appropriately justified community goals (cf. Schaller 2004 pp645 - 646). However, we still need some account of what is to count as a suitably weighty interest and how they are to be balanced against one another. In this thesis I talk about fundamental interests rather than rights, following what seems to be Kymlicka's preference, in PV at least (cf. Kymlicka 2001 p90 n32).
} 
work by Kymlicka where he concedes this point. ${ }^{25}$ My defence of ethnocultural neutrality will also take this idea as its core. However as the example above shows it is far from clear that the rival justificatory account of ethnocultural neutrality captures the full extent of the liberal position and even suggests that, in some cases, it will be in tension with other, equally deeply held convictions.

We can put this another way. Kymlicka claims that his rejection of ethnocultural neutrality means that "few thoughtful people continue to think that justice can simply be defined in terms of difference-blind rules or institutions" (Kymlicka 2001 p33, emphasis in the original). If Kymlicka means by 'difference-blind' the separation of culture and state then he is correct although it is not clear who actually maintains such a position. But if he means by 'differenceblind' rules, rules that have a neutral justification (in the sense outlined by Chambers) then there are also reasons to think that justice cannot be simply defined in such terms. I shall argue that what is important about the justificatory sense of ethnocultural neutrality is its close link with the idea of reasonable agreement, on giving terms that it would be reasonable for others to accept (or, in T M Scanlon's formulation, which I shall later draw upon, would be unreasonable for them to reject). Once we do this we can see that those committed to the norm of ethnocultural neutrality can make the same kind of normative claims about the nation-building state that Kymlicka wants to make. Not only is ethnocultural neutrality not shown to be manifestly false by majority nation-building but it offers a plausible way for Kymlicka to make the kind of fairness based claims that he wants to make about such nationbuilding.

\section{The link between stages 2 and 3}

Kymlicka wants to make a set of specific fairness based judgements about majority nationbuilding. For example, he claims that it is intuitively fair that minority national groups also be given the necessary tools to nation-build (Kymlicka 2001 pp28 - 29) or that the rules and symbols regarding dress-codes, school curricula, public-holidays, and even weight and height requirements for certain roles are altered so as to permit fairer terms of integration for immigrants (ibid pp29-32, pp162-172). But, as Patten notes, it is unclear what general account of fairness is supposed to ground these specific fairness-based claims (Patten 2009

\footnotetext{
${ }^{25}$ Of interest here, for example, is Kymlicka's claim in Liberalism, Community and Culture that he is interested in the justificatory account of neutrality ("that governments cannot use as their justification for any action the fact that one person's way of life is more or less worthy that another's" (Kymlicka $1989 \mathrm{~b}$ p96 n2)) because this is what liberals such as Rawls, Dworkin, and Nozick understand by the term (ibid; Chambers 2003 p299).
} 
p123). Undoubtedly nation-building policies will place certain burdens on some people, especially those with different cultural beliefs from the majority. But then almost any policy is likely to place burdens upon somebody. It is not clear how we are supposed to weigh the burdens and benefits of majority nation-building against one another and against alternative, viable scenarios (including, for example, guaranteed representation for certain ethnocultural groups).

The question is, what makes majority nation-building unfair? One answer that I have looked at is that it is unfair because it places particular burdens upon members of minority cultural groups. But majority nation-building is also beneficial in helping to ensure equal access to mainstream institutions as well as enabling liberal-democratic principles of justice by enabling social solidarity and trust, as we saw in the introduction (Kymlicka 2001 p26). But until we know what is to count as a weighty burden and why, it is difficult to assess the fairness of majority nation-building or the fairness of alternative proposals such as exemptions from generally applicable laws on cultural grounds, guaranteed representation, and selfdetermination. ${ }^{2627}$

Kymlicka could, on the other hand, be making an appeal to the inconsistency of the position of those who would permit majority nation-building but oppose minority nation-building. This seems to be the case when he argues in favour of minority nation-building. If the tools to nation-build are to be granted to members of the majority nation then a concern with fairness seems to require that they be granted to members of the minority nation too. And here the opponent of minority nation-building cannot point to some ideal of separation of culture and state to ground her opposition because this is not a viable, coherent alternative (Kymlicka

\footnotetext{
${ }^{26}$ This argument will feature in chapter 4. It is similar to an argument that Simon Caney makes regarding
} Brian Barry's Culture and Equality (Caney 2002 pp81 - 98).

${ }^{27}$ Some of the burdens of majority nation-building may seem intuitively unfair, as Kymlicka argues. But then there are cases where our intuitions may pull us away from granting minority cultural rights. If I am exempted from paying my employees social security contributions, on cultural-religious grounds (as was argued, unsuccessfully, by a member of the Amish community in US v Lee ((1982) 455 US 252)) then I might be thought to have gained an unfair advantage over those businesses that do have to pay social security contributions. Or take the proposal that certain groups should be guaranteed representation in the legislature of the state in order that the legislative process reflects, in some way, the diverse makeup of the population. Thomas Pogge has argued against favouring some groups in this way on the grounds that it violates the "ideal of treating all citizens as equals, regardless of their identities and affiliations" (Pogge, cited in Brock 2002 p289). Pogge's argument is based upon the idea that group affiliations are important to people but that it discounts "the value and equality" (ibid) owed to members of non-favoured groups. So, in New Zealand, Māori have guaranteed representation in the legislature. But this is not extended to members of other cultural groups and nor is it extended to other (non ethnocultural) groups with which people may feel a deep identification. The important point for our purposes here is that intuitions about fairness cut both ways. What is required is some broader account of fairness. 
1995 p111). Minority nation-building should be subject to the same set of liberal limitations on the treatment of members of the nation as majority nation-building but, assuming this is met, then "all else being equal", consistency requires that minority nation-building be undertaken (Kymlicka 2001 p29).

On the face of it, then, we seem to have two arguments regarding the fairness of majority nation-building. The first is that it places burdens on members of the minority which ought to be removed. I have already noted a problem with this and that is that we require some account of what is to count as a burden and of what weight we are to attach to different burdens. The second argument is that it is inconsistent to deny to one set of people what is granted to another, the tools to nation-build, so long as the latter are subject to the same limitations as the former. This second argument makes reference to the fact that nationbuilding is inevitable and also normatively desirable insofar as it helps to ground liberal principles of justice but that these features can apply, inter alia, to minority nations too. That is, by appealing to the inevitability of nation-building policies and the multi-nation status of many liberal states it seems that Kymlicka can by-pass the need to provide some account of what is so burdensome, in particular, about majority nation-building. Minority nation-building rights are required as a matter of consistency. I shall spell out this argument again in chapter 4 in terms of reasonable agreement. Put in those terms we can say that it would be unreasonable to expect members of some national group to agree to nation-building for others but not themselves.

But this second consistency based argument faces problems. Firstly, of course, it only really applies to minority national groups. For Kymlicka immigrant groups have a different set of entitlements because they have made a choice to leave behind their own societal culture and enter a new one and so can be reasonably expected to have waived their right to access to their own societal culture (Kymlicka 1995 p96; Kymlicka 2001 p55). As such immigrants differ from national-minorities insofar as the former have made a choice whilst the latter's position is a result of external circumstance. Despite the role that choice plays in distinguishing the fairness of national-minority claims and immigrant claims, Kymlicka wants to argue that immigrants can nonetheless demand fairer terms of integration into the majority societal culture. But if the requirements of fairness are being determined by the choice/ circumstance distinction then it is not clear why immigrants should be entitled to demand fairer terms of integration at all. It is not clear why they should not be expected to bear all the costs that arise from their choice (Quong 2006 pp56 - 57). As Kymlicka admits, the requirements of fairness are not always clear and that this is brought to the fore when we consider the rights of immigrants (Kymlicka 2001 p30). When we try to see what broad account of fairness Kymlicka 
is working with we run into certain tensions with the specific claims that he wants to make, such as that provided by the choice/ chance distinction in the case of immigrants. In order to be a compelling account of the unfairness of majority nation-building Kymlicka needs to give just such a broad account of fairness that is able to ground the kinds of claims that he wants to make. In chapter 4 I shall argue that just such an account is provided by the justificatory account of ethnocultural neutrality.

The second problem relates less to the broad account of fairness that Kymlicka is using and more to a need to give some account of what is to count as a burden. Here we need only look at minority nation-building. Kymlicka's qualification that support for minority nation-building is fair 'all else being equal' is important. One set of limitations will be provided by Kymlicka's stipulation that minority nation-building should be subject to the same liberal constraints as majority nation-building. He spells this out in terms of a prohibition on ethnic-cleansing or the violation of basic human rights (Kymlicka 2001 p29). Although these are important limitations and, sadly enough, not always adhered to by majority or minority national groups I think that liberals will want to give a more complete account of when nation-building is permissible. They will want to say something about how the costs of such nation-building ought to be distributed. And they will need to say something about those occasions where there is conflict between national groups, for example over territory. And there will also be occasions where the benefits of assimilation into a larger national group might seem to outweigh the benefits of maintaining one's own societal culture, operating in one's own, ancestral, language. As we shall see Brian Barry argues that this will be the case when maintaining one's own language (and institutions operating in that language) will condemn people to unemployment or deadend jobs (Barry 2001 p228). Kymlicka claims that what is required is a theory of permissible nation-building. That is, we should be asking why national-minorities should not have the same tools to nation-build as the majority (Kymlicka 2001 p29). But in order to answer this question we do not need a new theory of nation-building, we need some account of when access to our own societal culture, rather than assimilation in some other, should be a determinate factor when weighing up the distribution of burdens and benefits that will be likely to befall individuals as result of minority nation-building or maintaining the status quo. ${ }^{28}$ Kymlicka's fairness based claims require both a general account of fairness, which I shall claim can be provided by a norm of ethnocultural neutrality, and an account of what is to count as a burden or a benefit and what weight we ought to attribute to them as against other burdens and benefits.

${ }^{28}$ Or, indeed, taking some other course of action. 
So, I do not think that Kymlicka's third-stage, nation-building argument can stand alone from some account of the role and importance that nations, language, culture, and identity ought to play in liberal-democracies. These questions need to be answered because otherwise Kymlicka's specific fairness based claims are indeterminate. These questions, Kymlicka notes, are questions that belong in the second-stage of the debate over minority cultural rights (Kymlicka 2001 p21). Fortunately enough Kymlicka's work is full of accounts of why belonging to our own national group is of significant importance for individuals. There is, for example, his much discussed claim that access to our societal culture is necessary to provide us with a context-of-choice that allows us to realise our fundamental interest in leading an autonomous life.

Unfortunately Kymlicka's second-stage, context-of-choice argument is not only not accepted by all liberals but is also of little help when we come to think about the fair distribution of burdens and benefits in nation-building states. As this is one of the themes of the next chapter I shall leave further discussion until then. The important point for the moment is this; Kymlicka's third-stage, fairness based nation-building argument not only requires some general account of fairness if it is to be plausible, which Kymlicka does not provide, but also needs to make reference to the sort of conclusions reached by the argument of the secondstage if we are to obtain any substantive conclusions regarding the fairness, or otherwise, of majority nation-building policies.

\section{Autonomy and toleration liberalism}

So far I have cast doubt upon Kymlicka's reliance on the Walzerian distinction between a state committed to the strict separation of culture and state, on the one hand, and a state "committed to the survival and flourishing of ... a (limited) set of nations, (and) cultures" (Walzer $1992 \mathrm{p99}$ ) on the other. Whilst I do not think that liberals committed to ethnocultural neutrality are committed to anything like the former of the two positions I have also doubted whether the justificatory account of ethnocultural neutrality is an unproblematic feature of liberal justice in culturally diverse states. In the previous section I noted that Kymlicka wants to make a set of specific fairness based judgements about majority nation-building but that he does not make it clear on what basis these are made or how we are to weigh the burdens and benefits of majority nation-building against one another and against alternative, viable scenarios (including, for example, guaranteed representation for certain ethnocultural groups). 
A further important distinction drawn by Kymlicka is that between autonomy as the fundamental value of liberal theory and toleration as that fundamental value. For Kymlicka, who endorses the former, liberal principles are grounded by the importance to human lives of being able to stand back from and revise our ends (Kymlicka 1995 p81). This focus on autonomy as the fundamental liberal value can be used to ground a number of distinctively liberal rights such as freedom of conscience and speech. It is also used by Kymlicka to ground the kind of minority cultural rights that help to protect societal cultures which, as we saw in section 3, he claims provide us with the context-of-choice required to exercise our autonomy. A commitment to autonomy will also place limits on the kind of rights that minority groups can claim. Groups cannot legitimately claim rights that aim to restrict the basic civil liberties of their members or that seek to oppress other groups (ibid p152). If we accept that autonomy is the fundamental liberal value then only cultural practices and beliefs that support the exercise of critical reflection, and hence autonomy, will be of value.

Kymlicka suggests that autonomy liberalism is compatible with a norm of liberal neutrality (Kymlicka 1989a pp883 - 886; Kymlicka 2004 p116). But as, in this thesis, I am concerned with Kymlicka's claim that ethnocultural neutrality is manifestly false I am more interested in exploring autonomy liberalism as a rival to that neutrality in grounding a response to majority nation-building. If Barry is correct and autonomy is not compatible with liberal neutrality, insofar as the former is a second-order conception of the good (Barry 1995 p129), then it might be able to ground a plausible alternative to ethnocultural neutrality. This is important to Kymlicka's project for, as we have seen, he wants to make specific normative judgements about the fairness, or otherwise, of majority nation-building. One way of grounding such fairness claims is by comparing such nation-building with the norm of ethnocultural neutrality and seeing how far it falls short. As this appears not to be an option for Kymlicka, autonomy might provide the answer. Although Kymlicka does not make this argument there is some precedent for this approach that takes autonomy to be a rival to liberal neutrality, not only in the work of supporters of such neutrality, such as Barry, but also in defenders of the value of autonomy such as Joseph Raz ( $\operatorname{Raz} 1986)$ as we shall see in more detail in the next chapter.

I do not think that autonomy liberalism provides a plausible response to majority nationbuilding. I shall argue this in more detail in the next chapter. In fact, I shall argue, a reliance on autonomy sits somewhat uneasily with the fairness based arguments of the third stage. In chapter 4, however, I will argue that Kymlicka's fairness based, third-stage argument relies upon the kind of account provided by his autonomy based context-of-choice argument to convincingly ground the kind of normative claims that he wishes to make about majority nation-building. That is, to return to our question of the link between the second and third 
stages that we considered in the previous section, the second-stage context of choice argument requires the third-stage fairness based argument and vice versa. The problem, as we shall see in the next chapter, lies in specifying what, exactly, our higher-order interest in autonomy (if we have one) requires us to do in nation-building situations. Where difficulties arise they arise, I think, at this second-stage. Chapter 2 will thus support my contention that the justificatory account of ethnocultural neutrality can provide a plausible response to majority nation-building (where autonomy fails) but that the important normative debates remain firmly rooted in the debates "about the proper role of language, nationality, and ethnic identities" (Kymlicka 2001 p21) of the second-stage. Focusing on autonomy is of little help in grounding a plausible fairness based response to majority nation-building policies as Kymlicka's argument stands.

If I am correct and autonomy cannot ground an adequate response to majority nation-building then, following Kymlicka's dichotomy, we might expect to have to rely upon toleration liberalism instead. Further weight is given to this conclusion if we accept that there are minority cultural groups that do not value Kymlicka's comprehensive autonomy but who, nonetheless, might be willing to accept the legitimacy of liberal institutions and principles of justice just so long as those principles do not require them to endorse a position that they reject. One way of spelling this out is in terms of reasonable agreement amongst suitably situated moral agents. This is the position that, spelt out in more detail, I will end up defending in chapter 4. But before we reach that point we will need to look at Kymlicka's rejection of toleration liberalism.

Given that Kymlicka's second-stage argument in favour of protecting societal cultures as contexts-of-choice relies upon the acceptance of autonomy as being of fundamental value it is perhaps not surprising that Kymlicka wishes to reject any grounding for liberal principles of justice that does not rely upon that autonomy. It will be important to look in some detail at Kymlicka's rejection of toleration liberalism. If neither autonomy liberalism nor toleration liberalism can be expected to ground a fairness based response to majority nation-building then it appears that the third-stage, nation-building project of viewing minority cultural rights as Patten's "injustice- preventing condition of majority nation-building" (Patten 2009 p122) is in some jeopardy. Whilst I think that Kymlicka is correct to reject some kinds of toleration liberalism, notably that put forward by Chandran Kukathas (cf., chapter 3 ), he also attempts to reject the political liberalism of John Rawls, in particular, as a version of toleration liberalism. I think that Kymlicka's criticisms of Rawls miss their mark and that, although Rawls' particular account of political liberalism and reasonable agreement might be rejected, this enables us to begin putting together an alternative to the autonomy/toleration dichotomy that Kymlicka 
puts forward. This alternative will draw upon the idea of justificatory ethnocultural neutrality as a feature of reasonable agreement and thus forms part of my defence of the principle of ethnocultural neutrality as against Kymlicka's charge that it is manifestly false.

Kymlicka's distinction between autonomy and toleration liberalism can be said to form the structural core against which this thesis is constructed. I use it not only to raise what I consider to be some pertinent questions about the third-stage nation-building account of the state (and the questions that such an account asks in return of liberal theory) but also, in part, to motivate the argument in favour of my preferred justificatory account of ethnocultural neutrality as a feature of reasonable agreement in chapter 4 . I should point out, however, that the argument in chapter 4 does not rely solely upon the acceptance of the autonomy/ toleration distinction.

\section{Conclusion}

In this chapter I have attempted to spell out some of the features of Kymlicka's third-stage, nation-building argument that will be important in the rest of this thesis. The core of the thesis contests Kymlicka's claim that ethnocultural neutrality is manifestly false. Kymlicka's rejection of the idea of the ethnoculturally neutral state seems to rest, in large part, upon Walzer's account of Liberalism I and Liberalism II. Pointing out that ethnocultural neutrality, understood in terms of a strict separation between state and culture, is not in general what liberals mean when they talk about neutrality is the easy part. As Chambers notes, in early work Kymlicka himself admits this (Chambers 2003 pp289 - 299). Things become more difficult when we come to look at how the rival view of ethnocultural neutrality, that claims that a state of affairs is fair just so long as it has a neutral justification, fits in with majority nation-building policies. As we saw in section 2, when we looked at the Jawoyn, it appears that justifications that meet such a criterion may conflict with other deeply held and intuitively plausible principles of justice. Justificatory ethnocultural neutrality does not seem to be sufficient to secure the fairness of majority nation-building policies.

Kymlicka wants to make certain fairness based claims about majority nation-building, that they place burdens on members of minority cultural groups. But an account of the fair distribution of burdens and benefits cannot rest with the simple elucidation of a list of such burdens. Kymlicka needs to provide an account of what broad principles of fairness he is relying on to ground the specific judgements he makes about, say, the right to minority nation-build (and to receive the tools to do so). Even with such an account in place, however, he also needs to say 
what weight we are to give to different burdens. Without such an account it is unclear how we are to weigh the burden of not having access to one's own ancestral societal culture (but access to a societal culture) against the costs involved in putting the relevant institutions in place to support such a societal culture. In some instances, especially where minority nationbuilding has already had some success in maintaining a discrete societal culture (such as in Quebec), such questions of balance may not be as pressing as they would be in situations where the minority societal culture has largely been lost (i.e., where assimilation has been successful). Kymlicka's answer that autonomy is what is of fundamental interest in human lives is, as we shall see in the next chapter, of little help here.

One way of thinking about what could ground the kind of fairness based claims that Kymlicka wants to make in his third-stage, nation-building argument is in terms of Kymlicka's distinction between autonomy based liberalism and toleration based liberalism. Both could provide the grounding that Kymlicka's fairness claims seem to require. However, I shall suggest that neither is very satisfactory. Autonomy, at least as Kymlicka spells it out, actually appears to be in tension with fairness in nation-building situations whilst toleration, in the form of Kukathas' defence of a policy of benign neglect, is equally flawed (as we shall see in chapter 3 ). It is at this point, however, that we can turn once again to the account of ethnocultural neutrality as an alternative to both autonomy and toleration. But whilst the justificatory account of ethnocultural neutrality can ground a plausible criterion for the distribution of burdens and benefits (and can ground much the same answers as those that Kymlicka wishes to achieve) it also highlights where the differences between the defenders of group-differentiated minority cultural rights on the one hand and those who are sceptical of such claims on the other, lie. They do not lie, as Kymlicka suggests, in the acceptance or rejection of ethnocultural neutrality understood in terms of the separation of culture and state. They lie in the second-stage debates concerning our higher-order interests in our own societal culture, an area where Kymlicka's autonomy based arguments are important but, as we shall see, far from conclusive. 


\section{Chapter 2: Autonomy Liberalism}

\section{Autonomy as an alternative to ethnocultural neutrality}

In this chapter I want to consider Kymlicka's argument that autonomy is the fundamental liberal value and what this means for his third-stage, nation-building argument. In particular I shall consider the following problem for Kymlicka's account. The principle of ethnocultural neutrality offers us an account of what liberal democratic states ought to do if they are to be considered just. So, if we were to accept Kymlicka's picture of ethnocultural neutrality as the complete separation of state and culture we could say that liberal democratic states failed to be just insofar as they fell short of this goal. Kymlicka's argument, of course, is that liberal democratic states cannot help but fall short of this goal. Such a picture of the state is incoherent. I do not think that liberals would want, or need, to be committed to such a view of ethnocultural neutrality as I pointed out in chapter 1 . However, another problem arises. If Kymlicka is correct, and such a picture of ethnocultural neutrality amongst liberals has been the norm, and if we do reject it as manifestly false, on what grounds are we to now assess majority nation-building? That is, if we have removed a widely accepted feature of liberal accounts of the legitimate state, on what grounds are we to argue that minority nationbuilding is fair?

The answer that I shall consider here is that a commitment to autonomy as the fundamental liberal value can ground the kind of response that Kymlicka wants to make to majority nationbuilding. In chapter 1 I noted that Brian Barry does not consider a commitment to autonomy to be compatible with a commitment to neutrality (Barry 1995 pp128 - 133). Kymlicka's commitment to autonomy, then, might provide adequate normative grounds from which to make the kind of judgements that he wants to make. If successful, Kymlicka might be able to offer a coherent rival to ethnocultural neutrality whether that is understood in terms of the strict separation of culture and state or, more importantly for this thesis, in terms of ethnoculturally neutral justifications.

When we come to look at Kymlicka's arguments that link access to our societal culture with this interest in our autonomy, however, it will become clear that the autonomy argument not only fails to ground an alternative, liberal approach to majority nation-building and, in particular, the kind of claims that Kymlicka wishes to make about it, but actually stands in 
some tension with those fairness based arguments that he wants to make. This will be important in chapter 4 where I argue that in order to get the fairness based results that he wants in the third-stage, nation-building argument, Kymlicka must rely upon the conclusions reached by his autonomy based, context-of-choice argument which will be considered in this chapter. So this chapter serves a dual purpose. I shall argue against the idea that a commitment to autonomy can ground a viable alternative to ethnocultural neutrality when faced with majority nation-building. I shall also return to a point made in the previous chapter and that is that Kymlicka's third-stage, fairness based argument requires some account of the relative weights of (cultural) burdens and benefits. Such an account is provided by Kymlicka's autonomy based argument. I shall express doubts as to how effectively this is done.

\section{Autonomy, societal culture, and perfectionist moral pluralism}

Let us begin by looking at Kymlicka's account of autonomy. For Kymlicka autonomy is closely linked with our interest in living a good life. In arguing this he makes use of Dworkin's 'endorsement constraint', the idea that "lives do not go better by being led from the outside, in accordance with values the person does not endorse" (Kymlicka 1995 p81, Kymlicka 2004 p115). In addition to the endorsement constraint Kymlicka also notes that we should be free to question our beliefs in the light of new information (Kymlicka 1995 p81). If we find that they are no longer worthy of our continued allegiance then we should be free to reject them. It is this emphasis on the value of autonomy that Kymlicka says lies at the heart of the fundamental individual freedoms that define liberalism (ibid p80). Individuals have a fundamental interest (in terms of leading a good life) in autonomy. The state is justified in acting to preserve that autonomy (which may mean rejecting some of the 'internal restrictions' that Kymlicka claims that tolerance permits).

Moreover Kymlicka links his emphasis on autonomy to a defence of societal cultures. The crux of Kymlicka's argument is that autonomy requires that we be able to make choices that are meaningful to us, and revise those choices, from a set of options. Autonomous decision making does not take place in a social vacuum. This set of options is provided by our 'societal culture $^{\prime 29}$. If autonomy is necessary for individual lives to go well and if societal cultures

\footnotetext{
${ }^{29}$ As I mentioned in the introduction, interestingly the definition of societal culture given in Multicultural Citizenship is somewhat 'thicker' than that offered in PV insofar as it makes reference to shared conceptions of the good other than language; In Multicultural Citizenship it is "a culture which provides its members with meaningful ways of life across the full range of human activities, including 30
} 
provide us with the set of meaningful options that allow such autonomous choice then individuals can be said to need to have access to a societal culture. Group-differentiated rights can be justified just so long as they "secure and promote this access" (ibid p84).

What does all of this have to do with neutrality? As Kymlicka notes, a commitment to autonomy stands in a complicated relationship with a commitment to state neutrality (Kymlicka 2004 p116). Complicated or not, in PV Kymlicka presents the autonomy argument as being designed to meet the burden of proof set by a commitment to neutrality, as offering morally weighty reasons to abandon it in some cases (cf. Kymlicka 2001 p24). For Kymlicka, a commitment to autonomy as the fundamental liberal value is seen as perfectly compatible with a commitment to state neutrality. Kymlicka notes, however, that Joseph Raz makes similar autonomy based arguments for cultural preservation (ibid p21). This is interesting because in earlier work Raz considers autonomy to be a rival account to neutrality.

Raz offers two arguments that are of interest to this thesis. The first is that neutrality is conceptually incoherent in the sense that states cannot even approximate such a position (Raz 1986 p120). The second is that liberal principles of justice can be grounded by a "perfectionist moral pluralism" (ibid p133), i.e., the value of autonomy. Although the two arguments are connected I will take them independently of one another. Even if Raz cannot show that neutrality is conceptually incoherent it might still be the case that autonomy offers a more appealing grounding for liberal principles of justice. We should bear in mind that Raz's aim is broader than Kymlicka's in that the latter need only be concerned with ethnocultural neutrality. I shall argue in the remainder of this chapter that neither Raz's rejection of neutrality nor a focus on autonomy as a replacement for neutrality is adequate for Kymlicka's purpose.

Let us begin with Raz's account of neutrality. What does Raz think that neutrality requires of the state? Although Raz recognizes that there are various ways of understanding neutrality (ibid pp114- 115) he assumes that those who advocate neutrality as a response to diversity and disagreement actually advocate a form of neutrality of effect (ibid p112). Neutrality of effect (or 'neutral political concern' as Raz calls it) requires the state to ensure that the chances of differing conceptions of the good being taken up are (as near as possible) equal (ibid p124). As Kymlicka puts it this conception of neutrality requires that "government action should have neutral consequences" (Kymlicka 1989a p883).

social, educational, religious, recreational, and economic life, encompassing both public and private spheres" (Kymlicka 1995 p76)). 
If this is a plausible characterization of neutrality (and inter alia for ethnocultural neutrality) then Kymlicka might well be able to follow Raz and make a convincing case that such neutrality is conceptually incoherent. Take Kymlicka's discussion of the demands of the Cossacks. The Cossacks, Kymlicka claims, see their conception of the good (and, indeed, identity) as being tied up with "the right to rule over others" including "the restoration of unjust privileges" (Kymlicka cited in Chambers 2003 p296). But such conceptions of the good are directly antithetical to others (those which value self-government for example). It would be impossible for a state committed to neutrality to realize both equally even if it wanted to. Indeed almost any action (or non-action) taken by the state will be likely to affect which conceptions of the good gain or lose followers over time. ${ }^{30}$

We can deal quickly with Raz's argument here, for this way of understanding ethnocultural neutrality is neither Kymlicka's picture of the separation of state and culture nor the justificatory sense of ethnocultural neutrality that I am endorsing in this thesis. Those committed to some principle of neutrality need not be committed to neutrality of effect. As Kymlicka points out, Dworkin, Rawls, and Nozick are not concerned to defend neutrality of effect (Kymlicka 1989b p96; cf. Rawls 2005 ppp193 - 194; Nozick 1974 pp271 - 274). Dworkin, Rawls, and Nozick all endorse an idea of neutrality of justification.

Liberals who are committed to ethnocultural neutrality are committed to neither the complete separation of culture and state as Kymlicka claims, nor are they committed to neutrality of effect as Raz claims. Both kinds of ethnocultural neutrality, we might say, commit liberals to an implausible position.

\footnotetext{
${ }^{30}$ This discussion ties in with Raz's discussion of 'helping' and 'non-hindering' (Raz 1986 pp120 - 121). The upshot of this, as Wojciech Sadurski puts it, is that in any given situation "two opposite types of conduct may occur, both of which may be described as neutral, or as non-neutral; hence the notion of neutrality is incoherent" (Sadurski 1990 p103). That is, when the state, in adjudicating between conflicts, does not help one side (i.e., the side who most needs help) it hinders it and so is not neutral. On the other hand ("according to the common understanding of neutrality" (Raz 1986 p121)) entering into the dispute to aid one side (after the conflict begins) would also be non-neutral. As this argument regarding 'helping' and 'hindering' rests upon the kind of consequential neutrality outlined above I will not go into detail regarding it here. It is worth pointing out, however, that even if we do not think that it rests ultimately on neutrality of effect this argument might show that neutrality is not always possible but not that it is never possible (and thus retains a certain political desirability as an ideal). In any conflict what would be crucial in determining neutrality (even the kind of neutrality Raz attributes to liberals) is a set of reasonable expectations (regarding help and hindrance) (cf. Sadurski $1990 \mathrm{p} 105$ ). The question is not whether action $A$ helps $X$ (who needs the help) but hinders $Y$ (and so is both neutral and non-neutral). The question is whether that hindrance is unjust or not. Relying on neutrality of effect as our criterion of legitimacy it would seem to be unjust. But this, as we shall see, is not the only (or most plausible) way of understanding neutrality.
} 


\section{Autonomy and nation-building}

Let us turn now to look at the autonomy argument. It could still be the case that autonomy could ground liberal principles, independently of (and perhaps better than) any rival account of neutrality, and in such a way that Kymlicka could make the group-differentiated claims regarding majority nation-building that he wants to. To look at this let us consider the specific claim that minority nations (e.g., sub-state nations such as the Welsh, Quebecois, Scots, and Catalans, and indigenous peoples such as First Nations in Canada and the USA or Māori in New Zealand) should (as a requirement of fairness) be given the same tools as those available to the majority to nation-build (subject to 'liberal principles' ${ }^{31}$ ) (Kymlicka 2001 pp28 - 29).

We have seen that Kymlicka thinks that autonomy is in some way compatible with neutrality. For Raz, on the other hand, autonomy based liberalism, whilst requiring that individuals develop and pursue their own conception of the good, nonetheless holds that it is a legitimate aim of the state to foster conditions so that individuals pursue "valid" rather than "evil or empty" conceptions of the good (Raz 1986 p133). Autonomy is a perfectionist principle (and thus at odds with the anti-perfectionist approach of neutral political justice). Although a commitment to autonomy values moral pluralism this is not the same as neutrality. Some conceptions of the good (those that preserve the grounds of autonomy) are more valuable than others (cf. Lehning 1990 pp196 - 199).

I certainly do not wish to deny that autonomy can, and has, been used to ground the kinds of principles often associated with liberalism. A commitment to the value of autonomy (and with it the endorsement constraint and rational revisability) seems to entail certain civil rights such as freedom of conscience, freedom of the press as well as (perhaps) the substantive opportunities for individuals to realize their ends (cf. Barry 1995 p129). Nor do I want to claim that autonomy liberalism is 'really' a disguised form of neutrality even though it is not a conception of the good in the sense, say, that 'Cossack-ness' is. Rather we can follow Brian Barry and call autonomy a second-order conception of the good. Autonomy makes no particular judgements as to what is to count as an acceptable conception of the good so long as that conception is arrived at in a way that fulfils the requirements of autonomy (ibid).

\footnotetext{
${ }^{31}$ I.e., such "principles will preclude any attempts at ethnic cleansing, or stripping people of their citizenship, or the violation of human rights. These principles will also insist that any national group engaged in a project of nation-building must respect the right of other nations within its jurisdiction to protect and build their own national institutions" (Kymlicka 2001 p29).
} 
As I have mentioned Kymlicka's autonomy argument has been much discussed and criticised. The important point is that the realization of autonomy as a fundamental value for individuals to lead worthwhile lives requires a secure context-of-choice (i.e., a societal culture). As such, a commitment to liberal justice seems to require the preservation of sub-state nations and indigenous communities that provide such a context. Concern with ensuring the grounds of autonomy justify and perhaps require the state to intervene to protect those societal cultures that require support.

Of course this argument presupposes that autonomy is a fundamental good for individuals. ${ }^{32}$ This is not a position endorsed by all liberals. Take the requirement that societal cultures, at least on the definition put forward in Multicultural Citizenship (hereafter MC), are required to offer their members "meaningful" ways of life (Kymlicka 1995 p76). It does not seem implausible to suggest that some groups that do not offer their members a particularly wide range of options or the usually understood liberal rights (and Kymlicka gives examples of the Amish, Mennonites, and Pueblo as such communities (ibid p164)) nevertheless offer their members "meaningful" lives (cf. Kukathas 2003 pp60 -64). For others, such as Bhikhu Parekh, autonomy $^{33}$ is a vague (and controversial) value that is of little help in setting rules and principles to guide (fair) group interaction (Parekh 1996 pp255 - 256).

Given Parekh's complaint, it is worth saying a little more about the value of autonomy. The first thing to note is that for Kymlicka autonomy is instrumentally valuable. It is valuable insofar as it enables individuals to lead good lives. The second point is that Kymlicka argues that rational revisability is an essential component of autonomy. One way of thinking about this is in terms of first order and second order preferences. Immediate wants and desires are examples of first order preferences whereas the choices we make, following critical consideration, are second order preferences. The process of critical consideration (and rational revisability) should see our first order preferences suitably altered to fit with our second order preferences which themselves should be independent of coercion (either by outside forces or

\footnotetext{
${ }^{32}$ It also requires us to accept that access to our societal culture is necessary to ground autonomy. If we do not accept this then it seems that using the autonomy argument to ground a response to majority nation-building will not be able to generate the kind of claims that Kymlicka requires. I think that there are problems even if we do accept Kymlicka's claim and I argue that the context-of-choice argument is in tension with the fairness based argument later in this chapter. If we do not accept Kymlicka's autonomy based claim then Kymlicka's fairness based claims become even more problematic and this supports my general contention although I do not rely upon such an argument here. For a recent argument that Kymlicka (and Raz) do not establish that a 'context-of-choice' is necessary for autonomy, cf. Parvin 2008 pp315- 318 .
}

\footnotetext{
${ }^{33}$ Parekh understands autonomy as a particular kind of claim within a broader range of views that attempt to show some values to be universal to all cultures and that all cultures should thus endorse (Parekh 1996 p254).
} 
certain psychological dispositions) (cf. Levey 2006 p44). This is why it is not sufficient for autonomy that an agent is 'doing what they want' but should rather have both options and awareness of options from which to choose from (ibid). The final point is one of appropriate scope. For Kymlicka, as for Raz, autonomy is a comprehensive second-order good; it includes an account of what is valuable in human life generally and not in some particular sphere of human life (e.g., the political sphere) (cf. Rawls 2005 p13). Kymlicka is committed to such an account for two reasons we have already seen. Firstly autonomy is a necessary feature of a worthwhile life and secondly he specifically rejects those accounts that seek to limit its scope to the political sphere.

Kymlicka's commitment to autonomy as a comprehensive, second order conception of the good lies at the heart of the prohibition on internal restrictions which permit cultural groups to restrict the individual civil and human rights of their members (Kymlicka 2001 p22). A community cannot have rights that restrict the fundamental freedoms of individuals because such rights would deny individuals the means to lead good lives. A right for some members of a group to enforce 'forced marriages' on other members of the group would seem to be ruled out for example. 'Forced marriages' deny those forced a genuinely autonomous choice. This will also place limits on acceptable majority nation-building which must ensure that members of minority nations within their territory are provided with the full range of liberal civil and human rights (necessary to ensure autonomous decision making). We have also seen that Kymlicka thinks that the autonomy argument might be used to make claims regarding the preservation of the grounds of autonomy in the form of group-differentiated rights designed to protect minority societal cultures from the activities of those outside of the group, especially the majority nation (i.e., external protections). A commitment to autonomy as a ground for fundamental liberal values that does not rely on the normative or conceptual force of the neutral state seems (on the face of it) to be a plausible candidate to ground a liberal response to nation-building. Autonomy can ground specific justice based claims about the nation-building model of the liberal democratic state. It can place plausible limits on how majority societal cultures can nation-build. Does it ground a right to minority nation-build?

To get an idea of how we should answer this question it will be useful to say a few words about what constitutes a nation (whether minority or majority). I will say more about nation-building in Chapter 4 but for now we can follow Kymlicka and say that a nation represents "an intergenerational community, more or less institutionally complete, occupying a given territory or homeland, sharing a distinct language and history" (Kymlicka 1995 p18). To this account we might wish to add that membership of such a group is important in some way to how we identify ourselves (cf. Margalit and Raz pp443 -447) and that members of such groups typically 
aspire to national self-determination of some kind (cf. Miller 1995 p11; Buchanan 2007 p380). Some states, such as the UK or Canada, will be multinational in character.

I will not investigate here whether all (or even many) national minorities (or, for that matter, majorities) meet all of these criteria (cf. Barry 2001 pp81 - 90; Buchanan 2007 p381 for doubts on this score). We can say, instead, with Yael Tamir that these are "cluster concepts" requiring a group to have a "sufficient number" of such features, but not necessarily all, to count as a nation (Tamir 1993 p65; cf. Tierney 2004 p35). However one of the criteria, for Kymlicka and the autonomy argument, seems to be indispensable. That is that the nation has a societal culture that it can assert. Indeed, for Kymlicka "nations are almost invariably societal cultures" (Kymlicka 1995 p80). This distinguishes national minorities from immigrant groups who have not established institutionally complete cultures (often because they lack some of the other features of nation-hood) (ibid pp77 - 78). Scotland, Wales, Quebec, and Catalonia are all examples of minority nations that have (with some success) engaged in minority nationbuilding despite (or perhaps because of) majority nation-building and have done so whilst creating modern, liberal institutional frameworks.

Scotland, Wales, Quebec, and Catalonia aside, however, it is not clear that many national minorities have the kind of societal cultures required to establish a context-of-choice and thus support autonomy. As Joseph Carens points out, certain immigrant groups are able to create and sustain culturally based institutions within the host country that provide social, educational, religious, recreational, and social services (Carens 2000 p62). Despite this immigrant communities do not constitute societal cultures. But it is also unclear that many national minorities (especially indigenous groups) would qualify either. Many are affected by "low numbers, territorial dispersion, low economic status" (Patten 2009 p114). In such cases there may not be a viable societal culture to defend. On the other hand for those that are not vulnerable there seems to be little need for a 'right' to nation-build. The nation-building model as a description seems to account for the societal cultures of Scotland, Quebec, and Catalonia. This does not mean that such societal cultures might not be vulnerable to the majority in the state they find themselves and they may have some important rights against majority nationbuilding. But this is because these societal cultures are already established. They do not need to claim a right to the tools necessary to nation-build. They already have them.

Kymlicka has a response to the objection that there are perhaps few sufficiently viable societal cultures able to ground autonomy. Societal cultures (even weak ones) can become viable again given the right conditions (ibid pp 100 - 101). Kymlicka does, after all, endorse giving minority 
nations the tools to nation-build as a matter of fairness. The question is how is a right to minority nation-build grounded by the autonomy argument?

The autonomy argument attempts to establish that individuals have a weighty moral interest in a thriving societal culture. The problem for Kymlicka's right to nation-build (especially for members of societal cultures who already find themselves as citizen-members of a larger nation-state such as Māori in New Zealand) is that his autonomy argument can only establish that people have a fundamental interest in belonging to a societal culture. It does not establish that we have a right to any particular societal culture (Waldron 1992a p762; Patten 2009 p112). Thus the right to a societal culture does not necessarily entail a right to build the societal culture of the group to which you belong. Kymlicka may be correct in claiming that leaving one's own societal culture is a costly business (Kymlicka 1995 p85) but so is nationbuilding and nation-maintaining, i.e., "creating and sustaining a set of public institutions which enables a minority group to participate in the modern world through the use of its own language" (Kymlicka 2001 p159). The question of justice is where these costs should lie (cf. Carens 2000 pp60 -61). ${ }^{34}$

The point that autonomy does not clearly ground minority nation-building becomes even more vivid when looked at as a response to majority nation-building. As Kymlicka points out, majority nation-building (at least within the modern, liberal democratic states that Kymlicka is concerned with) is closely tied up with, for example, "standardized public education in a common language (which) has often been seen as essential if all citizens are to have equal opportunity to work in the modern economy" (Kymlicka 2001 p26). In short, majority nationbuilding can plausibly be seen as increasing the range of options open to individual thus providing a richer and more diverse societal culture. Indeed, this was the conclusion reached by John Stuart Mill who can also be seen as grounding his liberalism on a commitment to autonomy. ${ }^{35}$ Mill argued that it is often more beneficial for members of minority nations to be assimilated into a broader citizenship within the majority nation-state than to remain as

\footnotetext{
${ }^{34} \mathrm{Cf}$. Carens 2000 p60 for a good discussion of how these questions of balancing interests against one another creates a very real tension for some, in particular indigenous peoples who must often choose between access to their own societal culture on the one hand and "access to other primary goods like income, wealth, opportunities, and power" (ibid) on the other.

${ }^{35}$ E.g., "Human beings owe to each other help to distinguish the better from the worse, and encouragement to choose the former and avoid the latter. They should be for ever stimulating each other to increased exercise of their higher faculties... But neither one person, nor any number of persons, is warranted in saying to another human creature of ripe years, that he shall not do with his life for his own benefit what he chooses to do with it" (Mill 1964 p133).
} 
members of a smaller nation with fewer substantive opportunities (Mill 1964 p363). ${ }^{36}$ If we are concerned with societal cultures that offer "meaningful ways of life across the full range of human activities" then majority nation-building appears to give "meaningful" and "full" wider scope than can be managed by minority nations.

The foregoing assumes that autonomy can best be measured in terms of a wide range of options. This is the sense in which the USA offers a great deal of autonomy for its citizens. The USA, as Kymlicka puts it, is a 'capacious' societal culture (Kymlicka 1995 p77; Kymlicka 2001 p245). If the societal culture of the USA offers a greater range of options than, say, the societal culture of the Cherokee nation then the autonomy argument seems to suggest the integration of the latter into the former.

We can note two mutually supportive responses that Kymlicka gives to this objection. The first is that the autonomy argument is satisfied so long as a societal culture offers a "satisfactory" context-of-choice (Kymlicka 2001 p55). The criterion of satisfactory-ness can be understood in terms of the deep bonds that individuals often have to their own societal culture. Individuals most value, and can make use of, autonomy within their own societal culture (Kymlicka 1995 p93). It is a societal culture that they identify with (Kymlicka $2001 \mathrm{p55}$ ). The second response is to add a liberal commitment to equality to the commitment to autonomy. This means that there should be (some kind of) equality and autonomy within the societal culture but also equality between societal cultures (ibid pp108-115; p 194). This last argument seems to appeal to the same kind of liberal principles that are usually thought to underwrite neutral political justice (i.e., the importance of equality). Neutrality, however, might be more plausibly seen as the best way of adjudicating between equal citizens. Liberals might be sceptical of an account that focuses on equality between groups as well as individuals. Surely equality between groups is potentially in tension with individual autonomy? This, however, need not be the case once we remember the importance of societal cultures to individual autonomy (as the fundamental value in human life). Individuals have a fundamental interest in belonging to a thriving societal culture. A right to minority nation-build would ensure that the good of belonging to a societal culture is equally protected for all members of all national-minorities (ibid p113). Whilst these arguments deepen the account of autonomy and, in particular, its

\footnotetext{
${ }^{36}$ Mill expresses these thoughts in terms that contemporary liberals will likely eschew, so that a member of the Breton or Basque minority-nations will "sulk on his own rocks, the half-savage relic of past times, revolving in his own little mental orbit, without participation or interest in the general movement of the world" (Mill 1964 pp363 - 364). If it were the case in the nineteenth century such a desire to have little contact with the outside world does not seem to be true of minority nations now (Kymlicka $2001 \mathrm{p20}$ ). The point remains though that if we equate autonomy with a range of viable options then membership of a larger political community would tend to give more such options than membership of a smaller one. This would include the right to practice one's own cultural beliefs. 
links to liberal principles of justice I do not think that, separately, or taken together that they are adequate to establish autonomy as a viable normative response to the nation-building model of the state. I will take each response in turn.

\section{Autonomy, attachments, and justice}

It cannot be denied that individuals often have deep, enduring bonds to their own societal culture. Let us also accept that individuals are attached to a societal (i.e., institutionalized) culture rather than some idea of deep rooted cultural (or even biological) homogeneity. Although there may be examples of the latter Kymlicka is correct to point out that not all minority national movements take such a course. The survival (and in some cases flourishing) of minority societal cultures and minority nation-building in the face of majority nationbuilding throughout the nineteenth and twentieth centuries, suggests the importance of such identities to members of those national groups (Tierney 2004 p26). The question is, are such deeply held attachments relevant to Kymlicka's autonomy argument? Whilst they may explain the continued existence of minority nations in the face of majority nation-building I do not think that they can support a normative right to nation build for majority or minority. Deep attachments to differing conceptions of the good are one of the givens that neutrality is supposed to deal with. So is disagreement and conflict about those attachments. It is the latter that the nation-building model of the state brings to the fore and with which the autonomy model is singularly ill equipped to deal.

What the nation-building model of the state presupposes is some kind of conflict and disagreement about territory and, especially, about what ought to be the societal culture within that territory. This need not be a case of imperialist nation-building on the part of the majority (Kymlicka 2001 p26). There may be a genuine dispute over whether it is better for children to learn English as their first language rather than, say, Welsh (within the Welsh territory). There are also disputes over land. One of our 'national' criteria was territorial concentration. If we talk of attachment to a societal culture it would be naïve to dismiss the importance of a particular piece of territory (or a 'home-land') to members of that nation (cf. Levy 2000 pp197 - 203; Buchanan 2007 p380). For some national minorities there may be little dispute over the limits of their territory (e.g., both Wales and Scotland have fairly well established boundaries within the British Isles). On the other hand there may be disputes over territory within a formally unified nation-state. (This will often be the case with indigenous peoples. This can be seen in New Zealand with the ongoing conflict between the Crown and Māori concerning ownership of the seabed and foreshore (cf. Brookfield 2006 pp188 - 194)). 
Even in cases where there is no obvious dispute over land (although there may be dispute over certain resources within the territory) there may be conflict. Although many Scottish were no doubt attached to their societal culture (and showed this in a referendum) there were those (in the rest of the UK as well as some in Scotland) who were deeply attached to the Union. Or take Quebec. Whilst there may be fairly uncontested borders between it and the rest of Canada, there remain contested areas within Quebec between the Francophone majority and indigenous minorities reflected in a raft of historic agreements. In short, the nation-building model of the state presupposes conflict and division. To assume as Kymlicka does (cf. Kymlicka 1995 p100; Kymlicka 2001 p27) that the decision whether to integrate or not ought to lie with members of the minority group is simply to beg the question when we confront the situation of conflict implied by the nation-building model of the state.

In conditions of conflict to have an attachment to something, however deep, is not sufficient to be granted a right to do that thing. Nor, in cases where the object of the attachment is a legitimate one, does the attachment itself ground any particular way to achieve that end (cf. Barry 2001 p66). Those in England, say, may have been very attached to belonging to the United Kingdom. Of course this needs to be offset by the attachment that the Welsh felt for their own nation - an attachment they wanted to see thrive through the promotion of their societal culture throughout Wales. How are we to deal with this conflict of attachments? The autonomy argument itself is no help here because it only requires that Welsh (or English) individuals have a context of choice, not any particular context of choice. And membership in the wider 'British' societal culture already gave them a capacious context of choice. And the same will go for many other minority nations which are already partly or wholly integrated into a majority societal culture. The autonomy argument does not ground the right to any particular societal culture and the attachment argument seems to add nothing in those cases of conflict assumed by the nation-building model of the state. What are needed are principles of justice. As Joseph Carens puts it; "the question is how to fit all these differences together, both morally and politically" (Carens 2000 p68). The autonomy argument with its focus on distinct contexts-of-choice cannot adequately do this. Adding that individuals are deeply attached to some institutional arrangement (or the idea of some institutional arrangement) is simply to highlight that there is often a conflict of interests. It does not tell us how we ought to deal with that conflict. ${ }^{37}$

\footnotetext{
${ }^{37}$ The attachment argument also sits somewhat uncomfortably with a commitment to autonomy itself irrespective of conflict. As mentioned above, in section two, autonomy is to be distinguished from people getting what they want because they are attached to that thing. Recall that autonomy suggests the adaptation of our first order preferences in the light of critical reflection.
} 
There is, however, a sense in which a deep attachment might be said to directly affect the autonomy of the individual. To lose access to one's own societal culture (due to majority nation-building) may be to see one's own identity threatened in some way. This is an argument put forward by Margalit and Raz and endorsed by Kymlicka (Margalit and Raz 1990 pp447 449; Kymlicka 1995 pp 88 -90). A feeling of one's nation being of secondary importance to that of the majority (say by one's own language not being a language of the public sphere (cf. Kymlicka 2001 p27)) could engender feelings of alienation and marginalization from the majority societal culture (Margalit and Raz 1990 p454). If I do not feel myself to be a worthwhile member of the societal culture to which I belong then I might be less able to make use of the options provided by that societal culture. My autonomy will be directly affected by the loss of my own societal culture. This might justify limits on acceptable majority nationbuilding and also justify the right to minority nation-build when the autonomy of individuals is at stake.

Even if we accept that members of minority nations can feel alienated (and thus see their effective autonomy restricted) by majority nation-building this account raises problems. We come up, again, against the need for some principles of justice to regulate (in this case) the distribution of the grounds of autonomy (i.e., the distribution of rights and responsibilities and also the resources required to build and maintain a viable societal culture). One way of doing this is to refer to a general liberal commitment to equality, and this is what Kymlicka does (Kymlicka 1995 pp108-115). Equality in this case requires equal access to a secure societal culture. This, Kymlicka claims, is a question of fairness (ibid p113). If individuals have a fundamental (i.e., autonomy based) interest in their own societal culture then the equality argument seems to provide criteria for distributing the rights and resources necessary for minority nation-building in such a way so as to compensate for the unchosen circumstance of majority nation-building. We can here draw a parallel with Kymlicka's third-stage argument in PV. Majority nation-building, we might say, puts pressure on minority societal cultures and this constitutes an unfairness (or, perhaps, inequality) for members of those minority societal cultures.

But the equality argument does nothing to clarify the requirements of the autonomy argument or vice versa. To see this consider the fact that even if we accept that marginalization caused by majority nation-building can result in a loss of autonomy for individuals, it still remains indeterminate as to how we are supposed to redistribute the grounds of autonomy. What does it mean to have equal access to societal cultures and to autonomy? The problem remains that we lack any useful metric for measuring the value of a societal culture (Dworkin 2004 p359) and the autonomy argument, as we have seen, does not provide one. Majority nation- 
building is held to be an unchosen circumstance and thus one that can be legitimately compensated for (i.e., the right to minority nation build is not simply an 'expensive taste'). But the autonomy argument does not give us an idea of the extent of the obligations of those outside the national minority to facilitate minority nation-building as a means of securing an adequate context of choice (Carens 2000 p 60). In some (maybe many) cases the long term advantage of members of minority nations will be to integrate into the majority societal culture (Dworkin 2004 p359). This may be costly in terms of the marginalization of some individuals and if so there may be a prima facie case for compensation. It is far from clear, however, that such compensation ought to take the form of minority nation-building rights as a response to majority nation-building.

The equality argument, rather than augmenting the autonomy argument, merely highlights the deficiencies of the latter when faced with majority nation-building. Equality when related to autonomy could either require equal access to a societal culture or equal access to a societal culture of one's choosing. The latter, however, needs to be balanced against the claims of those outside the group in question (in situations of conflict) whilst the former needs to consider the extent of potential autonomy loss. In short, equality, when tied to indeterminate autonomy requirements, becomes itself indeterminate. ${ }^{38}$

\section{Conclusion}

In this chapter I have attempted to argue that autonomy cannot ground the kind of fairness based response that Kymlicka wants to make to majority nation-building. In fact I have suggested that the autonomy based argument, far from grounding an account of fairness, requires some additional account of the fair distribution of the conditions of that autonomy to be plausible. It is at this point that we begin to run into problems. Kymlicka's autonomy based arguments are indeterminate as to what exactly is to be distributed and how that which we can say is going to be distributed, the societal grounds of autonomy, is to be weighted against other deep attachments that individuals (both within and outside of the group in question) might have. Given such indeterminacies we might be inclined to think that the third-stage argument is intended to stand independently of Kymlicka's second-stage context-of-choice arguments as I suggested in the previous chapter.

\footnotetext{
${ }^{38}$ That is, assuming that we do not already consider the demands of equality to be indeterminate in any case (an argument that will be looked at briefly in the next chapter).
} 
If autonomy, as the fundamental liberal value, is not doing the normative, fairness based work of the third-stage argument then what is? One of the reasons that Kymlicka seems to advance the autonomy argument is because he rejects what he sees as its undesirable alternative, a political liberalism founded on the value of toleration which (minus a substantive commitment to autonomy) "cannot by itself defend the full range of liberal freedoms" (Kymlicka 1995 p163). Toleration based liberalism seems to be closely bound up for Kymlicka with the idea of benign neglect and 'difference-blind institutions' that requires official indifference "to the ability of ethnocultural groups to reproduce themselves over time" (Kymlicka 2001 p23). Kymlicka, of course, rejects such a position as both conceptually incoherent (Kymlicka 1995 p111) and also normatively undesirable insofar as "difference-blind rules can cause disadvantages for particular groups" (Kymlicka 2001 p33). Despite this, the kind of toleration based liberalism that Kymlicka rejects is held by Chandran Kukathas. I shall argue in the next chapter, however, that Kymlicka is correct to reject benign neglect and that, although Kukathas' version of it is not conceptually incoherent (as Kymlicka claims) it is normatively undesirable. On the back, then, of the rejection of autonomy liberalism as a suitable grounding for a plausible fairness based response to majority nation-building considered in this chapter and the rejection of toleration liberalism, in the form of Kukathas, in the next I shall argue that a plausible alternative can be found in an account of justificatory ethnocultural neutrality. 


\section{Chapter 3: Toleration Liberalism}

\section{Autonomy and toleration}

Kymlicka, in dismissing ethnocultural neutrality as a suitable criterion of justice and legitimacy when faced with majority nation-building, must not only say why he considers such an approach to be 'manifestly false' but also, insofar as he wants to make specific, fairness based claims about majority nation-building, give some plausible alternative grounds from which to make such claims. In the previous chapter I looked at the possibility that a commitment to autonomy as the fundamental liberal value might prove to be a plausible alternative to a norm of ethnocultural neutrality. As, on Kymlicka's account, access to our own societal culture is necessary for individual autonomy the 'right to nation-build' could possibly be grounded by the fundamental interest we have in autonomy which I considered as a second-order conception of the good.

I argued that autonomy liberalism could not adequately ground the kind of fairness based claims that Kymlicka wants to make about majority nation-building. The nation-building model of the state presupposes conflict between rival nation-building programmes, on the one hand, and between nation-building programmes and other cultural groups within the state on the other. Autonomy liberalism offered some, albeit controversial, account of why we might think that access to a societal culture is important for individuals but said little as to how that access ought to be distributed or how it should be weighted against other interests that individuals might be thought to possess.

Autonomy liberalism not only failed to ground the kind of fairness claims that Kymlicka wants to make in regards to majority nation-building but also gave indeterminate answers when a criterion of fair distribution was applied. In other words I argued that autonomy liberalism presented us with an insufficient response to the nation-building model of the state. If autonomy liberalism cannot adequately ground a plausible fairness based response to majority nation-building then we can perhaps turn instead to the other side of Kymlicka's dichotomy and try to base such an account on a commitment to toleration liberalism. Toleration liberalism, according to Kymlicka, requires that the state not interfere with the practices of those groups that reject liberal principles (including individual autonomy) (Kymlicka 1995 pp152-158; cf. Barry 2001 pp118-123). The idea of a separation between culture and state is an example of toleration liberalism which, of course, Kymlicka rejects. Kymlicka's discussion of 
toleration liberalism is centred on the work of Chandran Kukathas and John Rawls. Kymlicka rejects the kind of toleration liberalism endorsed by Kukathas and argues that the kind of toleration liberalism endorsed by Rawls in fact collapses into autonomy liberalism if it is to ground individual civil and political rights (Kymlicka 1995 p158).

In this chapter I want to look in more detail at Kymlicka's rejection of toleration liberalism. This is important because I have rejected autonomy liberalism as a plausible ground for a fairness based response to majority nation-building. If Kymlicka is both correct to reject toleration liberalism and correct to claim that toleration liberalism represents the only alternative to autonomy liberalism, then the chances of grounding a liberal fairness based response to majority nation-building is in jeopardy. The two 'fundamental values' of liberalism will have been both found wanting. As we shall see the kind of toleration liberalism endorsed by Kukathas offers no hope of grounding a fairness based response to majority nation-building for the simple reason that it repudiates fairness as a normative concern for the state altogether. Instead Kukathas highlights the need for compromise that avoids, as far as possible, ongoing conflict.

I shall argue that Kymlicka is correct to reject the kind of toleration liberalism as endorsed by Kukathas but that he is wrong to think that Rawls' political liberalism must ultimately rely upon autonomy liberalism. Rawls' political liberalism, in endorsing the liberal ideal of reasonable agreement, is in any case just one example of a general, plausible alternative to both autonomy liberalism and toleration liberalism. It can also ground the kind of fairness based claims that Kymlicka wants to make about majority nation-building. ${ }^{39}$ Crucially, it also supports a norm of (justificatory) ethnocultural neutrality. In short, I shall argue that the dichotomy between autonomy liberalism and the kind of toleration liberalism represented by Kukathas is a false dichotomy and that there is an alternative, plausible account of liberal (ethnocultural) neutrality.

\section{Toleration and benign neglect}

In MC, Kymlicka rejects the idea of benign neglect, understood as the complete separation between culture and state, as being incoherent. It is an idea that he thinks reflects "a shallow understanding of the relationship between states and nations" (Kymlicka 1995 p113). If we assume that benign neglect is identical with the 'difference blind institutions' of PV then we can see a second claim. This is the claim that justice cannot be defined in terms of benign

\footnotetext{
${ }^{39}$ This point will be explored in the next chapter.
} 
neglect (Kymlicka 2001 p33). If the first claim is true (i.e., that benign neglect is incoherent) then it looks like the second claim will also be true insofar as a conceptually incoherent account of (ethnocultural) justice would be an insufficient account. However, the second claim could be true (i.e., that there is no necessary link between benign neglect and justice) without this rendering a policy of benign neglect incoherent (except as a theory of justice). This latter position is taken by Chandran Kukathas who claims both that benign neglect is a coherent position (Kukathas $2003 \mathrm{p237}$ ) and that benign neglect, which he dissociates from questions of justice, should be preferred to the pursuit of justice. ${ }^{40}$ Kukathas' position, if plausible, represents a major challenge to Kymlicka's position. Although both reject the link between benign neglect (i.e. ethnocultural neutrality) and justice Kukathas nonetheless holds, contra Kymlicka, that the former is both conceptually coherent and normatively desirable. As Kukathas' position is singled out as a paradigmatic account of toleration liberalism (Kymlicka 1995 pp154 - 155), if his argument is successful then we might look to toleration liberalism, and benign neglect, to ground our response to majority nation-building.

I will make two arguments in relation to benign neglect. Firstly I will argue that Kukathas is wrong to reject questions of justice in favour of benign neglect. More precisely, I do not think that the idea of benign neglect can adequately account for the issues thrown up by polyethnic and (especially) multinational diversity and disagreement. Whilst this seems to be a partial vindication of Kymlicka's position it nevertheless highlights the need for adequate principles of justice to account for such diversity and disagreement. It is at this point that I will suggest that the dichotomy between autonomy liberalism and Kukathas' toleration liberalism is a false dichotomy and that there is an alternative, plausible (and, I shall suggest, normatively desirable) account of liberal (ethnocultural) neutrality; political liberalism.

So why does Kymlicka hold the idea of benign neglect to be conceptually incoherent? Kymlicka's argument is quite simple; it is not possible for a state to avoid taking decisions that support some societal culture or other (Kymlicka 1995 p113). Benign neglect may be an appropriate response to religious diversity (e.g., there should be no official, state sponsored, religion and religious oaths can be replaced in public institutions with secular ones (ibid p111)) but it is not possible for the state to avoid "at least partial establishment" of a particular societal culture when it decides on which languages ought to be used in providing public services and in public education (ibid). This position lies at the heart of the nation-building model which adds to this that such decisions are not only unavoidable but have, in fact, been

\footnotetext{
${ }^{40}$ Kukathas views the pursuit of justice as the attempt to view society through some "particular egalitarian lens" on the grounds that to make individuals equal in one respect will be to make them unequal in some other (ibid pp237-238).
} 
made intentionally as a way of spreading and promoting participation in a shared societal (i.e., national) culture (Kymlicka 2001 p27).

Whether we accept the nation-building model or not Kymlicka claims that the breakdown in the analogy between religion and culture represents "a significant embarrassment" for proponents of benign neglect (Kymlicka 1995 p111). If, however, we do accept Kymlicka's nation-building mode ${ }^{41}$ then benign neglect is not only incoherent but attempts to realize it would merely valorise the position of the majority societal culture. A liberal account of benign neglect will tend to defend individual civil and political rights as it does, for example, with religion and the protection of freedom of conscience. But such individual civil and political rights, Kymlicka claims, are not only insufficient to protect minority societal cultures but, in fact, may play a role in undermining minority cultural groups, especially minority nations, within the state. For example, internal settlement policies may see members of the majority societal culture, or new immigrants, moved into the traditional homelands of national-minority groups. Kymlicka claims that this will often be done in order to politically disempower the minority group or to gain access to certain resources (Kymlicka 2001 pp73-75). Such a situation is exacerbated by individual rights such as freedom of movement (ibid p74). Or take the political right to vote and run for political office. A policy of benign neglect would seem to rule out self-determination or guaranteed representation. Although supporters of benign neglect might insist upon a principle of non-discrimination this fails to take into account that the basic institutions of society already reflect the identities and interests of the majority societal culture within the state (ibid p32). A policy of benign neglect, in such circumstances, may in fact create and perpetuate injustices for minority cultural groups.

Kymlicka's nation-building model of the state merely formalizes his basic complaint; that the endorsement of a policy of benign neglect is unable to account for the fact that any government action (or inaction) will have some influence on the make-up of a culturally diverse society. For Kymlicka this renders the idea of benign neglect manifestly false. It is an incoherent position. Kukathas, on the other hand, claims that endorsement of a policy of benign neglect does not fail to realize that government action will influence the cultural structure of the state but instead is characterized "by a willingness to accept the consequences of neglect" (Kukathas 2003 p237). This, Kukathas claims, is a coherent, if controversial, position (ibid). It is worth looking in more detail at what Kukathas understands by benign neglect.

\footnotetext{
${ }^{41}$ And this is a position that seems to be implied by the failure of benign neglect as an appropriate response to cultural diversity. That is, the failure of benign neglect, as Kymlicka presents it, seems to entail a set of social institutions based upon shared language(s) (Kymlicka 2001 p27).
} 


\section{Kukathas and benign neglect.}

In this section I will assess Kukathas' account of benign neglect and his rejection of fairness as an important normative concern. One line of argument, that has been pursued by both Kymlicka and Barry, is that this means that cultural groups will have full control over their members, including, crucially, vulnerable ones, and that this consequence is morally undesirable (Kymlicka 1995 p155; Barry 2001 pp142 - 143). I will not focus on this aspect of Kukathas' account. ${ }^{42}$ I want to look instead at how Kukathas' account can deal with the (cultural) conflict and disagreement which, I noted in chapter 2, is a feature of nation-building programmes. I will argue that what is doing the normative work in Kukathas' rejection of fairness is a concern to avoid ongoing grievances and conflict. I will not argue that trying to ensure fairness will altogether avoid such conflict. ${ }^{43}$ I will argue that there is no reason to think that Kukathas' account of benign neglect will fare any better as a way of avoiding conflict. In fact, I shall suggest, there are reasons to think that it will lead to, rather than avoid, ongoing conflict. Toleration liberalism, as represented by Kukathas, cannot ground an adequate fairness based response to nation-building (avowedly) and, crucially, it cannot provide an answer to nation-building that succeeds on its own terms, the avoidance of ongoing conflict.

As Kymlicka presents it, a policy of benign neglect is incoherent because governments must support particular societal cultures thus undermining the supposed separation between culture and state. For Kukathas on the other hand there is no requirement that a government should (or even could) avoid any intervention whatsoever. The institutions of the state are often already deeply involved in cultural matters (Kukathas 2003 p237). In some cases, such as New Zealand, the growth of the legal-institutional sovereign state involved the specific (legally valid) extinguishing of, for example, customary rights (by, e.g. turning customary title into freehold). This is a contentious programme that continues now in the shape of the Foreshore and Seabed Act 2004 (cf. Brookfield 2006 pp131 - 135; ibid pp188 - 194). No matter which way the government of a state turns they cannot force open a gap between culture and state.

\footnotetext{
${ }^{42}$ Although I think that Kymlicka and Barry are both correct to raise doubts about the desirability of an approach that would seem to allow parents to beat (and presumably) kill their children with impunity because it is a part of their culture.

${ }^{43}$ This is because, as Barry notes, "Every theory of justice is bound to be contentious, if all that means is that some people will not like it" (Barry 1995 p122).
} 
If Kukathas does not think that a policy of benign neglect requires a policy of complete nonintervention (which in any case seems impossible to achieve) what does it require? Kukathas claims that it "amounts essentially to a refusal to be guided by the goal of equality in social policy or institutional design" (Kukathas 2003 p237). Those who endorse a policy of benign neglect, then, need not be interested in ensuring that there is equality between and within groups $^{44}$. Such equality, Kukathas claims, is impossible to achieve because ensuring equality in one respect will lead to inequality in some other. ${ }^{45}$ Moreover, for Kukathas, different groups will understand equality differently. The ideal of equality can only be pursued by the use of "a high level of coercive power" (Kukathas 2003 pp 237 -238). Kukathas seems to be able to offer us a response to majority nation-building. Insofar as majority nation-building aims to create a standard set of social institutions across the state then this will be resisted by a policy of benign neglect. A policy of benign neglect aims to resist efforts by the state to create a population with standardized attributes that simply make them easier to control by that state (ibid p238). Moreover, a policy of benign neglect specifically requires the state to stay out of "cultural construction" even if (or, more accurately, precisely because) historically the state has intervened to create particular cultural outcomes. Attempting to overturn that situation in the name of some principle of equality is likely to disrupt "the lives and livelihoods of numerous groups and individuals" (ibid)

If the state is not required to do nothing then what does Kukathas think that it ought to do? This question becomes pressing when we remember that we are concerned not only with diversity amongst cultural affiliations but also disagreement. The state will, as Kukathas recognizes, be faced with "practical demand for action on matters of public policy that arise because of cultural concerns" (ibid). The nation-building model, as we have noted, is an account of such conflict. There may be conflict over the language of education, as well as the language of public institutions for example, or, as we saw in chapter 2, the ownership of territory and resources. Let us follow Kukathas and look at what the endorsement of a policy of benign neglect means in terms of language policy.

\footnotetext{
${ }^{44}$ This is, of course, in contrast to Kymlicka's position (cf. Kymlicka 1995 pp 108 - 115; p194), outlined in the previous chapter.
}

\footnotetext{
${ }^{45}$ That is, we can always ask with Amartya Sen 'equality of what?' (cf. Sen 1980). The same point is made by Marx in the Critique of The Gotha Programme (Marx 2002 p615). For example, to make people equal in well-being (cf. Cohen 2004 pp3 - 29) might mean that so-called 'expensive tastes' should be subsidized if this is what is required to make people equal in terms of well-being. But if 'expensive tastes' are to subsidized in order to achieve this particular kind of equality then this will mean making people unequal in terms of the resources with which they face their lives (Dworkin 2004 p340). To make people equal in well-being is to make them unequal in the resources that they have to reach whatever end they want.
} 
Kukathas distinguishes between two separate questions. The first concerns the preferred language within the group. The second concerns the official status of a language, the language in which law courts are to be run for example, or which children will learn through public education (ibid). The latter case can also be usefully divided. There may be issues with the accommodation of those who lack the ability to speak the official language well enough to, say, understand court proceedings. The policy in such cases will normally be to ensure effective communication (in order to ensure a fair trial in our example) (Patten 2009 p109). On the other hand those who speak a minority language may press for it to become one of the official languages used in public institutions. In this case a speaker would have the right to use it whether or not they actually spoke the majority language sufficiently fluently. I will assume that by "official language" Kukathas understands the latter.

In our first case, i.e. the language used within a group, Kukathas claims that acceptance of a policy of benign neglect means that the state should not seek to obstruct minority groups from using the language of their choice. This may seem fairly clear in some cases. For example, any attempt by the New Zealand government to shut down the Māori language newspaper Te Paki o Matariki would seem to contradict a basic right to freedom of speech. As Patten puts it, "any defensible principle of free expression would protect not just the content but also (the) style and form" of such speech (ibid p108). But not all cases are as clear as this. Kukathas includes not only the publication of newspapers or the use of language within the private sphere as being beyond the scope of legitimate interference but also the choice of the primary language of children's education. To educate children primarily in a minority language, Māori, to take Kukathas' example, rather than a widely spoken alternative (both within and outside the state) such as English might be seen as unfairly disadvantaging those children who learn Māori (Kukathas 2003 p238). Kukathas responds by pointing out that forcing Māori to educate their children in English (because it opens up more opportunities for them) is to arbitrarily favour one idea of what it is to lead a good life (e.g., "advancement in the wider world") over another (e.g., "holding on to a cultural inheritance" ). Māori parents face a choice on Kukathas' account. What is important for Kukathas is that the decision ought to be in the hands of those parents who must "make assessments of what risks to take". ${ }^{46}$ Kukathas, as part of his endorsement of benign neglect, claims that taking the decision out of their hands would be the wrong thing to do insofar as it "fosters resentment and a sense of grievance" (ibid p239).

\footnotetext{
${ }^{46}$ As Barry points out it is not clear that Kukathas' argument establishes a right for any cultural group. The argument merely claims that any decision should lie with the parents (Barry $2001 \mathrm{p} 143$ ).
} 
Kukathas may be correct to resist taking such choices out of parents' hands although given his emphasis elsewhere on the importance of a 'right of exit' this might be doubted. This right of exit means that the authority of the group only extends as far as the members' recognition of the authority of the group. This recognition takes the form of electing not to leave the group which would be meaningless without the "fundamental" right to leave the group (ibid pp96 98)). Preparing children primarily for a world in which Māori is spoken might seem to severely limit a meaningful ability to exit, thus effectively undermining the 'fundamental' right of exit by limiting opportunities to do just that (cf. Barry 2001 pp239 -241) ${ }^{47}$.

There is, however, a further issue. Kymlicka's complaint against benign neglect is not that it does not allow groups to look after their education. It is rather that those languages that are not the language of government (or are not used in publicly funded schools) are at a serious disadvantage. The resources of the state are behind the 'official' language. Other languages are at a serious disadvantage in the 'cultural marketplace'. As Kukathas notes this requires the government to make decisions about which languages to support and which not given that, in a modern, multicultural society it will not be possible to support every language. Nor can we rely on those in the majority to choose to set aside resources for the preservation of a language (Kukathas 2003 p240). Given a multitude of languages and limited resources it will not be possible to meet every claim that is made. It is this issue that lies at the heart of Kymlicka's complaint about benign neglect and which is captured in the nation-building model of the state; there is disagreement about what the state ought to do when faced with cultural diversity. It cannot, however, do nothing. So what does the proponent of benign neglect recommend? Here is what Kukathas says:

"The stance of benign neglect suggests not that nothing needs to be done but rather that there is, in most cases, no determinate solution that will conform to an ideal of equality. Such solutions as might be reached will have to be compromises. All that can reasonably be assured to all groups is the freedom to pursue their aims to secure or promote their languages" (ibid p242)

But what does it mean to suggest that any solution will need to be a compromise? This depends upon what sort of thing we think that a compromise is. We might think, for example, that a compromise is reached when those in conflict put aside those features of their initial position that would render agreement untenable (Weinstock 2006 p18). We might, further, be concerned to ensure that such a compromise is fair. We could do this by giving some idea of what kind of features it is reasonable or unreasonable to insist upon, or by ensuring that those

${ }^{47}$ I do not mean to suggest, however, that learning both English and Māori is impossible. It clearly is not. 51 
putting aside features of their position are not doing so because they are coerced in some way into setting aside more than they would otherwise be willing to give up. Kukathas rejects all of this. Compromise, he claims, is incapable of "a precise theoretical formulation - or even a general one" and will instead simply reflect individual circumstances and "the bargaining strengths of different parts of the society in question". The only condition he gives is that, in searching for compromise, we should not think especially important "the idea of securing an outcome which honours the ideal of equality for groups. It cannot be attained" (Kukathas 2003 p243).

What Kukathas requires, then, is that individuals and groups are assured the freedom to pursue their ends. But this assurance, at least in any meaningful sense, is what is at stake. He criticises those positions that seek to arrive at some determinate solution, some way of ensuring the end state of equality between groups. He might be correct to claim that such equality is unobtainable and that no determinate solutions are possible. But Kymlicka's argument is that nation-building policies constrain the range of possible choices that individuals make and the outcomes that they can reasonably expect from those choices. The third-stage, nation-building argument does not need to be concerned with obtaining particular outcomes amongst cultures. The point is that the institutions of the state, which reflect the identities and interests of the majority, place unfair pressures on the cultural choices that individuals make. What Kymlicka is picking out is that the basic institutions of the state systematically disadvantage some cultures and advantage others. ${ }^{48}$ Rather than requiring a particular outcome, as Kukathas has it, Kymlicka is concerned to highlight the ways in which existing social institutions count against the ability of members of minority cultural groups to pursue their chosen ends (Kymlicka 2001 p32). ${ }^{49}$

Kukathas seems to recognize this. As we have seen he notes that many governments are already deeply involved in cultural issues. He notes also that a policy of benign neglect does not seem to take account of past wrongs to, for example, indigenous peoples. Although he recognizes that the claims of such groups need to be assessed he nonetheless claims that such a "problem needs to be treated independently" of his account of benign neglect (Kukathas 2003 p242). A full treatment, however, would need to recognize that the position of indigenous peoples (and other minority nations generally) is not simply the result of individual

${ }^{48}$ This is similar to point that Barry makes about Robert Nozick's libertarianism (Barry 1995 p214).

${ }^{49}$ Alan Patten makes a useful distinction between arguing for a particular end-state and arguing that the terms and social processes that lead to particular end-states are in some way unfair (Patten 2009 p111). Kukathas seems to have in mind the former argument whilst Kymlicka seems to be talking about the latter. 
decisions divorced from a shared institutional framework that reflects, according to the nationbuilding model, the interests and identities of the majority and systematically marginalizes those of minority groups. Take the case of efforts at a kind of compromise between two cultural groups; the negotiations over land and cultural property rights in contemporary New Zealand between the Crown and iwi (through 'Treaty settlements'). According to Roger Maaka and Augie Fleras the iwi, as a unit of Māori social organization, has been hampered in its ability to evolve to meet contemporary Māori needs by government policies that have sidelined it or, in some cases, aimed to diminish its influence altogether. Because of the ongoing effects of such policies iwi find it difficult to meet an inflated set of expectations on behalf of both Māori and Pakeha (Maaka and Fleras 2005 p79). Negotiations with iwi as the primary structural unit for negotiations also mean that individual Māori must align themselves to iwi to receive the benefits of negotiations, whether they wish to or not so align themselves (ibid pp87-90). This is not to say that the New Zealand government is wrong to negotiate with iwi, or that Māori are necessarily worse off than they would have been had there been no colonization, merely to emphasise the general point that institutional structures shape and constrain the range of individual actions. Kukathas, in focusing on outcomes, seems to miss this point.

I have suggested that we must be careful to keep the issue of attaining fair outcomes separate from the issue of identifying fair terms and conditions that give rise to outcomes. Kukathas is surely correct to claim that the outcome of any compromise will be unsatisfactory for some people (ibid p244). This will go for non-cultural outcomes too. If a local authority wants to build a library, which is popular with some, whilst I want them to build a football pitch then the chances are high that someone is going to be disappointed with the eventual outcome ${ }^{50}$. But although the outcome might lead to disappointment we can nonetheless insist that the method by which that outcome is reached is fair, perhaps by insisting that the issue be put to a popular vote (cf. Barry 1995 p109). Kukathas' complaint at this point must be that this answer merely pushes the problem back. We need to reach a compromise on what voting system we are going to use for example and this, too, will be rejected by some. Likewise, the current institutions of society may well favour certain interests, and any compromise will be a result of superior bargaining positions (because of past and ongoing injustice). But any institutional scheme, including any attempt to make that institutional scheme fair, will be unsatisfactory for some.

But Kukathas' claim must be a stronger one than that any set of institutions will make some people unhappy, for this does not rule out efforts to at least ensure that such institutions are

\footnotetext{
${ }^{50}$ I am assuming that they cannot do both or that building a smaller football pitch and a smaller library will still be disappointing to some.
} 
fair (even if some do not see it this way). For Kukathas fairness is simply not a relevant concern. What is important is making "conflict over such issues as language less troubling and potentially damaging" (Kukathas 2003 p243). The error lies in thinking "that a solution can be found that somehow treats all groups equally or 'fairly'" (ibid p245). Any solution would make someone unhappy thus leading to an ongoing sense of grievance (ibid). Conflict can be avoided, however, by ensuring that cases of cultural disagreement are not treated as matters of justice but, rather as a matter of "history and accident". Outcomes that favour one cultural group over another, Kukathas claims, should be viewed as if they were the result of a lottery, thus diminishing the sense of anger that may be felt by the losers (ibid p246). We can put Kukathas' point another way. Rather than focusing on the attempt to realise certain principles of justice and fairness, either as outcomes or in the institutional structure that constrains the range of such outcomes, we should focus on avoiding cultural conflict. A policy of benign neglect, as Kukathas understands it, is better placed than a theory of ethnocultural justice to achieve this goal.

Kukathas thus eschews fairness as a relevant normative criterion in establishing a compromise. What is relevant is that conflict be avoided. But if the attempt to identify either a fair outcome or a fair procedure for reaching some outcome is likely to lead to further conflict then there is little reason to think that the kind of benign neglect that Kukathas endorses will fare any better. Kukathas certainly gives us little reason to think that this might be the case. To take up Kukathas' metaphor, the outcome of a lottery will favour some (the winner(s)) more than others (the loser(s)). But fairness is not irrelevant here. What the lottery metaphor is supposed to indicate is that we should view cultural outcomes as a matter of luck. But what makes this acceptable in the case of a lottery is presumably that the background conditions of that lottery are fair, that it is not weighted in anybody's favour, that no-body cheats etc (cf. Rawls 1973 p86). If we were running a lottery that favoured certain individuals (or results) over others then participants would seem to have good reason to feel aggrieved. ${ }^{51}$ And the same would seem to go for cultural outcomes. If, say, indigenous ownership is not recognized by the courts of the state then this is not simply a matter of historic bad-luck but the result of majority laws that favour certain kinds of ownership over others. Crucially, it seems implausible (not to mention patronising) to think that minority cultural groups will accept that the status quo is simply a matter of accident.

\footnotetext{
${ }^{51}$ This sense of grievance might be even more keenly felt if participation was compulsory. In the same way, indigenous peoples, for example, might complain that not only is the lottery weighted against them (and their interests) but that they have no choice but to participate in it.
} 
Leaving behind Kukathas' odd metaphor of a lottery let us turn to look at his idea of a compromise that is based on the "realities of political power" as opposed to a commitment to fairness (Kukathas 2003 p246). Fortunately enough for us we do not need to come up with a thought experiment to explore this idea. History is full of agreements and compromises that reflect the political realities of their times. We can take New Zealand's Treaty of Waitangi as an example of such a compromise between Māori iwi and the British Crown. I have already said a little about some ongoing concerns with this compromise. Here I want to note that even when there is general agreement that a compromise is required to avoid ongoing conflict there is no reason to think that one party or another should stick to such a compromise when it would advance their interests to go back on their word. If the compromise reflects only the realities of political power then with a change in the relative powers of those who reached the compromise ${ }^{52}$ we can expect a change in the terms of that compromise to reflect this new situation. This, for example, was the fate of the Treaty of Waitangi which, when the settler majority was suitably entrenched (institutionally and increasingly in terms of resource control), was declared a "simple nullity" (Wi Parata v Bishop of Wellington ((1877)3 NZ Jur (NS) SC 72) cited in Brookfield 2006 p99). Once the balance of power has shifted in favour of some group or other any compromise can be challenged by the newly powerful group (cf. Barry 1995 pp37 -38). Without even the pretence of fair dealing, including sticking to compromises made in other circumstances, any compromise will most likely be at best a temporary end to conflict. And the perceived rejection of the terms of the compromise by the stronger party will be likely to give rise to ongoing grievances and future conflict. To return to example of New Zealand, as I write the New Zealand government are involved in ongoing, and controversial, negotiations with the Tūhoe iwi over Te Urewera National Park. Neither the compromise that was the Treaty of Waitangi nor the political expediency of its rejection by the majority has succeeded in avoiding ongoing conflict. Indeed, it is plausible to suggest that the ongoing conflict and sense of grievance is due precisely to the perception of historic unfairness and injustice. Nor, to return to Kukathas' concern, is any compromise on this issue now likely to make everyone happy. ${ }^{53}$

The problem with Kukathas' account of compromise, such as it is, is that it seems to offer perverse incentives to increasingly powerful majority groups, as in the case of the Treaty of

\footnotetext{
${ }^{52}$ Changes in the relative power of participants may also be a result of the initial compromise itself.

${ }^{53} \mathrm{Cf}$. http://www.nzherald.co.nz/opinion/news/article.cfm?c id=466\&objectid=10644143 (retrieved 18/05/2010).
} 
Waitangi, but also to violent belligerent minority groups. If we are to base the terms of a compromise, and ongoing adherence to those terms, upon the realities of political power then those groups that threaten destabilization of a country or region seem more likely to succeed in getting their demands met, in the name of ensuring future stability, than do groups that have repudiated violence and who do not, for that reason, threaten conflict and instability. ${ }^{54}$ In short, if avoiding an ongoing sense of grievance and conflict is the primary aim of a policy of benign neglect then there is little reason to think that it is any better suited to this task than a concern with ensuring that such a compromise is in some sense fair ${ }^{55}$, as even a cursory glance at history suggests. Certainly Kukathas gives us no good reason to think that this is the case.

Ultimately Kukathas' account of benign neglect offers us no substantive answer at all when faced with cultural diversity and disagreement. But Kukathas could nonetheless be correct that the attempt to find principles of justice to regulate what he calls compromise may fare no better. There remains a need, then, to offer some plausible account of justice that answers sceptics such as Kukathas. One such grounding was Kymlicka's autonomy argument but I rejected this as unsuitable in chapter 2 . The other alternative offered by Kymlicka is 'toleration' based liberalism of which Kukathas represents only one version. Kymlicka also considers political liberalism, such as that endorsed by the later Rawls, as a version of toleration liberalism. Kymlicka claims, however, that in order to ground civil and political rights it must, in fact, be grounded by exactly the kind of autonomy liberalism that he endorses (Kymlicka 1995 pp158 - 163). I shall suggest that political liberalism (which Kymlicka calls 'liberal toleration') does not in fact need to collapse into autonomy liberalism in order to ground a plausible set of justice based rules and principles that can regulate cultural conflict effectively. Political liberalism, moreover, can ground a plausible alternative to the autonomy/toleration dichotomy. As we shall see in chapter 4, I also do not think that Kymlicka need see it as hostile to his project.

\footnotetext{
${ }^{54}$ In recent work Kymlicka has made a similar point in relation to an international norm of 'effective participation' for minority cultural groups that is designed solely to offset the extent to which conflict (and the capacity for instability) exists, rather than to realize any general principles of fairness (Kymlicka 2007 pp258 - 259).
}

\footnotetext{
${ }^{55}$ I do not mean to suggest that conflict can be avoided if only we ensure that the initial compromise was fair. Clearly it is possible for initially fair compromises to be challenged by a newly strengthened party. But a concern with fairness does give us the normative tools to condemn such a situation. Kukathas' account simply requires that this situation be accepted so long as it avoids further conflict. But if this is our only concern then incentives remain in place for ongoing challenges to the initial terms of compromise. In making the avoidance of conflict the primary concern Kukathas seems to offer incentives for groups to foster that very same conflict.
} 


\section{Political liberalism}

I do not think that either autonomy liberalism or the kind of toleration liberalism endorsed by Kukathas offer normatively appealing responses to majority nation-building. Let us remind ourselves of the key criteria of toleration liberalism according to Kymlicka. Toleration requires the accommodation of illiberal groups just so long as they are also tolerant of others and do not expect support from the state (Kymlicka 1995 p155). It is not clear that Kukathas' account of benign neglect can meet these criteria and, as such, he falls back upon an underspecified notion of compromise to shore up his account, as we saw in the previous section. For Kymlicka, however, there is a further distinction to be drawn within toleration liberalism. Kymlicka distinguishes between toleration that allows groups to restrict the freedom of members of their group and what he calls liberal toleration which protects cultural groups from maltreatment by the state but also protects the rights of individuals to disagree, and leave, that group. For Kymlicka liberal toleration is characterized by a commitment to autonomy (e.g., in its support of freedom of conscience) (ibid p158).

The picture of a liberal state that allows freedom of association whilst offering protection, in the form of rights, for those who wish to leave such associations and which certainly refrains from using its resources to support particular groups against (ex)members is a familiar one. As Kymlicka notes, it is a form of liberal toleration that has been historically endorsed by most liberals (ibid). The question is whether such liberal toleration requires an endorsement of autonomy, as Kymlicka suggests, or whether it can be grounded by some other consideration. Kymlicka's implication seems to be that if we do not accept the fundamental value of autonomy then we end up with a version of the toleration liberalism as endorsed by Kukathas. Thus he argues that Rawls' attempts to ground liberal civil and political rights and duties in what Rawls calls political autonomy (i.e. autonomy restricted to political contexts amongst citizens) collapses into the kind of comprehensive autonomy endorsed by Kymlicka (cf. Chapter 2). This is because otherwise Rawls cannot explain why someone could accept political autonomy, and thus individual civil and political rights, when they reject the value of autonomy in other areas of their life (ibid p160).

But I think that Kymlicka is mistaken. We are not faced with a choice between the kind of toleration liberalism endorsed by Kukathas on the one hand and a liberal tolerance that is in fact a disguised form of autonomy liberalism on the other. Barry, for example, argues that liberalism will impose some restrictions on groups over the members of their group. It will insist that those who seek to leave the group are not harmed and that those who dissent face 
only the threat of expulsion by the group. It will also tend to restrict the rights of groups against particular vulnerable members of that group by imposing limitations on what can be legitimately done to those members (e.g., by restricting the rights of parents over their children) ${ }^{56}$. Finally, although liberalism, according to Barry, is mainly concerned with how states treat people it can impose certain restrictions on certain aspects of non-state associations that are central to people's lives (e.g., by enforcing anti-discrimination laws with regard to private, as well as public, employers) (Barry 2001 pp123 - 124).

There are clear overlaps between Barry's liberalism and Kymlicka's own prohibition on internal restrictions. But, crucially, this overlap depends upon limiting the prohibition on internal restrictions to the claim that the liberal state ought not to ignore physical punishments imposed upon those members who dissent in some way, the protection of the vulnerable, and guaranteeing an effective right of exit (ibid p163). This is crucial because it does not involve the group itself advocating the value of individual autonomy by, say, allowing its members to reject the way of life of the group whilst still remaining a member. That is, there can be a framework of civil and political rights that permit individual, comprehensive autonomy as an option for both individuals and the groups that they belong to, to endorse. But this is very different from requiring that the state should be concerned with ensuring that people live fully autonomous lives (ibid p120). Insofar as autonomy liberalism requires the state to only support ways of life that support autonomy then political liberalism, which restricts autonomy to the political sphere, ${ }^{57}$ will avoid basing its principles upon the fundamental value of comprehensive autonomy. ${ }^{58}$

\footnotetext{
${ }^{56}$ This is based on precisely the fact that many of our attachments are involuntary and this may leave certain individuals, such as children, vulnerable. It is the importance of this consideration that leads liberals such as Barry to reject the kind of toleration liberalism espoused by Kukathas based upon noninterference with cultural groups (Barry 2001 p149).
}

\footnotetext{
${ }^{57}$ For Rawls political autonomy requires "the legal independence and assured integrity of citizens and their sharing equally with others in the exercise of political power" (Rawls 2005 pp 455 - 456). Political autonomy does not require "a certain way of life and reflection, critically examining our deepest ends and ideals" which is characteristic of comprehensive autonomy (ibid p456) such as that endorsed by Kymlicka.
}

\footnotetext{
${ }^{58}$ Kymlicka complains that this means that Rawls cannot hope to accommodate illiberal groups. By illiberal, however, Kymlicka simply seems to mean those who reject comprehensive autonomy (Kymlicka 1995 p158) which somewhat begs the question. Kymlicka writes, for example, as if Rawls needs to be able to accommodate all conceptions of the good. Rawls' idea of an overlapping consensus clearly does not achieve this as it leaves out unreasonable conceptions of the good. But Rawls clearly does not need to (and indeed cannot) allow unreasonable conceptions of the good into political justice any more than comprehensive autonomy need allow internal restrictions. Those who do not want to cooperate with others on reasonably acceptable terms must necessarily remain outside the overlapping consensus as 58
} 
Even if we accept that political liberalism avoids the kind of autonomy liberalism endorsed by Kymlicka we still require some account of what is supposed to ground the kind of principles endorsed by liberals. The answer that I want to explore is that the rules and principles that are to regulate the disagreements and conflict that arise between people with different cultural beliefs and affiliations should be such that they could not be reasonably rejected as the basis for un-coerced compromise. ${ }^{59}$ The requirement that such compromise be such that it could be reasonably expected to be endorsed (or, at least not be reasonably rejected) by those who are to be governed by it makes it a more exacting account of compromise than that offered by Kukathas. It is more exacting because it cannot simply rest upon the balance of power but must also rest upon the agreement of those who are to be regulated by it, abstracting from such imbalances of power.

\section{Conclusion}

In this chapter I have looked at toleration liberalism as an alternative to the autonomy liberalism explored in the previous chapter. Toleration liberalism, understood as noninterference (Kymlicka 1995 p155), could not ground a plausible fairness based response to nation-building. In the hands of one of its more high profile proponents, Chandran Kukathas, this is hardly surprising as fairness as an aim of the state is specifically rejected. But, I argued, Kukathas could not avoid dealing with cultural disagreement within the state that demanded some action by that state. Kukathas' notion of benign neglect, and in particular his account of 'compromise' based upon political realities, provided a normatively unappealing response to

must those who reject diversity in society altogether (Freeman 2007 p371). Kymlicka's error lies in assuming that those who reject autonomy reject liberal principles (Kymlicka 1995 p164). This assumption fails to distinguish between a comprehensive autonomy and the far less demanding political autonomy required by an overlapping consensus of reasonable conceptions of the good.

59 In this I follow T M Scanlon's formulation of the requirement that focuses on reasonable rejection (Scanlon $1982 \mathrm{p} 110$ ) rather than Rawls' own account which focuses on terms that can be reasonable accepted, although, I think, that little hangs on this difference for my discussion. I follow the Scanlonian line as this is what Barry does and Barry's account plays a major role in the next chapter. 
such disagreement insofar as it offered little reason to think that it could succeed on its own terms; the avoidance of ongoing conflict. ${ }^{60}$

We saw that Kymlicka claimed that toleration liberalism that did not collapse into Kukathas' rejection of external protections and acceptance of internal restrictions instead collapsed into accepting comprehensive autonomy as the fundamental liberal value. I argued that this was not the case if by autonomy liberalism it was meant that non-state groups should support individual autonomy as a condition of their continued tolerance by the state. Instead I pointed to Barry's account that argued that the liberal state should be concerned to ensure that conditions are such that those who wish to leave their group are free to do so by putting in place a series of civil and political rights. Living an autonomous life, in Kymlicka's sense, is one option amongst many offered by the liberal state. What grounded this liberalism, I suggested, was not the acceptance of autonomy as the fundamental liberal value or the rejection of the idea that the liberal state can legitimately enforce certain standards of treatment of individuals, as with toleration liberalism, but rather that the rules and principles that form the terms of compromise amongst divergent (cultural) conceptions of the good be such that could not reasonably be rejected by those who they regulate. I think that such an approach can ground the kind of fairness based claims that Kymlicka wants to make about majority nationbuilding. This argument forms the basis of the next chapter.

I will argue in the next chapter that the idea of reasonable agreement can ground the kind of fairness based claims that Kymlicka wants to make about majority nation-building. In particular I will argue that it can give us a plausible account of ethnocultural neutrality, understood as the claim that policies that are based upon the superiority of some cultural way of life can be reasonably rejected by others. I will also argue that it can offer Kymlicka the tools to make the kind of judgements that he wants to make about the distribution of burdens and benefits that result from majority nation-building programmes. That is, political liberalism that focuses on the importance of reaching reasonable terms of agreement can offer a plausible alternative to Kymlicka's autonomy/ toleration dichotomy when evaluating the fairness of nation-building. I do not mean to suggest, of course, that the idea of fairness understood as terms of reasonable agreement is beyond criticism. ${ }^{61}$ My aim will be more modest in attempting to show a

\footnotetext{
${ }^{60}$ As well as requiring liberals to accept that vulnerable people, such as children, should be dealt with as their cultural group saw fit.

${ }^{61}$ One important kind of criticism is that there can be reasonable disagreement on principles of justice as much as there are on conceptions of the good. More precisely the criticism is that reasonable agreement rests upon an untenable epistemic distinction between principles of justice (on which we can find agreement) and conceptions of the good (about which we must exercise 'epistemological restraint' (cf. Nagel 1987) or scepticism (cf. Barry 1995)). The problem is that there seems little reason to think that such scepticism should not also be applied to the idea of reasonable rejection as the criterion of 60
} 
significant amount of common ground between Kymlicka's third-stage, nation-building argument and liberalism understood as principles for compromise that it would be unreasonable to reject.

fairness (cf. Clarke 1999 p635). I do not have space to consider this argument in this thesis. For a reply that bases the contractarian concern with reasonable rejection on the equality of persons, rather than reasons cf. Lecce 2003 pp524 - 541. 


\section{Chapter 4: Nation-Building as Reasonable Agreement}

\section{The burdens of nation-building}

In this chapter I want to look in more detail at the idea of justificatory ethnocultural neutrality as a coherent response to multicultural pluralism. ${ }^{62}$ I want to argue that when ethnocultural neutrality is understood in terms of a limit upon relevant justifications within a broader account of reasonable agreement, it is not only not manifestly false but can also be used to ground precisely the kind of fairness claims that Kymlicka wants to make about nationbuilding. As such it can be seen as a plausible alternative to both autonomy liberalism (chapter 2 ) and toleration liberalism (chapter 3 ) in grounding a liberal response to cultural (and national) disagreement. Indeed I shall suggest in section 4 (below) that Kymlicka sometimes relies on precisely the reasoning endorsed by those who accept a principle of ethnocultural neutrality. Kymlicka, in short, misrepresents the position of liberals who endorse ethnocultural neutrality. Indeed, I shall be concerned in this chapter to explore some areas where critics of multicultural policies, in particular Brian Barry, who endorse ethnocultural neutrality make strikingly similar claims to those made by Kymlicka as part of his third-stage argument. That such an overlap exists has been remarked upon in the literature (Caney 2002 pp83 - 84; Parekh 2002 pp147 - 148). I will argue that this overlap can be explained by agreement upon the broad principle of fairness captured by the idea of reasonable agreement. Where there are differences these arise because of disagreements about what kind of fundamental interests people have, how they should be weighted against one another and thus what can be legitimately supported by the liberal state (and to what extent). These differences involve the proper role of culture, nationality, ethnicity etc. They are, in short, matters for Kymlicka's second-stage argument (cf. Chapter 1). In particular I shall argue that Kymlicka is wrong to think that the debate over minority rights has moved on from the second stage to the third stage; that is, he is wrong to think that minority cultural rights can be understood solely as a requirement of fairness in nation-building states independently of debates about the proper

62 In a recent article, for example, Alan Patten has put forward the view that "the state...can show neutrality if it can establish that its policies did not have as their fundamental rationale the advantaging or disadvantaging of particular attachments or commitments" (Patten 2009 p123) and is, for that reason fair, as a possible rival view to Kymlicka's nation-building model of the state. 
role of culture, nationality, ethnicity etc within liberal theory bounded by a norm of justificatory ethnocultural neutrality.

We can approach the argument of this chapter in another way. As we shall see Kymlicka makes the claim that his third stage, nation-building model of the liberal democratic state shifts the burden of proof away from the defender of minority cultural rights so that it falls equally on those who seek to defend the status quo. However, there is no reason to think that those who endorse reasonable agreement limited by ethnocultural neutrality support the status quo. There are probably no societies that are set up in such a way so that their institutions and laws realize the demands of justice as put forward by liberal political theorists. Some will contain stigmatized minority groups, in some cases the vestiges of a shared colonial past in which one group (the settlers) were dominant and often treated the original inhabitants unjustly. ${ }^{63}$ The

\footnotetext{
${ }^{63}$ The extent to which present generations should seek to rectify past injustices is a morally complex matter and, as such, I have not really touched upon it in this thesis. Kymlicka, for example, accepts that indigenous peoples will retain certain common law property rights but is concerned that returning all the land in a (former) colony would cause "massive unfairness" now. In short Kymlicka agrees with Waldron that there are circumstances in which historic injustice ought to be superseded by current conditions (Kymlicka 1995 pp219 - 221 n5; Waldron 1992b pp4 - 28). As I mentioned in the previous chapter, in relation to iwi in New Zealand, however, past policies can be reflected in contemporary institutions which can be problematic when contemporary expectations are themselves subsequently hindered by these past actions. Past injustices may also affect the self-respect of current generations. As Maaka and Fleras note; "colonialism entails a complex system of racial, cultural, and political domination that establishes a hierarchical arrangement between the coloniser and colonised...In asserting the racial and cultural superiority of the coloniser, colonialism dehumanises indigenous peoples and renders them dependent by internalising a sense of inferiority and worthlessness" (Maaka and Fleras 2005 p40). Frantz Fanon captures the ethical, as well as the political, dimension of this relationship when he writes that the "native is declared insensible to ethics; he represents not only the absence of values, but also the negation of values" (Fanon 1971 p32).
}

Given such a relationship, and its ongoing effects, it is perhaps hard to disagree with Charles Taylor, and Kymlicka, when they claim that the misrecognition of others can cause real harm to individuals (Taylor 1992 p25; Kymlicka 2001 p32). It is in this light that we might see the strength in the concerns over an ahistorical neo-Kantian liberalism (such as Rawls' Theory of Justice) that brackets off such features as irrelevant to justice (Requejo $2001 \mathrm{p} 165$ ). In the first instance, however, those committed to a justificatory account of neutrality are not necessarily committed to some kind of veil of ignorance in order to derive their norms and can be concerned with the application of such norms to (as T M Scanlon puts it) our "imperfect world" (Scanlon 1982 p111). Barry, for example, recognizes the difficulties presented by stigmatized minorities whose views are looked down upon by the majority and (like Kymlicka) recommends group representation as a possible antidote (although he is pessimistic about the efficacy of such a solution, understandably given the points made above) (Barry 1995 pp100 - 103). The question is, given this fact of stigmatization, what needs to be done to adequately 'recognize' people (e.g., is it enough to secure their full citizenship, as was argued, for example, in the case of Indigenous Canadians in the 1969 White Paper or does this act in itself indicate "a thinly disguised programme of extermination through assimilation" (Cardinal 1969 p1) that fails to recognize Indigenous peoples as forming legitimate political entities in their own right (Turner 2006 pp31 - 32)?).

It should be pointed out that indigenous peoples are not the only stigmatized minority groups. Iris Marion Young, for example, includes (in the USA) "women, blacks, Native Americans, Chicanos, Puerto Ricans and other Spanish-speaking Americans, Asian Americans, gay men, lesbians, working-class people, poor people, old people, and mentally and physically disabled people" (Young 1989 p261). Kymlicka complains that this list would "include 80 per cent of the population" (Kymlicka 1995 p145). 
nation-building model of the state can help to focus our attention on features of the modern, liberal state that some find burdensome. But the point is not to simply point out things that are burdensome, at least within normative political theory, but rather to establish whether those burdens are shared fairly. Such an account is given by the idea of reasonable agreement. The question is what kind of burdens people can legitimately expect the state to correct and how are they to be weighed up one against another. Answers to these questions are what are needed before we can leave the second-stage of the debate.

\section{Reasonable agreement, ethnocultural neutrality and nation- building}

The basic idea behind the justificatory account of ethnocultural neutrality is that principles of justice that are to regulate the pursuit of cultural (and other) goods are those that could be agreed upon without relying on the claim of the truth or superiority of any particular cultural conception of the good. ${ }^{64}$ In Rawlsian terms we can say that political principles of justice are free-standing. What is important in justifying these principles is that they are what reasonable people could be expected to consent to. Of course there are many agreements that might fulfil some account of what it is reasonable for people to agree to. If, for example, we understood reasonable agreement as mutual benefit (as, I suggested, Kukathas seems committed to) then we might conclude that those historic treaties between European colonists and indigenous peoples that were often concluded on the back of the latter being "driven into signing...by the destruction of villages, crops, and game as well as by the indiscriminate killing of men...women and children" (Barry 1995 p41) would be fair and just even if they would have been rejected

Kymlicka wants to focus on "national and ethnic differences" (ibid p18) which is fine so long as it is remembered that there are other identities that will cut across these and which, in their own way, may be stigmatized by others and which may be stigmatized in their own way by certain cultural groups and practices. As Joseph Carens notes Kymlicka's stipulation also carries normative weight within his justification of minority rights (at the second stage) as he specifically links the cultural differences in with societal cultures which in turn guarantee individual autonomy thus ignoring the role of cultural differences within society (Carens 2000 pp69 - 70; Phil Parvin has, more, recently made a similar argument, (Parvin 2008 pp315 - 333). Interestingly in the later PV societal cultures become less comprehensive (in the third stage) indicating merely a "common language and social institutions" (Kymlicka 2001 p25) which seems to diminish Caren's particular criticism at the expense of making it less clear why access to one's own societal culture represents the kind of compelling moral interest that Kymlicka seems to require.

${ }^{64}$ Such principles of justice, however, can be endorsed from within some particular conception of the good. They do not require us to take a 'god-like' view outside of our own commitments. This idea is what motivates Rawls' account of an 'overlapping consensus' between reasonable conceptions of the good (cf. Rawls 2005 p150). 
(or at least renegotiated) in other circumstances. Most liberals, certainly those within the contractarian tradition, will therefore attempt to stipulate a set of fair background conditions in the form of a 'state of nature' (e.g., Locke and Rousseau), original position (e.g., Rawls and Scanlon and Barry) or in the form of ideal speech conditions (e.g., Habermas (cf. Habermas 1990) and Ackerman (cf. Ackerman 1989)). In the last chapter this was briefly spelt out in the general, Scanlonian, terms of people being uncoerced. Legitimate principles of justice will thus be the result of 'reasonable agreement' amongst appropriately situated moral agents.

Neutrality enters the picture insofar as it is claimed that the principles that could reasonably be chosen by moral agents thus situated would avoid resting upon the superiority or truth of any of the particular cultural positions that those principles are to regulate. Reasonable agreement, according to this account, can be said to generate neutrality (cf. Barry 1995 p129).

The principle of ethnocultural neutrality, as I am interpreting it, then, is a claim about what kind of principles it is reasonable to expect others, who do not share our cultural beliefs or practices, to accept. When Barry claims, in Culture and Equality, "that the way liberalism is neutral is that it is fair" (Barry 2001 p28) we can understand this claim as meaning that liberal principles are the result of reasonable agreement (cf. Barry 1995 pp142 - 145). Barry grounds his account of reasonable agreement in the Scanlonian original position which claims that any "act is wrong if its performance under the circumstances would be disallowed by any system of rules for the general regulation of behaviour which no one could reasonably reject as a basis for informed, unforced general agreement" (Scanlon 1982 p110; Barry 1995 p67). I shall focus here on the aspect of Scanlon's formulation that bears on Kymlicka's claims about nationbuilding. Kymlicka, recall, points out that majority nation-building can impose burdens upon those who are not members of the majority national group. However, it is not enough to point out that some general rule will impose burdens, since this is unavoidable given any set of general rules. The Scanlonian formulation requires that just principles are such that they could be the subject of reasonable agreement (or, more precisely, could not be reasonably rejected ${ }^{65}$ ). This means that a principle cannot simply be rejected because it places burdens on some; rather, it can be reasonably rejected only if there is a viable alternative principle under which those burdens can be lessened without greater burdens being imposed on others.

\footnotetext{
${ }^{65}$ Although Barry relies on the Scanlonian original position he does "not think that anything crucial turns on the distinction between a formulation of the criterion in terms of non-rejectability and a formulation in terms of acceptability" (Barry 1995 p70). I shall use 'reasonable rejection' and 'reasonable agreement' interchangeably too, mainly for ease of exposition.
} 
Let us imagine a situation in which members of some minority group were denied the right to vote. This could be reasonably rejected by them on the grounds that there is a viable alternative principle in which no-one need bear the burden of disenfranchisement (i.e., a universal franchise $)^{66}$. As Barry points out the Scanlonian formulation, in regards to such 'basic rights', "leads directly to a very strong presumption in favour of equality here, since it invites us to ask why anybody should freely consent to being treated less well in respect of rights than anybody else in his society" (ibid p70). There may be good reasons to give some people different rights or subject them to differential treatment but there is a prima facie case for equal treatment based upon reasonable agreement. Now, one way of arguing for a restriction of the franchise might be on the grounds that the culture of those entitled to the vote is superior to those who are to be denied the vote. ${ }^{67}$ Such a move would be blocked by a commitment to the principle of ethnocultural neutrality which precludes (as unsuitable for reasonable agreement) such claims. The principle of ethnocultural neutrality enters the picture as a limit on the permissible grounds for such differential treatment (i.e., that they cannot be based upon the truth or superiority of some cultural practice or other). It is the claim that what is important about principles of justice is that they could be the subject of reasonable agreement that places the burden of proof on those who seek to argue in favour of differential treatment on the basis of culture (or, indeed, any other basis). That is, the idea of reasonable agreement gives us a prima facie reason to treat people in the same way, to give them the same set of basic rights, duties and opportunity sets and to ensure that circumstances that people may fall into work in the same way for everybody (cf. Waldron 2007 p129). There may be many good reasons to require differential treatment and this will be recognized in the laws and institutions of most liberal states. ${ }^{68}$ But the crucial point is that this requires some

\footnotetext{
${ }^{66}$ Where there are restrictions on this right they must be appropriately justified. For example, usually minors are denied the right to vote (even though they will most likely be affected by the results of any vote). Any plausible reason for this would need to rest on what we can call, following Waldron, a difference in condition-status, i.e., "conditions into which anyone might fall" and which say nothing about "the underlying personhood" of the individual concerned (as, for example, legal codes based upon race do) (Waldron $2007 \mathrm{p} 140$ ). More difficult are questions of scope. For example the right to vote in a state's elections is often restricted to citizens of that state (as in the US). The problem is, of course, that we cannot settle the problem of who belongs to this group democratically without hitting upon an infinite regress (Gould 2004 p174; Benhabib 2006 p35). One way of settling the issue of scope would be an appeal to the shared values and belonging engendered by a nation. Part of the argument of this chapter, however, is even if we do accept this there remain areas of contention and disagreement. I say a little more about questions of scope in n.73, below, (cf. p73).

${ }^{67}$ It is probably more likely that this would be expressed in racial terms as with Apartheid South Africa.

${ }^{68}$ As Jeremy Waldron notes, "law recognizes all sorts of differences between people, actions, transactions and situations, without compromising legal equality" (Waldron 2007 p130). He goes on to argue that the ability of the law to do this cannot be unlimited. Waldron's fear is of a "multiplicity of 66
} 
justification and this justification cannot be made by reference to some supposed cultural superiority or inferiority. Liberals who wish to maintain the location of this burden of proof do not need to appeal to some mythical ideal of a separation of state of culture to ground it. Nor, on the other hand, do they have to passively accept the status quo as being just, as Kymlicka suggests. As we shall see in the next section existing laws and institutions can themselves be evaluated as being fair or unfair to cultural minorities according to the same criteria as those that face those cultural minorities who seek differential treatment. ${ }^{69}$

Armed only with the outline of fairness as reasonable agreement we can ask whether Kymlicka needs to replace 'ethnocultural neutrality' (now understood only as a limit on claims that it is reasonable to expect others to accept) with his nation-building model of the state. For example Kymlicka suggests that; "Intuitively, the adoption of...minority nation-building projects seems fair. If the majority can engage in legitimate nation-building, why not national minorities...?" (Kymlicka 2001 p28). But this intuition can be spelt out in terms of reasonable agreement. Assuming that nation-building is unavoidable and also desirable (in terms of enabling liberal values of social justice and democracy, as Kymlicka claims) then the claim that the shared resources of the state should be used only for the furtherance of majority nationbuilding (which often comes at the expense of minority nations (ibid p230)) could be reasonably rejected by those who do not share in the identity of the majority. This, at any rate, seems to be the kind of argument that Kymlicka is making and it can be given some plausibility

legal systems or subsystems in a given society" (ibid). One way of drawing this limit is through the requirement that such differential treatment be appropriately justified.

${ }^{69}$ In this sense Kymlicka is correct when he writes that the "burden of proof no longer falls solely on defenders of minority rights to show that their proposed reforms would not create injustices" (Kymlicka 2001 p33). But the problem might be thought to be the appropriate starting point from which we engage in giving appropriate justifications. For example, we might think that people from different cultural groups fundamentally cannot understand one another and that the institutions of the state ought to reflect this so that people attempt to reach compromise as members of groups (rather than, say, starting out as individual citizens). There is something of the 'group centred' approach in the approach of Iris Marion Young, for example when she advocates group vetoes (Young 1989 p189). Kymlicka cannot go as far as Young here as he endorses integration for immigrant groups (for example). Group vetoes would run the risk of undermining any nation-building project, on Kymlicka's account, because the latter involves building the social solidarity necessary for liberal social justice rather than a politics of sectional interest. That is, unlike for Young, it is not cultural group difference per se that is doing the normative work for Kymlicka because this would not adequately distinguish between immigrants and national-minorities (or, indeed, other 'oppressed' groups). It is, rather, the worth of the national unit that is important for Kymlicka as what should be given normative weight in any justification of the distribution of burdens and benefits. This, I am claiming, is a second stage argument. All that the fairness argument can establish is that the distribution of burdens and benefits should be distributed in such a way that that distribution could be reasonably agreed to by those that it will affect. As the difference between Kymlicka and Young (and liberals in general) suggests, what is important is establishing what worth we are to give to different attachments. The third-stage nation-building argument, I suggest, cannot on its own give us an adequate answer to this question. 
on the contractualist account outlined here. However, what is important, from the liberal point of view, is the worth of national units in furthering valuable individual ends and, as such, any such claim to minority nation-building tools must be balanced against the costs to both the individuals within the putative minority nation and those outside of it. Thus both Barry and Kymlicka agree that national self-determination can be desirable (for individual selfdevelopment) (Barry 2001 p117; e.g., Kymlicka 2001 pp227 - 228) and both accept that democratic politics operates best when citizens speak the same language as one another (Kymlicka 2001 p213, 314; c.f. Barry 2001 pp226 - 228). In those instances where a linguistic group already supports a workable economy and political sphere Barry claims that a right to minority nation-build could be viable (Barry 2001 p228). However, in other instances Barry thinks that such minority nation-building along language based lines is to be avoided as it is likely to lead to future generations being condemned to "dead-end" employment (if they find employment at all) and a limited role in political life other than as a ready source of votes to support sectional interests (ibid; also cf. Carens 2000 p60). Despite this limitation placed by Barry there is clearly an overlap between the positions of Barry and Kymlicka on this score despite the former endorsing the idea of ethnocultural neutrality. In addition it is not appeal to some norm of ethnocultural neutrality that informs the limits that Barry places upon minority nation-building but rather an evaluation of the burdens that such an alternative to the current policy of "pursuing a course that leads to a linguistically homogenous polity" (Barry 2001 p228) would impose on members of the majority and minority. I do not want to discuss whether Barry is right to identify the particular burdens that he does, simply that someone who endorses ethnocultural neutrality as a requirement of reasonable agreement can ask the same kind of questions as those raised by Kymlicka's nation-building model of the state (and get similar answers).

\section{The rule-and-exemption approach}

The foregoing is not intended to imply that there are no differences between Kymlicka's position and that of someone who endorses justificatory ethnocultural neutrality as a requirement of reasonable agreement. Thus Barry's critique of the 'rule-and-exemption' approach supposes that it is incumbent upon the minority who are affected by the general law in question to argue both that there is a good reason to have the law but that it should not apply to minority group $x$ although it should apply to everyone else. In most cases, Barry contends, where the argument for an exemption works there will be good grounds to dispense with the law altogether (Barry 2001 pp32 - 50). For Barry the burden of proof clearly lies with 
those who seek differential treatment. In some cases I think we will want to say that this is as it should be. A general law prohibiting female genital mutilation intuitively seems a legitimate law to enforce (the cultural practice could be reasonably rejected by those whom it would harm $^{70}$ ). There may be grounds for allowing some exemptions but the burden of proof would fall on those who seek exemption. Intuitively this seems correct and, given Kymlicka's prohibition against internal restrictions, a position that Kymlicka ought to endorse. In other cases it might not be so clear. A general rule prohibiting shop opening on a Sunday would seem to burden those, such as Jews, who consider a different day to be unsuited to shop opening by effectively ensuring that they are closed for two days a week instead of one (for everyone else). One option is to seek an exemption from this generally applicable law (whilst another is to revoke the law altogether). There is, however, another option, as noted by Simon Caney, and that is neither to modify the law with an exemption nor to abolish it altogether but to "recast or replace" the law with another one. So, to take our example above (which Caney also uses) we can think of Jews (and others) as arguing for a general law that prohibits trading on one day of the week (Caney 2002 pp88 - 89). This would be an example of re-casting a generally applicable law with another one.

Caney is keen to point out that not all cases can be recast in this way (ibid p89). Nevertheless, the possibility of recasting general laws suggests that we should be alive to those aspects of our general laws that, like the Sunday closing legislation are both weighted in favour of the majority and bring disadvantages to members of minority groups that could easily be avoided (without placing similar burdens upon others). One way, suggested by Jeremy Waldron, is to replace the idea of concrete rules with abstract standards "which allow that there may be a variety of different ways of conforming to a given goal" (Waldron 2007 p150). Waldron uses the case of State $v$ Kargar ((1996)679 A. 2d 81)to illustrate his point. In this case an Afghani refugee living in Maine was seen kissing the penis of his baby son, in contravention of a law prohibiting 'sexual contact' between adults and minors, with sexual contact being understood solely in terms any physical contact between genitals and mouth. However, as became clear in the trial, such a practice is common in Afghanistan and involves no sexual aspect. Waldron

\footnotetext{
${ }^{70}$ Even here, though, there might be grey areas especially regarding whether it could count as a valid choice for an adult. Liberals would need to be alert not only to any disadvantages that such a procedure might bring about to women (which could, after all, be chosen) but also to the existence of pressure, or influence, to make a decision that is disadvantageous to them (especially where this is advantageous to someone else). These Clare Chambers has called the 'disadvantage' and 'influence' factors (Chambers 2002 pp154 - 157) which can, I think, be seen as a way of spelling out Kymlicka's 'internal restrictions' (Kymlicka 1995 pp35 -44). So, for example in the case of female genital mutilation there are a number of disadvantages including difficulties with sexual intercourse (as well as menstruation and obstetrics) (Thierfelder et al 2005 p87). Where disadvantages, say in sexual intercourse, also result in advantages to others (perhaps by increasing male control of female sexuality) as a result of social norms, Chambers argues that the liberal state has a good claim to intervention.
} 
suggests that the relevant law of Maine itself had a strong cultural bias ("the intense sexual meaning...of mouth-genital contact in contemporary American culture (ibid p152, emphasis in original)) and that the application of a standard (taking into account the sexual meaning rather than simply the behaviour) is more appropriate than a rigid application of a rule (ibid).

In certain respects, then, it seems that Kymlicka is correct to claim that the burden of proof does not lie only with those who seek exemptions (if only because the language of exemptions itself presupposes that the laws in question, the status quo as Kymlicka might put it, form a suitable normative baseline from which argument must proceed. As we have seen we cannot assume that this must always be the case). However, although Barry takes a rigid line in Culture and Equality, we should not think that this is a necessary feature of liberal thinking that emphasises reasonable agreement (and, hence, a justificatory ethnocultural neutrality). We have already seen that one requirement of reasonable agreement is that a principle (or, perhaps, law in this case) can be reasonably rejected if there is some viable alternative that does not place any such burden on anyone or lessens the burden (without placing greater burdens on others than those placed by the original law or principle). This would account for Caney's discussion of Sunday opening legislation in which, in the case of the new law, no-one need suffer the burdens imposed by the original law (or, at least, that everyone must suffer them equally).

One of the fears of immigrant multiculturalism, Kymlicka notes, is that the accommodation of multicultural diversity (and attendant practices) means that liberal states must come to accept those practices, such as Female Genital Mutilation, that are incompatible with liberal ideals of justice (Kymlicka 2001 p152). Kymlicka is keen to point out that the acceptance of multicultural policies implies no such thing (ibid p174). On this our justificatory conception of ethnocultural neutrality reaches the same conclusion. There are also going to be cases where the status quo, general rules as they exist now, are going to burden some unnecessarily (i.e., there is a viable alternative rule or standard). Kymlicka writes that these kinds of issues, those involving the burdens placed on individuals from certain backgrounds, must be assessed on the basis of "particular....proposals in particular contexts" (ibid p34). Again, there is little reason to think that a justificatory norm of ethnocultural neutrality does not require much the same thing. Kymlicka complains that the 'religion model' (which does preclude the establishment of an official religion) is not suitable when dealing with culture (where, as noted in the previous chapter, there can be no separation of state and culture) and that a new model of the state is required. What the justificatory account of neutrality says is that it is unreasonable to expect those with a different religion (or none) to accept general principles and rules that are to 
regulate permissible religious practices that are based on the supposed truth of one religion.

Faced with pluralism of religious beliefs it is possible for the state to, for example, support no religion. ${ }^{71}$ In the case of culture, if Kymlicka is correct, such a separation is not possible. However, in both the religious and the cultural case the fundamental rationale for these general, regulatory principles remains the same even if, by necessity, they result in different public policy. In both cases what is important is that acceptable rules cannot rest on the truth (or, presumably in the case of culture, superiority) of some set of religious or cultural beliefs. But, as we saw with the Jawoyn in chapter one, if this is all that reasonable agreement requires then some who lose out in some way from those rules might have grounds for complaint. A policy of ensuring education is in a common language, for example, can be justified on the grounds that it is "essential if all citizens are to have an equal opportunity to work in the modern economy" (ibid p26). But this is not the end of the story for liberals committed to a norm of reasonable agreement. As we have seen, reasonable agreement requires, for example, the justification of burdens to those who are affected by such a policy.

Now, those who defend minority cultural rights might think that different things should count as burdens in comparison to those who are sceptical of the need for such rights. Or they might put different weight on the same goods, or interpret how they are to be realized in different ways. For example, both critics and defenders of minority cultural rights might agree that

\footnotetext{
${ }^{71}$ Even this is not obviously a requirement. As Barry points out "almost every liberal democratic polity...provides public funding on some basis or other for schools run by or on behalf of religious denominations" (Barry 2001 p29). What is important is that such funding does not rely upon the truth of the religion or any other conception of the good (the requirement of neutrality) and that they are "even-handed" (i.e., treat like cases alike) (as a requirement of public practical reasoning). Barry seems to run together the requirement of neutrality (as I have it) and the more substantive features of reasonable agreement (such as prima facie equality of basic rights or even-handedness) in Culture and Equality, claiming that "policies are neutral in the sense that they are even-handed, and that is the only sense that matters" (ibid). I have separated the two aspects of reasonable agreement. I have done this because it seems that there can be reasonable disagreement on principles of justice that nonetheless do not rely on the truth of any particular conception of the good (cf. Sen 2009 pp12 - 18). The claim of political liberalism (and the idea of reasonable agreement) is that there are a set of things (broadly speaking conceptions of the good) that we cannot hope to find agreement on leaving those general rules and principles where we can. This is often spelt out in epistemic terms (e.g., Rawls talks about the 'burdens of judgement' (Rawls 2005 pp54 - 58). Even more clearly Barry, in Justice as Impartiality, appeals to scepticism to ground the exclusion of conceptions of the good from the specification of principles of justice (Barry 1995 pp168 - 173)). Running together the claim that neutrality requires that we put aside our conceptions of the good with other (putative) requirements of reasonable agreement (such as the prima facie claim to equal treatment) runs the risk of suggesting that any principle is consistent with contractarian justice just so long as its fundamental rationale is not provided by some conception of the good or other, a position that I suggested was inadequate in chapter one. I do not, then, argue that there need be only one, unique acceptable set of rules to regulate cultural diversity. It is for this reason that I endorse Scanlon's contractarianism which, as Sen notes, can accommodate more than one acceptable set of rules (Sen 2009 p 200). For example, a number of different 're-castings' of general laws may be acceptable.
} 
having the social bases of self-respect is a primary $\operatorname{good}^{72}$ but disagree on whether this requires differential treatment in order to secure this. Kymlicka, for example, suggests that it is required (Kymlicka 1995 pp89 - 90; 2001 p47) whilst Barry argues that it is not (Barry 2001 pp267 - 269). Here is not the place to decide which of the two is correct. The point is this; this question can (and does) arise within those liberal accounts of justice that are committed to reasonable agreement and ethnocultural neutrality. Kymlicka claims that accepting the nationbuilding model of the liberal democratic state "gives us a very different perspective on the debate...The question is no longer how to justify departure from a norm of neutrality, but rather do majority efforts at nation-building create injustices for minorities?" (Kymlicka 2001 p27). Whilst it might be plausible to suggest that some of the particular burdens imposed by nation-building policies might be highlighted by focussing on nation-building policies (as opposed to, say, environmental policies) it is not clear that thinking about nation-building does give us a very different perspective on the debate at all. There seems to be little reason (and Kymlicka does not, explicitly at least, give us much reason) to think that the principles of justice that have been put forward by Barry or Rawls could not be applied to the issues raised by such nation-building. As we have seen, there is also reason to think that they might tend to come up with the same kind of answers.

\section{A Change in the terms of the debate or a change in focus? Francophone commercial road signs in Quebec.}

It might be thought that the difference between Kymlicka's position and those of contractarian liberals such as Rawls or Barry is simply one of philosophical focus. We might be tempted to say that Kymlicka is concerned with non-ideal theory whilst our contractarian liberals are concerned with ideal theory. David Miller offers another way of spelling out this distinction when he distinguishes between deontological liberals (concerned with "liberal principles as mandatory guides to human action that can be derived from abstract reflection") and sociological liberals (who "ask about the social and political circumstances in which liberal aims and values are most likely to be achieved, without assuming that it is possible to adhere to liberal principles in all cases") (Miller 2007 p204). Kymlicka certainly seems to take this latter line in his discussion of the prohibition, in Quebec, on using any language other than French on commercial road signs (Kymlicka 2001 pp286- 288). Kymlicka's position can be usefully compared with that of Charles Taylor who argues that such laws can be justified on grounds

\footnotetext{
${ }^{72}$ Cf. Rawls 1973 pp440 - 446 for his argument that the social basis for self-respect is the most important primary good.
} 
that they "maintain and cherish distinctness, not just now but forever" (Taylor 1992 p40). The liberal fear, expressed by Barry, is that individuals "become mere ciphers, to be mobilized as instruments of a transcendent goal" (Barry 2001 p67) a position that they could reasonably reject as being based upon the worth of that transcendent goal - a goal they may not share or even repudiate. Kymlicka notes that Taylor assumes the Quebecois to have a "distinctively communitarian vision of the common good" which, he argues, is no more the case for Quebecois than other Canadians (Kymlicka 2001 p288- 289 n9). Kymlicka argues instead that the commercial road signage law was part of a number of measures designed to persuade Quebecois that immigrants would integrate into, and contribute to, the francophone society ensuring that Quebec became a multicultural society rather than a society based around an exclusivist ethnic self-understanding and a xenophobic rejection of outsiders.

Now Kymlicka claims that this has been successful and that policies like that regarding road signage have helped to ensure that Quebec is a post-ethnic, modern society operating in the French language. ${ }^{73}$ The important point is that, like Miller, Kymlicka's concern is not to defend

\footnotetext{
${ }^{73}$ More recent events in Quebec, centring on public debates over 'reasonable accommodation' for immigrants with different cultural practices, might cause us to pause in our acceptance of these claims. This would have been especially true in 2006/ 2007 which the Bouchard-Taylor Report called "a time of turmoil" (Bouchard-Taylor Report 2008 pp53 - 58) and given the electoral success of the anti-immigrant Action Democratique du Quebec. The Bouchard-Taylor Report reported that there was, in fact, no crises and that largely the anti-immigrant thrust of the debate surrounding reasonable accommodation was a result of inaccurate media reports of the requirements of reasonable accommodation. Nevertheless it is probably worth bearing in mind that there are dangers in invoking nationalism even where our intentions are benign. Whilst Kymlicka might endorse a post-ethnic conception of nation-hood there remains a tension between the idea of the state as "an egalitarian legal community" on the one hand and a "cultural community joined by origin and fate" on the other (Habermas 1996 p131).
}

This danger remains a possibility for Kymlicka because he seems to accept (like David Miller) the need for a pre-political sense of nationhood. Thus in a recent work he has claimed that "it is the nation that defines 'the people' who are to rule themselves" (Kymlicka 2006 p129). Seyla Benhabib queries this position as either circular (if the nation refers to all of the franchised citizens who decide questions of who belongs and who does not insofar as who is to count as a franchised citizen is defined by already being part of the people) or relies on an idea of the nation as somehow prior to the people as a community of fate (Benhabib 2006 pp167 - 168).

This latter ideal is unlikely to appeal to liberals insofar as it implies the kind of nationality endorsed by Michael Walzer which permits membership to be decided by those who are already members "in accordance with our own understanding of what membership means in our community and of what sort of community we want to have" (Walzer 1983 p32). If this is the case then there is no reason to exclude self-understanding based upon exactly the kind of ethnic nationalism that Kymlicka rejects (cf. Exdell 2009 p133). Of course, Kymlicka does not want to accept this Walzerian conception of nation-hood and it is true to say that questions of the scope of justice affect those who endorse non-cultural (e.g., democratic) conceptions of the polity (perhaps more so). The answer that liberal nationalists would want to give is that Walzer is correct in thinking that appeals to abstract rights and duties are too weak to motivate people to give the kind of strong mutual aid to one another that members of nation-states expect (Kymlicka 2001 pp225 - 226; Miller 1995 p83) requiring a shared sense of (national) identity but also recognize, as Miller puts it "that that identity is always in flux, and is molded by the various subcultures that exist within a national society" (Miller 1995 p128). This conception of national identity can be seen as a dialogical process involving negotiation between members of minority groups and 
some non-liberal ideal of the communitarian society but rather to investigate the conditions that best secure and protect liberal values. The deontological liberal might be characterized as being inflexible on certain basic rights, such as freedom of speech, dismissing limitations on the language of road-signs out of hand whilst sociological liberals are concerned with whether such limitations, in the longer term, will facilitate the creation of a society in which such rights are more secure (Miller 2007 p205). We might, then, see Kymlicka with his emphasis on the nation-building model of the state as falling securely into the latter camp. We must be careful when we draw such distinctions between those who accept liberal principles (as Miller recognizes his distinction "is no doubt too crude" (ibid)). In order to secure a liberal society, sociological liberals might indeed countenance what Kymlicka calls "mildly illiberal" policies (Kymlicka 2001 p288) such as dictating the language of commercial road signage. It is, however, far from clear what is to count as a mildly illiberal policy. Dictating the language of commercial road signage may be an infringement of freedom of speech but then so would be "restricting the language of newspapers, churches, or private schooling" (ibid). And Kymlicka, like most liberals, wants to draw a line between the two. Now we might want to say that this cannot (or should not) be done, that allowing the minor violation will lead to more egregious violations or that the minor violation is not to be countenanced in itself. How does Kymlicka attempt to draw this line? Well, interestingly for our purposes, he appeals to two claims. The first is that most immigrants in Quebec think that the trade-off in terms of some mildly illiberal policies rather than ethnic nationalism is reasonable, especially as such policies can be seen not as seeking to exclude them from further integration but rather as "clarifying the terms of integration" (ibid). The second reason reinforces the first. The mildly illiberal policy of requiring commercial road signs to be in French is unlikely to lead to Quebecois dismissing the ideal of freedom of speech. However, some minor violations of freedom of speech are permissible if they help to dispel the dangerous and violent phenomenon of ethnic nationalism (ibid).

Mandatory use of the French language for commercial road signage in Quebec is thus justified, in Kymlicka's treatment, in terms of reasonable agreement and in ways (unlike Taylor's) that respects the norm of ethnocultural neutrality. Firstly Kymlicka attempts to show that those who can be expected to do worse as a result of the policy (immigrants in Quebec) could be reasonably expected to accept it (and, indeed, the majority do). The second reason can be seen as attempting to meet the requirement that there is no viable alternative policy to the mildly illiberal one. Immigrants (and others) could expect to be worse off if such policies did

members of the majority (ibid p142). As I have mentioned, once nationalism is defined in these, dialogical terms then there is no reason why liberals who endorse ethnocultural neutrality could not accept it (as both Barry, as we have seen, and Rawls (Rawls 2002 p25) do). If they do not accept it, it will because they do not think that such a shared sense of national identity is particularly important (or they are sceptical) (cf. Buchanan 2007 pp390 - 393). 
not exist. That is, given the choice between having commercial road signs in French on the one hand and "the potential contained within all forms of ethnic nationalism for racism, xenophobia, and ethnic cleansing" (ibid) on the other, then it will be reasonable to accept the former (which helps create the conditions required to ensure that the latter does not emerge). The question is, of course, whether it is actually true that the kind of mildly illiberal policies accepted by sociological liberals are necessary to ward off the far greater evils of ethnic nationalism. This will, of course, be a subject of actual debate within liberal democracies and will require empirical evidence as well as theoretical, normative reasoning. Nevertheless the important point is this; there is no reason to think that the way of thinking about these issues developed by liberals within the contractarian tradition cannot be fruitfully applied to the sociological realities presented by ethnocultural issues (this is especially true of Scanlon's approach with its focus on fully informed agents, plurality of acceptable principles of justice, and application in the "imperfect world" (Scanlon 1982 p111)). ${ }^{74}$ To be sure, such contractualist reasoning can only give us an idea of the appropriate normative structures for thinking about the particular questions raised by nation-building. And this in itself might be thought to constitute something of a weakness faced by those who endorse it. (As Leif Wenar puts it, "contractualism leaves us clearer about why we are where we already were" (Wenar $2008 \mathrm{p403)).} \mathrm{This} \mathrm{might} \mathrm{be} \mathrm{true} \mathrm{and} \mathrm{the} \mathrm{nation-building} \mathrm{model} \mathrm{might} \mathrm{help} \mathrm{us} \mathrm{to} \mathrm{focus} \mathrm{our}$ attention on some of the ways that that the actual activities of states (activities that have, perhaps, received little attention from political theorists) are burdensome for immigrants or members of national-minority groups or indigenous peoples. But it is, I think, a mistake to imply that it offers a different kind of way of thinking about those issues, that it is an alternative that changes the terms of the debate. As we have seen Kymlicka relies upon that kind of normative reasoning to ground his particular fairness based claims about nationbuilding. ${ }^{75}$ This is not to dismiss the importance of the nation-building model of the state but merely to point out that at best it offers a change in focus in the debate rather than altering the terms of the debate itself.

\footnotetext{
${ }^{74}$ The Rawlsian approach that stipulates a veil of ignorance, and unanimous decision, might be more susceptible to such criticism (cf. Sen 2009 pp66 - 74).
}

\footnotetext{
${ }^{75}$ There is another way of thinking about Kymlicka's nation-building claims. The nation-building model of the state might not only be about focusing our attention on certain sociological features of the state but rather be the claim that we should only (or at least mainly) think about these normative issues in terms of nation-building. Thus, for example, Kymlicka takes the liberal nationalist line that nationbuilding is not only a contingent sociological fact about how states actually operate but also sees such nation-building as an enabling condition of the kind of social justice that liberals endorse. This is similar to the sociological liberal position outlined by Miller, above. Elsewhere, and more recently, Kymlicka has argued that "(i)f democracy is the rule 'of the people', then it is the nation that defines 'the people' who are to rule themselves" (Kymlicka 2006 p167). Kymlicka here specifically links the scope of those who are to reach reasonable agreement with the nation.
} 


\section{An overlapping consensus?}

So, I think that there is, potentially, a significant amount of agreement between the positions of those liberals, like Barry, who endorse ethnocultural neutrality and Kymlicka who claims to reject it. The 'potentially' is important here as can be seen by the fact that when Barry seems to get very similar answers to Kymlicka it is because there is a deeper agreement on the value of some practices for individuals, as we saw with Barry's discussion of self-government for certain minority nation groups. Where Kymlicka and Barry disagree, perhaps on the question of restricting the provision of tools for minority nation-building for those national groups who already support "an entire economy and polity within a state" (Barry 2001 p228) there is no reason to think that this need rest on some disagreement about the way in which burdens and benefits should be distributed but rather on the relative weighting of those burdens and benefits in trying to determine what it is reasonable to expect people to agree to. There is no particular reason why 'traditional liberal theorists' should ignore the role that nations play as an important feature of human lives. Some, such as Barry, as we have seen, but also Rawls (Rawls 2002 p25, especially n20), endorse some version of the liberal nationalist position.

This does not mean that there is agreement on what exactly constitutes a national group and these differences can make a difference. Margalit and Raz, for example, place a large emphasis on nations being "encompassing groups" with pervasive cultures that are important for selfidentity (Margalit and Raz 1990 p448). Some, including Barry, have doubted this pervasive cultural component of the nation (Barry 2001 p82) and, indeed, for the purposes of Kymlicka's nation-building model in PV the emphasis lies on a shared language and institutions rather than the 'thick' conception of the societal culture (as providing "its members with meaningful ways of life across the full range of human activities" (Kymlicka 1995 p76)) we see in MC. The difference between the two accounts of societal culture, I think, is significant and reflects the different argument strategies of what Kymlicka calls the second and third stages of the debate over minority rights. In the second stage the idea was to link access to a societal culture in with individual autonomy. The protection of minority nations was justified insofar as it would "supplement, rather than diminish, individual freedom and equality" (Kymlicka 2001 p24). As we saw in chapter 2 , the idea of this strong link has been the subject of some criticism in the literature (cf., Waldron 1992a p754; Carens 2000 pp69 - 71), regarding whether it requires access to any particular cultural group (Waldron 1992a p762), or whether there are many national cultures that would constitute a societal culture in Kymlicka's thick sense (Carens 2000 p62; Patten 2009 p114). Kymlicka claims that this debate has been replaced by one that recognizes the burdens placed upon minorities by the existence of majority nation-building as 
we have seen. Rather than attempting to show that societal cultures are necessary for autonomy Kymlicka is concerned to show how minorities are put under pressure to assimilate into the majority or face marginalization. And for this, it seems, he can jettison his controversial 'thick' conception of a societal culture. Or can he? Insofar as Kymlicka wants to make certain normative claims about the fairness of majority nation-building (a line of reasoning we saw Barry adopt too) then he needs to give some idea of the moral weight he attaches to membership in one's own societal culture rather than another's and how that is to be weighed up against other fundamental interests that we have. Kymlicka's work is full of answers to these questions, but they are all answers that take place within the second stage of the debate. We need to know what nations, and national belonging, are worth before we can pass judgement on the distribution of burdens and benefits that result from majority nationbuilding practices. The problem, outlined in chapter 2, is that it is not clear that Kymlicka's main answer, that nations are necessary for individual autonomy, is a particularly satisfying one.

We can put all of this another way. One of the criticisms that has been made of Barry's Culture and Equality is that it does not attempt to give a clear account of our higher order interests, the kind of things that the state ought to distribute, or say why we have those interests that Barry thinks that we do have (Caney 2002 pp91 - 92). Kymlicka's nation-building alternative to ethnocultural neutrality can be seen to be vulnerable to the same kind of criticism. When we are thinking about how burdens and benefits are to be fairly distributed it is all very well saying that the imposition of burdens must be justified to those who we can expect them to fall upon most heavily. If we think that people have a fundamental interest in the survival of their own culture then we might expect the state to distribute resources to secure that end where it is in jeopardy. If we think that people have a fundamental interest in access to a rich and vibrant culture then, depending on the circumstances, it might be better for members of minority cultures to be encouraged (and helped) to assimilate into the larger culture. We might think that the existence of cultural diversity itself is a fundamental interest and that public resources should be used to defend this interest (cf. Kymlicka 1995 pp121 - 123; Dworkin 2004 p359). Each of these interests may be qualified by other fundamental interests. Just as Barry does not deal with Kymlicka's claim that access to our own societal culture represents such a fundamental interest (Caney 2002 p93) so Kymlicka is too quick to move on to consideration of the burdens imposed by nation-building as an alternative to his second stage debate. Those liberals who endorse ethnocultural neutrality but reject the idea that access to one's own national culture should be considered a fundamental interest (or, to put it in Rawlsian terminology, primary good (cf., Kymlicka 1989b p199)) will be unlikely to think badly of 
majority nation-building that respects the fundamental interests that they think people do have.

\section{Conclusion}

Kymlicka's third stage nation-building account fails to establish that the principle of ethnocultural neutrality is manifestly false. In part this is because Kymlicka seems to be arguing against the idea of a "rigorously neutral state...without cultural...projects" (Walzer 1992 p99), a characterization of liberalism put forward by Michael Walzer that is not shared by liberals who actually endorse ethnocultural neutrality. The norm of ethnocultural neutrality, spelled out in terms of reasonable agreement, on the other hand, offers a plausible (although by no means universally accepted) account of fairness. I have not sought to defend ethnocultural neutrality as the claim that the institutions of the state are fair just in case they are capable of a justification that makes no reference to the superiority (or inferiority) of some cultural practice or other as Clare Chambers does in her defence of ethnocultural neutrality. For Chambers ethnocultural neutrality means that the nation-building actions of the state are fair if they have such a justification "regardless of the effect on cultures" (Chambers 2003 p299). In his recent qualified defence of Kymlicka's third stage nation-building argument Patten also considers something like Chambers' view as a 'rival view' to Kymlicka's own (Patten 2009 p123). There are two points that I would like to make in regards to this. Firstly it is misleading to think of ethnocultural neutrality, as Chambers and Patten characterize it, as separate from the normative goal of reasonable agreement. As we have seen for many liberals who endorse it, ethnocultural neutrality fits together with the claim that differential treatment must be justified to those who can be expected to be made worst off by it. Secondly what is important in providing such a justification is giving some account of what our fundamental interests are and how they are to be weighed against one another. If I do have a fundamental interest in being able to live my life within my own societal culture, as we have seen Kymlicka argue (chapter 2) then a policy that would undermine my ability to realise this interest might be reasonably rejected regardless of the fact that it is not based upon the inferiority of my societal culture (or the superiority of that of the majority). I cast doubt upon whether Kymlicka's argument successfully establishes that we have such a fundamental interest, or if we have how it should be measured against other interests. But whether we think that Kymlicka ultimately succeeds in establishing that we have such a fundamental interest or not, 
his attempt to establish this represents the kind of question that is relevant in assessing the debate amongst liberals concerning the fairness of various multicultural policies. ${ }^{76}$

To put this point another way, an account of our fundamental interests is of considerable normative import in approaching majority nation-building. Kymlicka's third-stage argument, rather than moving on from the second-stage, must return to it if we are to give an account of how the burdens and benefits of majority nation-building (or minority nation-building) ought to be distributed. This is especially important if Kymlicka, and other liberals, are to avoid the kind of compromise, relying on relative bargaining powers (themselves likely to be a reflection of majority nation-building practices), that we saw Chandran Kukathas endorse in the previous chapter. It is at the second-stage that the key debates must still take place.

\footnotetext{
${ }^{76}$ Here we might answer three questions that Alan Patten asks of Kymlicka's nation-building argument (Patten 2009 pp123 - 124). Firstly Patten asks what relationship Kymlicka's third-stage argument has with established theories of liberal justice and, in particular, what broad principle of fairness its particular claims about the fairness of nation-building is based upon. Although Kymlicka might have a different idea of fairness in mind he does not give us any indication of what this might be. I suggest that he can rely upon the broad principle of fairness tied up with justificatory ethnocultural neutrality and reasonable agreement. That is Kymlicka can endorse established theories of liberal justice and accounts of fairness. The second question asks how Kymlicka could respond to the 'rival view' of ethnocultural neutrality as an account of fairness. If I am correct then there is no reason to see this as a rival view at all. Finally Patten asks under what conditions fairness claims ought to be considered determinative. That is, how ought we to weigh up different ends against one another. I have argued that this is the relevant question that requires more work in giving some account of our fundamental interests. It is in regards to this kind of question that more work needs to be done.
} 


\section{Conclusion}

This thesis has attempted to argue that, contra Will Kymlicka, a liberal norm of ethnocultural neutrality is not manifestly false. Instead ethnocultural neutrality can be understood as part of a plausible, liberal alternative to Kymlicka's dichotomy between autonomy liberalism and toleration liberalism that stresses the importance of reasonable agreement in grounding the rules and principles that are to regulate cultural diversity and disagreement. This justificatory account of ethnocultural neutrality can also ground the kind of fairness based claims that Kymlicka wants to make about majority nation-building. I illustrated this by looking at areas of agreement between Kymlicka, who rejects ethnocultural neutrality, and Brian Barry who endorses it and seems, on the face of it, to be hostile to the idea of cultural groupdifferentiated treatment. Where disagreements arise, I suggested, they arise over accounts of our fundamental interests or, at least, how such interests should be balanced against one another to establish a fair distribution of burdens and benefits. This, I argued, was a feature of Kymlicka's second-stage argument.

It might be useful to offer a re-cap of the route that lead to this conclusion;

In chapter 1 I set out the three stages that Kymlicka claims represents the progress of the debate over minority rights. In the third-stage Kymlicka claims that the idea that states are ethnoculturally neutral is manifestly false. I argued that Kymlicka's characterization of ethnocultural neutrality as the strict separation of culture and state was flawed and introduced the idea of a justificatory account of ethnocultural neutrality instead. I outlined two themes that would be important in subsequent chapters. Firstly I noted that Kymlicka's fairness based third-stage argument seems to require some account of what is to count as a burden (and benefit) and why and that appropriate answers to such a question were to be found in his second-stage argument (that accepted ethnocultural neutrality). Secondly I introduced Kymlicka's distinction between autonomy liberalism and toleration liberalism. Given that Kymlicka wants to make specific fairness based judgements about majority nation-building that did not rely upon a commitment to ethnocultural neutrality, I suggested that a useful place to start looking for what general principles might ground such judgements is with Kymlicka's own dichotomy.

In chapter 2 I looked at autonomy liberalism, which Kymlicka endorses, and looked to see if it could provide adequate normative grounds for the kind of fairness based judgements that Kymlicka wants to make about majority nation-building. I argued that Kymlicka's autonomy argument failed to ground the kind of fairness based claims that Kymlicka wants to make. I 
went further than this, however, and suggested that in fact Kymlicka's autonomy arguments, and in particular his defence of societal cultures as providing a context-of-choice necessary for the pursuit of autonomy, actually stood in some tension with attempts to spell out the requirements of a fair distribution. I explored this by looking at Kymlicka's own 'Equality Argument' and argued that although the autonomy argument gave us some account of what is to count as a fundamental interest for individuals, access to a secure societal culture, Kymlicka's account is indeterminate as to what exactly is to be distributed and how that which is to be distributed, access to our own societal culture, is to be balanced against other plausible fundamental interests that we might be thought to possess. If I am correct and Kymlicka's fairness based arguments about nation-building do rely upon an account of our fundamental interests then Kymlicka's autonomy argument requires further argument if it is to provide a plausible account of such interests.

Having looked at autonomy liberalism, and found it wanting, in chapter 3 I turned to look at the other side of the dichotomy, toleration liberalism. Kymlicka rejects toleration liberalism and gives two examples of its proponents; Chandran Kukathas and John Rawls. I argued that Kymlicka was correct to reject the approach taken by Kukathas that aimed to give an account of benign neglect that dismissed fairness as a relevant normative concern and put in its place the ongoing avoidance of conflict. Kukathas, however, could not escape the need to give some account of what the state ought to do in cases of cultural disagreement. I argued that his answer of 'compromise' failed to meet Kukathas' own normative requirement of the avoidance of conflict. Turning to Rawls, taken as an example of political liberalism, I noted that Kymlicka argues that such an approach must collapse into autonomy liberalism if it is to hope to ground liberal civil and political rights. But as I rejected autonomy liberalism in chapter 2 , and as Kukathas' toleration liberalism rejected fairness as a normative concern, it seemed that we must either give up on finding some way of grounding a liberal fairness based approach to nation-building or give up on Kymlicka's dichotomy. I suggested that the latter course of action should be taken and suggested that political liberalism did not need to collapse into autonomy liberalism to ground a liberal approach to nation-building. Political liberalism introduced the plausible alternative of fair rules and principles as those that it would beunreasonable for people to reject. With such an account came the re-introduction of ethnocultural neutrality understood as the claim that one of the things that could be reasonably rejected would be principles that rested upon the superiority or inferiority of cultures.

In chapter 4 I explored how this account of reasonable agreement might be able to ground the kind of fairness based claims that Kymlicka wants to make about nation-building. I illustrated this by looking at how Brian Barry, who is generally critical of multiculturalism policies and 
endorses ethnocultural neutrality, can end up with similar conclusions to those put forward by Kymlicka. I also looked at an example of where Kymlicka seems to rely upon the idea of reasonable agreement to support minor limitations on freedom of speech in the case of compulsory French language commercial road signage in Quebec. As noted above, where disagreements occur they occur over what is to count as a fundamental interest and why and not over the norm of ethnocultural neutrality. This argument, if successful, seems to support my contention in chapter 1 that the third-stage argument relies upon the second-stage argument. The plausibility of Kymlicka's own second-stage account of our fundamental interest in access to our own societal culture, upon which I cast doubt in chapter 2, is also highlighted by this conclusion. It is on the plausibility of any such account that the conclusions of a fairness based argument regarding cultural rights will ultimately depend. 


\section{Bibliography}

Ackerman, B. (1989). "Why Dialogue?" Journal of Philosophy 86(1): 5-22.

Barry, B. (1995). Justice as Impartiality. Oxford, Clarendon Press.

Barry, B. (2001). Culture and Equality: An Egalitarian Critique of Multiculturalism, Polity Press.

Barry, B. (2002). Second Thoughts - and Some First Thoughts Revisited.

Multiculturalism Reconsidered: Culture and Equality and its Critics. P. Kelly (ed), Polity Press: 204-238.

Benhabib, S. (2006). Another Cosmopolitanism. Another Cosmopolitanism. R. Post (ed). New York, Oxford University Press: 13 - 80.

Brock, G. (2002). "Are There Any Defensible Indigenous Rights?" Contemporary Political Theory 1(3): 285 - 305.

Brookfield, F. M. (2006). Waitangi and Indigenous Rights: Revolution, Law and Legitimation. Auckland, Auckland University Press.

Buchanan, A. (2007). Justice, Legitimacy, and Self-Determination: Moral Foundations for International Law. New York, Oxford University Press.

Caney, S. (2002). Equal Treatment, Exceptions and Cultural Diversity. Multiculturalism Reconsidered: Culture and Equality and its Critics. P. Kelly (ed), Polity Press: 81-101.

Cardinal, H. (1969). The Unjust Society: The Tragedy of Canada's Indians. Edmonton, M G Hurtig.

Carens, J. (2000). Culture, Citizenship and Community. Oxford, Oxford University Press.

Cassatella, A. (2006). "Multicultural Justice: Will Kymlicka and Cultural Recognition." Ratio Juris 19(1): 80-100.

Chambers, C. (2002). All Must Have Prizes: The Liberal Case for Interference in Cultural Practices. Multiculturalism Reconsidered: Culture and Equality and its Critics. P. Kelly (ed), Polity Press: 151-173.

Chambers, C. (2003). "Nation-Building, Neutrality and Ethnocultural Justice: Kymlicka's 'Liberal Pluralism'." Ethnicities 3(3): 295-319.

Clarke, S. (1999). "Contractarianism, Liberal Neutrality, and Epistemology." Political Studies 47(4): 627-642. 
Cohen, G. A. (2004). Expensive Taste Rides Again. Dworkin and his Critics: With Replies by Dworkin. J. Burley (ed), Blackwell Publishing Ltd.

Dworkin, R. (1985). A Matter of Principle. Oxford, Oxford University Press.

Dworkin, R. (2004). Replies: Will Kymlicka. Dworkin and his Critics: With Replies by Dworkin. J. Burley (ed), Blackwell Publishing Ltd: 358- 359.

Exdell, J. (2009). "Immigration, Nationalism, and Human Rights." Metaphilosophy 40(1): 131-146.

Fanon, F. (1971). The Wretched of the Earth, Penguin Books.

Flanagan, T. (2000). First Nations? Second Thoughts. Montreal, McGill-Queen's University Press.

Franck, T. M. (1999). The Empowered Self: Law and Society in the Age of Individualism Oxford, Oxford University Press.

Freeman, S. (2007). Rawls, Routledge.

Gould, C. (2004). Globalizing Democracy and Human Rights. Cambridge, Cambridge University Press.

Habermas, J. (1990). Moral Consciousness and Communicative Action. Cambridge, MA, MIT Press.

Habermas, J. (1996). "The European Nation State. Its Achievemant and Its Limitations. On the Past and Future of Sovereignty and Citizenship." Ratio Juris 9(2): 125-137.

Hamilton, C. (1996). Mining in Kakadu: Lessons from Coronation Hill. A Lecture to the Parliamentary Library 'Vital Issues' Seminar Series. Vital Issues, The Australia Institute: 19.

Jung, C. (2007). Democratic Engagement with Ethnic Minority Claims: A Methodological Intervention into a Normative Debate. Multiculturalism and Law a Critical Debate. O. P. Shabani (ed). Cardiff, University of Wales Press: 263-279.

Kukathas, C. (2003). The Liberal Archipelago: A Theory of Diversity and Freedom. New York, Oxford University Press.

Kymlicka, W. (1989a). "Liberal Individualism and Liberal Neutrality." Ethics 99(4): 883905.

Kymlicka, W. (1989b). Liberalism, Community, and Culture. Oxford, Oxford University Press.

Kymlicka, W. (1995). Multicultural Citizenship: A Liberal Theory of Minority Rights. New York, Oxford University Press. 
Kymlicka, W. (2001). Politics in the Vernacular: Nationalism, Multiculturalism, and Citizenship. Oxford, Oxford University Press.

Kymlicka, W. (2004). Dworkin On Freedom and Culture. Dworkin and his Critics: With Replies by Dworkin. J. Burley (ed), Blackwell Publishing Ltd: 113 - 133.

Kymlicka, W. (2006). Liberal Nationalism and Cosmopolitan Justice. Another Cosmopolitanism. R. Post (ed). New York, Oxford University Press: 128-144.

Kymlicka, W. (2007). Rights to Culture, Autonomy and Participation: The Evolving Basis of Minority Rights in Europe. Multiculturalism and Law a Critical Debate. O. P. Shabani (ed). Cardiff, University of Wales Press: 235-262.

Lecce, S. A. (2003). "Contractualism and Liberal Neutrality: A Defence." Political Studies 51(3): 524-541.

Levey, G. B. (2006). Identity and Rational Revisability. Identity, Self-Determination and Secession. I. Primoratz and A. Pavkovic (eds). Aldershot, Ashgate Publishing Limited.

Levy, J. (2000). The Multiculturalism of Fear. New York, Oxford University Press.

Locke, J. (1977). Two Treatises of Government, Everyman's Library.

Maaka, R. and A. Fleras (2005). The Politics of Indigeneity: Challenging the State in Canada and Aotearoa New Zealand, Dunedin, University of Otago Press.

Margalit, A. and J. Raz (1990). "National Self-Determination." The Journal of Philosphy 87(9): 439-461.

Marx, K. (2002). Critique of the Gotha Programme. Karl Marx: Selected Writings. D. McLellan (ed). New York, Oxford University Press.

Mill, J. S. (1964). Utilitarianism, Liberty, and Representative Government. Representative Government. London, Everyman's Library: 171 - 393.

Mill, J. S. (1964). Utilitarianism, Liberty, and Representative Government. On Liberty, London, Everyman's Library: 61-170.

Miller, D. (1995). On Nationality. New York, Oxford University Press.

Miller, D. (2007). Crooked Timber or Bent Twig? Berlin's Nationalism. The One and The Many: Reading Isaiah Berlin. G. Crowder and H. Hardy. New York (eds), Prometheus Books: 181 - 206.

Nagel, T. (1987). "Moral Conflict and Political Legitimacy." Philosophy and Public Affairs 16(3): 215-240.

Nozick, R. (1974). Anarchy, State, and Utopia, Blackwell. 
Parekh, B. (1996). "Minority Practices and Principles of Toleration." The International Migration Review 30(1): 251- 284.

Parekh, B. (2002). Barry and the Dangers of Liberalism. Multiculturalism Reconsidered: Culture and Equality and its Critics. P. Kelly (ed), Polity Press: 133-150.

Parvin, P. (2008). "What's Special About Culture? Identity, Autonomy, and Public Reason." Critical Review of International Social and Political Philosophy 11(3): 315-333.

Patten, A. (2009). "Survey Article: The Justification of Minority Language Rights." The Journal of Political Philosophy 17(1): 102-128.

Pole, J. R. (1978). The Pursuit of Equality in American History. Berkeley, University of California Press.

Quong, J. (2006). "Cultural Exemptions, Expensive Tastes, and Equal Opportunities." Journal of Applied Philosophy 23(1): 53-71.

Rawls, J. (1973). A Theory of Justice, Oxford University Press.

Rawls, J. (2002). The Law of Peoples with 'The Idea of Public Reason Revisited', Harvard University Press.

Rawls, J. (2005). Political Liberalism. New York, Columbia University Press.

Raz, J. (1986). The Morality of Freedom. Oxford, Oxford University Press.

Requejo, F. (2001). Democratic Legitimacy and National Pluralism. Democracy and National Pluralism. F. Requejo (ed). London, Routledge: 157-177.

Rousseau, J.-J. (1979). The Social Contract, Penguin Books

Sadurski, W. (1990). Moral Pluralism and Legal Neutrality. Dordrecht, Kluwer Academic Publishers

Scanlon, T. M. (1982). Contractualism and Utilitarianism. Utilitarianism and Beyond. A. Sen and B. Williams (eds). Cambridge, Cambridge University Press: 103-128.

Sen, A. (1980). Equality of What? Tanner Lectures on Human Values I. S. McMurrin (ed.). Cambridge, Cambridge University Press.

Sen, A. (2009). The Idea of Justice, Allen Lane.

Tamir, Y. (1993). Liberal Nationalism. Princeton, Princeton University Press.

Taylor, C. (1992). The Politics of Recognition. Multiculturalism and 'The Politics of Recognition': An Essay by Charles Taylor. A. Gutmann (ed), Princeton University Press: $25-73$. 
Thierfelder, C., Tanner, M., et al. (2005). "Female Genital Mutilation in The Context of Migration: Experience of African Women With the Swiss Health Care System." European Journal of Public Health 15(1): 86-90.

Tierney, S. (2004). Constitutional Law and National Pluralism. New York, Oxford University Press.

Turner, D. (2006). This Is Not a Peace Pipe: Towards a Critical Indigenous Philosophy. Toronto, University of Toronto Press.

Waldron, J. (1992a). "Minority Cultures and the Cosmopolitan Alternative." University of Michigan Journal of Law Reform 25(3): 751-793.

Waldron, J. (1992b). "Superseding Historic Injustice." Ethics 103(1): 4-28.

Waldron, J. (2007). Status Versus Equality: The Accommodation of Difference. Multiculturalism and Law a Critical Debate. O. P. Shabani (ed). Cardiff, University of Wales Press: 129-155.

Wall, S. (2001). "Neutrality and Responsibility." Journal of Philosophy 98(8): 389-410.

Walzer, M. (1983). Spheres of Justice: A Defence of Pluralism and Equality. New York, Basic Books, Inc.

Walzer, M. (1992). Comment. Multiculturalism and 'The Politics of Recognition': An Essay by Charles Taylor. A. Gutmann (ed), Princeton University Press: 99 -103.

Weinstock, D. (2006). Is 'Identity' a Danger to Democracy? Identity, Self-Determination and Secession. I. Primoratz and A. Pavkovic (eds). Aldershot, Ashgate Publishing Limited: 15-26.

Wenar, L. (2008). What We Owe to Distant Others. The Global Justice Reader. T. Brooks (ed), Blackwell Publishing: 397-415.

Young, I. M. (1989). "Polity and Group Difference: A Critique of the Ideal of Universal Citizenship." Ethics 99(2): 250-274.

\section{Websites}

"Editorial: Tuhoe claim a minefield for national"

http://www.nzherald.co.nz/opinion/news/article.cfm?c_id=466\&objectid=10644143 (2010). Retrieved 18/05/2010. 


\section{Court Cases Cited}

Wi Parata v Bishop of Wellington (1877) 3 NZ Jur (NS) SC 72

US v Lee (1982) 455 US 252

State v Kargar (1996) 679 A.2d 81

\section{$\underline{\text { Legislation Cited }}$}

(New Zealand) Foreshore and Seabed Act 2004.

\section{$\underline{\text { Government Reports }}$}

Bouchard, G. and Taylor, C. (2008). "Building The Future: A Time For Reconciliation", Government of Quebec. 